March 15, 2012

Tye Aldana, PE

Multnomah County Bridge Shop

1403 SE Water Ave.

Portland, OR 97214

RE: Multnomah County Hydrokinetic Feasibility Study -

Final Feasibility Study Report

Dear Mr. Aldana:

HDR Engineering Inc. (HDR) is presently under contract with Multnomah County (the County) to complete a feasibility study of hydrokinetic energy generation on six of the County's existing bridges on the Willamette River near Portland, Oregon. The study includes an assessment of the costs and benefits of a potential hydrokinetic project at one or more of its bridges and an overview of the regulatory and environmental issues that might be associated with such a project. A hydrokinetic project at one or more of the downtown bridge sites could help to offset the energy consumed at the bridge and reduce the County's electrical utility bills and to provide an educational opportunity for local universities and the general public.

Prior to the feasibility study, HDR completed an initial screening study to determine which bridges have the most potential for a hydrokinetic project, and presented the results of the study to the County. Based on the results of that screening study, the County selected three sites it felt were most viable for a potential project: the Morrison Bridge, the Broadway Bridge, and the Sellwood Bridge. A copy of the screening study memorandum, submitted to the County on November 1, 2011, is included as Attachment 1 to this report.

This report provides a summary of the technical, regulatory, and economic feasibility of hydrokinetic energy generation at the three most promising sites selected by the County. The report also provides recommendations and suggested "next steps" for development of a potential hydrokinetic project in conjunction with one or more of the County's bridges.

Sincerely,

HDR Engineering, Inc.

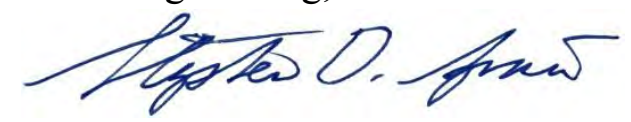

Stephen Spain, P.E.

NW Region Vice President 


\subsection{Executive Summary}

HDR has completed a study of the technical, regulatory, and economic feasibility of installing hydrokinetic turbines under the Morrison, Broadway, and Sellwood bridges. The primary objective of installing hydrokinetic turbines is a demonstration of in-stream hydrokinetic technologies for public education and outreach. Due to the low gradient of the Lower Willamette and the effects of the tide, velocities in the area in consideration are simply not high enough to economically support a commercial installation. While the velocities in the river may at times provide enough energy for a commercial turbine to reach capacity, the frequency and duration of high flow events which provide suitable velocities is not sufficient to support a commercial hydrokinetic installation. We have observed that over an 11 year period, daily average velocities in the Lower Willamette exceeded a nominal cut-in speed of $0.75 \mathrm{~m} / \mathrm{s}$ only $20 \%$ of the time, leaving net zero power production for the remaining $80 \%$ of days.

The Sellwood Bridge site was estimated to have the best hydrokinetic resource, with an estimated average annual production of about $9,000 \mathrm{kWh}$. The estimated production could range from 2,500 $\mathrm{kWh}$ to $15,000 \mathrm{kWh}$. Based on these energy estimates, the amount of revenue generated through either a power purchase agreement (PPA) or recovered through net metering is not sufficient to repay the project costs within the life of the turbine. The hydrokinetic resource at the Morrison and Broadway Bridges is slightly smaller than at the Sellwood Bridge. While the Broadway and Morrison Bridges have existing infrastructure that could be utilized, the project is not expected to generate enough revenue to repay the investment.

Despite low velocities and energy production, the sites themselves are favorable for installation of a demonstration or experimental project. With high public interest in renewable energy, the possibility exists to develop a hydrokinetic test site which could provide developers and scientists a location to temporarily deploy and test hydrokinetic devices, and also function as an educational tool for the general public. Bridge piers provide an excellent pre-existing anchor point for hydrokinetic devices, and existing infrastructure at the Morrison and Broadway Bridges may reduce installation costs.

Opportunity exists to partner with local universities with engineering and environmental interest in renewable energy. A partnership with Portland State University's engineering school could provide students with an opportunity to learn about hydrokinetics through senior design projects. Oregon State University and University of Washington, which are partnered through the Northwest National Marine Renewable Energy Center (NNMREC) to study and test hydrokinetic technology, are also relatively local to the site. In addition to providing an 
opportunity for both public and private entities to learn technically about in-stream kinetics, this approach will encourage grant funding for outreach, education, and product development, while also serving as a positive community relations opportunity for the County and its partners.

\subsection{HDR's Recommendations and Suggested "Next Steps"}

Should the County decide to pursue any of the potential projects listed in this report, HDR recommends the following next steps:

- Consultation with the Oregon State Hydropower Permitting Agencies: As discussed in detail below in Section 3.2, development of new hydropower in the lower Willamette River is currently prohibited by state statute that enforces strict protections for all anadromous fish habitat and waters. A determination whether the state will consider a hydrokinetic project that could be permitted under existing Oregon law is critical to defining the scope of additional studies discussed below.

- Track grant funding opportunities: There are several viable funding opportunities available from state, federal, non-for-profit, and private entities which may help to fund a hydrokinetic project on the lower Willamette River. Tracking these funding opportunities and applying for additional funding for project development, as appropriate, will be important to ensure success of a potential project.

- Explore potential partnerships: For an emerging industry like hydrokinetic energy, finding partners with expertise and resources to support a project will be critical. There are several university research programs and national labs studying marine and hydrokinetic energy in the Pacific Northwest that could partner on a potential project. The Good Company provides a list of potential partners in their attached memorandum (Attachment 6).

- Additional instream velocity measurements: In order to more fully understand the hydrokinetic resource at this location, HDR recommends the long-term deployment of a velocity measurement instrument (i.e., an Acoustic Doppler Profiler). This will allow for a more precise calculation of the in-stream velocities and generation potential, and support any future device deployments and testing for the site in consideration.

\subsection{Engineering Overview}

This section provides information about the potential hydrokinetic sites under consideration and the predicted energy resource available for hydrokinetic generation at each location, and gives an overview of potential turbine vendors. Based on information provided by interested 
turbine vendors, conceptual turbine sizing and energy-production estimates are given for each bridge location. This section also discusses potential navigational considerations for a hydrokinetic project on existing river users including recreational boaters and commercial operators. Energy usage at each of the locations was determined based on two years of historical data provided by Multnomah County.

\subsection{Site Descriptions}

\subsubsection{Morrison Bridge}

The Morrison Bridge is a double-leaf bascule bridge located at river mile 12.8 on the Willamette River in downtown Portland. Construction was completed in 1958. The bridge has an average electrical load of $23 \mathrm{~kW}$. United States Geologic Survey (USGS) gage 14211720 is located underneath the east dolphin, and provides river stage at 15-minute intervals. A USGS acoustic velocimeter is also installed on the east bascule pier and provides a measurement of the average channel velocity.

\subsubsection{Broadway Bridge}

The Broadway Bridge is a double-leaf Rall-type bascule bridge, completed in 1922. A granite pier is located on each side of the dredged shipping channel to support the span across the river; the rest of the river is free for non-commercial navigation. The average electrical load at the site is $11 \mathrm{~kW}$ with an electrical meter located on each side of the bridge. The east and west sides of the bridge are serviced by PacifiCorp and PGE, respectively. Abandoned AC and DC subsea cables are available at the site, which could be used for electrical interconnection of hydrokinetic turbines.

\subsubsection{Sellwood Bridge}

A design for a new Sellwood Bridge is currently underway. The new bridge will be of the steel-deck arch design, and will accommodate one lane of vehicle traffic as well as a 6.5-foot bike lane and a 12.5-foot pedestrian sidewalk in each direction. The design proposes two bent piers located approximately equal distances from the center of the river channel. Since the bridge is upstream of Ross Island, which is the upstream limit for commercial navigation, the potential for navigational impacts is significantly lessened. The potential exists to include any turbine mounting or interconnection details into the new bridge design, thereby reducing installation cost and increasing ease of maintenance. 


\subsection{Lower Willamette Flow and Velocity}

Since the available energy in the Willamette changes in each stretch of the river, HDR created a model of the lower Willamette River to identify which of the sites in consideration has the highest hydrokinetic potential. One-dimensional (1-D) hydraulic model software developed by the United States Army Corps of Engineers (USACE) called HEC-RAS was used to model the river starting approximately one mile upstream of the Sellwood Bridge and ending at the confluence of the Willamette and Columbia Rivers. Bathymetric data obtained from the USACE was used to define the contours of the river bottom. Using cross-sectional data from 160 stations along the river length in consideration, the model determines the energy loss in the flow due to frictional losses (roughness, channel shape, etc.) and interaction with instream structures such as bridges. The model was used to estimate the mean channel velocity at each cross section and bridge location based on the flow and friction data entered into the model.

The model was calibrated using velocity and stage data from a USGS gage located within the dolphin on the east bascule pier of the Morrison Bridge. HDR's analysis of the measured flow and velocity data from under the Morrison Bridge is included in Attachment 2 to this report. Model results were compared to velocity and stage measurements taken at the Morrison Bridge during six separate measured flow conditions ranging from 20,800 cfs to $110,000 \mathrm{cfs}$. Flow data was selected from days where the effect of tide on the Willamette River was minimized. Adjustments to the modeled channel roughness were made as needed to obtain agreement with known boundary conditions and gage measurements. Boundary conditions for the model were obtained from USGS river stage gages at Willamette Falls and Morrison Bridge, and from a National Oceanographic and Atmospheric Administration (NOAA) tide gage near the confluence of the Willamette and Columbia rivers. 


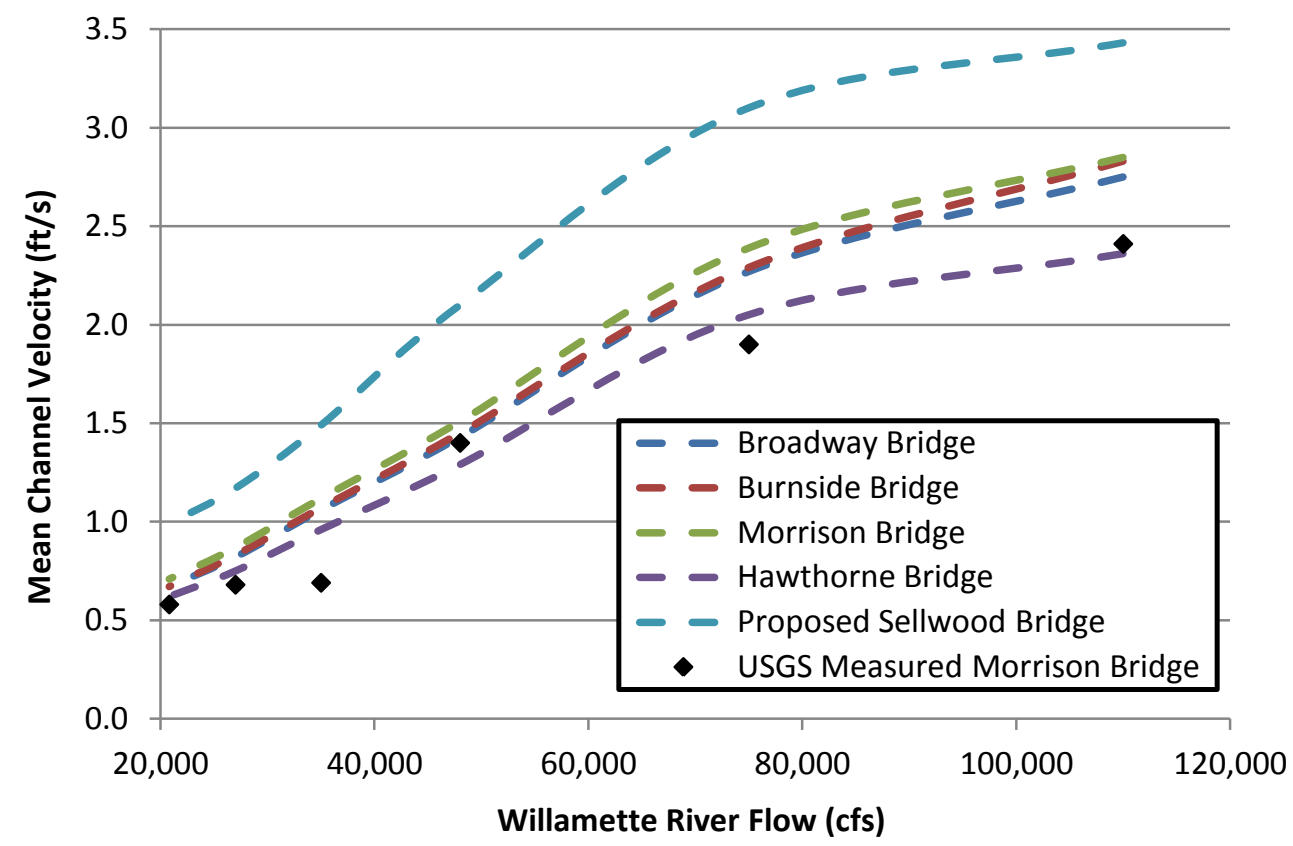

Figure 1. Predicted mean channel velocity under each bridge (from HEC-RAS) and measured velocity under the Morrison Bridge (USGS)

As can be seen in Figure 1, the mean channel velocity under each of the bridges, as predicted by the one-dimensional hydraulic model, varies from less than 1 to more than 3 feet per second over the range of river flows investigated. These flow velocities are lower than would typically be desired for a commercial hydrokinetic project (commercial project developers typically desire minimum velocities of over 3 feet per second). To assess whether areas within the channel could have velocity higher than the mean, HDR conducted measurements of the instream flow velocity under the Morrison and Sellwood bridges.

Instream velocity measurements were collected using a boat-mounted Acoustic Doppler Current Profiler (ADCP) on December 16, 2011. The instrument collects velocity data by emitting high-frequency sound waves and monitoring the return of the pulse for Doppler shift, which allows for the calculation of velocity. By repetitively emitting pulses through a range of frequencies, the device can resolve velocities in two-dimensional cells of approximately $0.5 \mathrm{~m}$ in width. Velocity data was collected along four transects at the Sellwood Bridge, both parallel and perpendicular to the bridge piers. At the Morrison Bridge site instream velocities were not high enough for an accurate measurement. A summary of the data collected during the instream velocity measurements is included as Attachment 8 to this report.

The velocity data collected under the Sellwood Bridge on December 16, 2011 confirmed a mean channel velocity of approximately 1.1 foot per second at a measured discharge of 
approximately 23,000 cubic feet per second. This mean channel velocity is consistent with the predictions of the 1-D hydraulic model at this low flow rate. In addition, acoustic velocimeter data provided by email by USGS indicates good agreement with the 1-D model at both high and low flows, with error of less than $8 \%$ at $20 \mathrm{kcfs}$ and $116 \mathrm{kcfs}$. Unfortunately, weather conditions during December 2011 did not allow for a measurement of the mean channel velocity and total discharge during a higher flow event. Additional measurements of the velocity and discharge at the Sellwood site during higher river flows could be used to calibrate the results of the 1-D model.

The measured velocity across the channel under the Sellwood Bridge included velocities as low as 0.01 feet per second and as high as 2.34 feet per second. This data indicates that there are areas within the channel where the velocity is up to $113 \%$ higher than the mean channel velocity at a flow rate of 23,000 cubic feet per second. At higher flow rates it is reasonable to assume that there would be areas within the channel where the velocity will be substantially higher than the mean. Based on the measured data, and experience with velocity distributions in similar channels, it is reasonable to assume that there will be areas within the channel where the velocity is at least $50 \%$ greater than the mean over the entire range of river flows.

The instream velocity measurements substantiate the assumptions made in the rest of this study. Velocities at the bridge sites when flows in the river are at 23,000 cfs or less are not sufficient to support power production. Velocity measurements at higher flows could better define the potential power production and help the County more precisely identify the appropriate location within the river cross section for placement of a kinetic machine.

\subsection{Navigation Considerations}

From its confluence with the Columbia River to Ross Island, the Willamette River passes through the commercial, industrial and downtown waterfront of Portland. This section of the river is utilized by numerous users including both commercial and recreational water craft. Upstream from the Ross Island Bridge, the river enters a greenbelt area and commercial navigation is reduced. Based on discussions with County bridge operators, the largest craft that typically transit between the Broadway Bridge and Ross Island are double-wide commercial barges transporting material to and from the Ross Island Sand and Gravel Mine (see Figure 2). Therefore, it is very unlikely that installation of hydrokinetic turbines under the Sellwood Bridge would impact commercial navigation since the bridge is upstream of the Ross Island Sand and Gravel Mine. A small amount of commercial navigation exists upstream of the mine; however, with the recent closure of Willamette Locks, this traffic will most likely be further reduced. Potential impacts on navigation are more likely for the bridges in downtown Portland. 


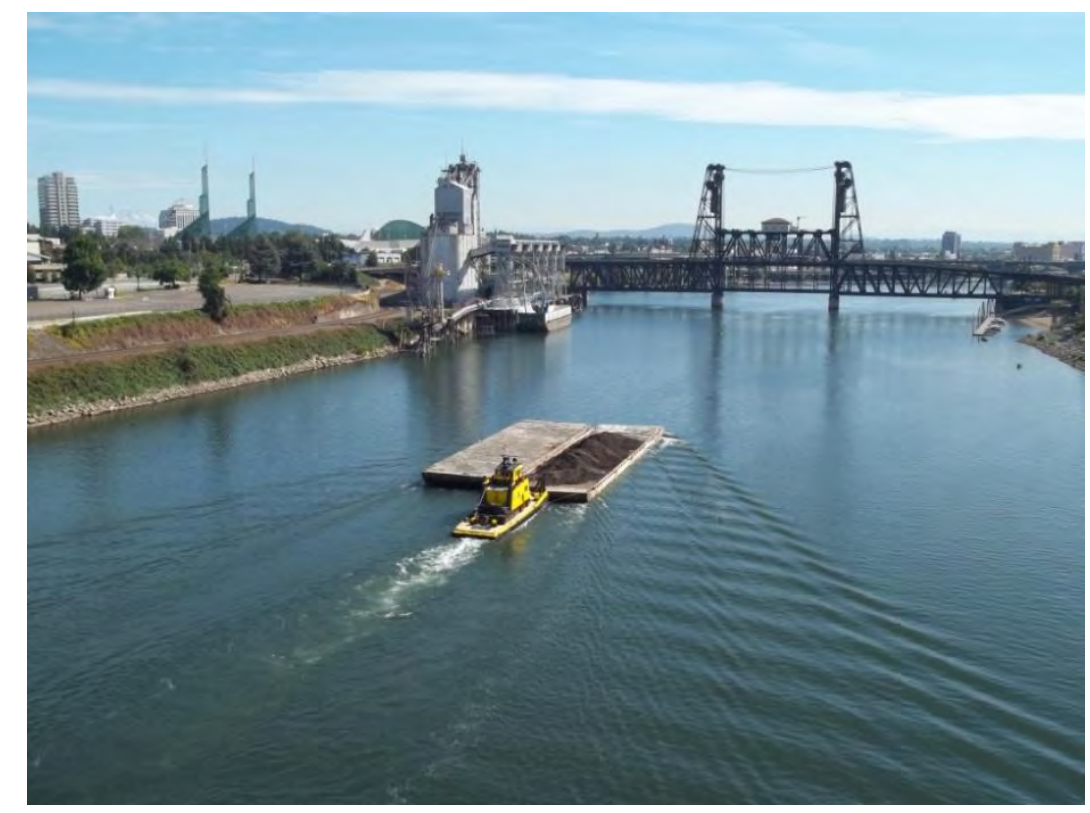

Figure 2. Barge transiting upstream from Broadway Bridge toward the Steel Bridge

Currently the minimum horizontal clearance in the downtown Portland navigation channel is at the Burnside Bridge, where the piers under the lift span are approximately 240 feet apart. The horizontal clearance between the lift span piers on the other downtown bridges range from approximately 250 feet (Hawthorne Bridge) to approximately 285 feet (Morrison Bridge). The horizontal clearance between the lift span piers at the Broadway Bridge is approximately 275 feet. Depending on the site-specific velocities under each bridge, the turbines might be positioned outside the navigational channel, reducing the potential navigational impacts of the turbines. The current concept for turbine installation under the Morrison and Broadway bridges would place the turbines outside the federal navigation channel.

HDR completed a preliminary analysis of bridge-opening log data provided by the County to assess the amount of commercial traffic transiting under the downtown bridges. Opening data for the Hawthorne Bridge for the period from 1994 to 2010 was used to estimate the number of large commercial vessels that transit that section of the river since the Hawthorne Bridge has the lowest vertical clearance. The relatively low vertical clearance at the Hawthorne Bridge requires the lift span to be opened for a larger number of vessels than the Broadway, Morrison, or Burnside Bridges.

The bridge-opening data from the Hawthorne Bridge indicates that the number of openings per year decreased from 1994 through 2009. In 2010 the number of bridge openings increased significantly, likely due to ongoing restoration work at the Ross Island Sand and Gravel Mine site. Opening log data from 1999 through 2009 was analyzed to estimate the seasonal variation in bridge openings in recent years. In general, the largest number of bridge openings occurred 
in June and July with significantly fewer openings during the winter months (January through March). The number of openings in the fall is typically less than in the summer, with the exception of December which has a relatively high number of bridge openings. A summary of the monthly bridge-opening data can be seen in Figure 3.

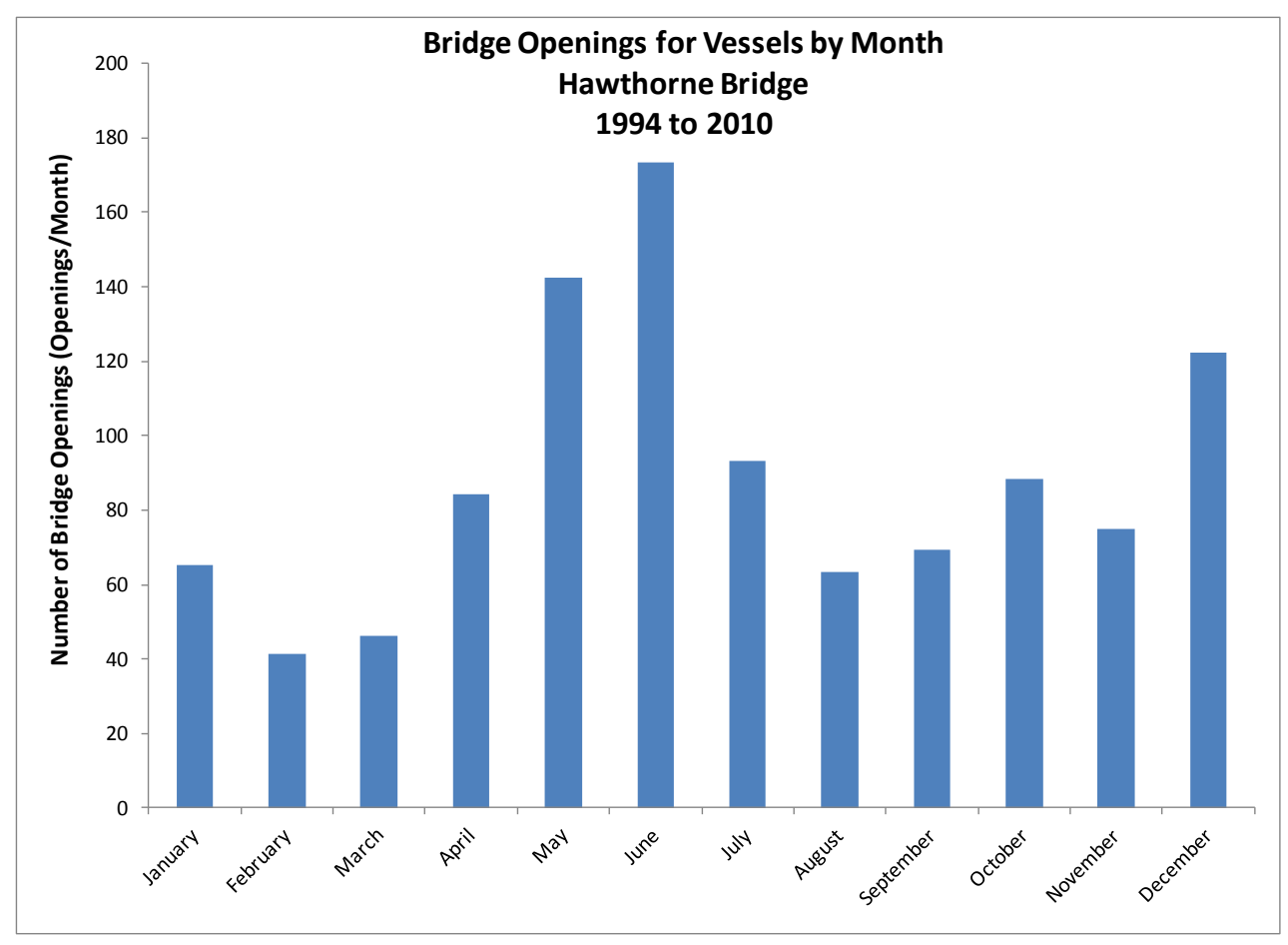

Figure 3. Hawthorne Bridge opening data by month

If hydrokinetic turbines are installed under either the Morrison or Broadway Bridges it is likely that they would be able to operate only in the fall and winter months when instream velocities are relatively high as a result of seasonal rain and upstream snowmelt. Based on the bridgeopening data from 1999 through 2010, commercial shipping traffic on the lower Willamette peaks during the summer months when the turbines could be removed from the water for maintenance. The timing of the peak commercial navigation traffic in relation to the hydrokinetic resource should reduce potential impacts of a hydrokinetic project on existing users of the river.

In addition to commercial barge traffic there are many other users of the lower Willamette who could be affected by a potential hydrokinetic project. Some of the other current users of the waterway include:

- Portland Boathouse - The Portland Boathouse is located on the eastern bank of the Willamette River near the Hawthorne Bridge. Many rowing and paddling clubs rent space at the Portland Boathouse including: Alder Creek Kayak and Canoe; Portland 
State University Crew; Portland Women's Rowing; Rose City Rowing Club; Station L Rowing Club; University of Portland Crew; and the Wasabit Paddling Club.

- Oregon Rowing Unlimited - A community rowing club with a boathouse at the south end of Oak Park near the Sellwood Bridge. This is the home club of the Lewis and Clark rowing team and the Willamette Rowing Club.

- Portland Rowing Club - A rowing club with a boathouse just south of the Sellwood Bridge.

- Waverly Marina - A private marina located just south of the Sellwood Bridge.

- Riverplace Marina - A private marina located just south of the Hawthorne Bridge.

- Willamette Jetboat Excursions - A jetboat tour operation with tours leaving from the Oregon Museum of Science and Industry (OMSI), just south of the Hawthorne Bridge.

- Portland Spirit - A dinner cruise boat normally moored on the west bank of the Willamette River just north of the Hawthorne Bridge.

\subsection{Hydrokinetic Turbine Options}

The development of modern hydrokinetic turbines began during the oil crisis of the 1970s. At that time, small demonstration projects were installed in both the US and Europe, but the development of the industry stalled when oil prices fell in the 1980s and 1990s. Recently interest in hydrokinetic technology development has increased due to rising fuel prices and concerns regarding global climate change. A number of projects have been developed recently in North America and around the world to demonstrate the viability of hydrokinetic energy generation.

Some notable projects in the US include:

- Ruby Hydrokinetic Project - Ruby, Alaska: In 2008 the Yukon River Inter-Tribal Watershed Council installed a 10-kW EnCurrent turbine in the Yukon River near Ruby, Alaska. The experimental turbine was installed in the river during the summer months to prove the concept of instream hydrokinetic generation for remote tribal communities.

- Hastings Hydrokinetic Power Station - Hastings, Minnesota: Hydro Green Energy installed two $100-\mathrm{kW}$ hydrokinetic turbines just downstream of an existing hydroelectric facility in January 2009. The project was the first federally licensed commercial hydrokinetic project in the United States.

- Eagle Hydrokinetic Turbine Project - Ruby, Alaska: Alaska Power and Telephone installed a $25-\mathrm{kW}$ EnCurrent turbine in the Yukon River near Eagle, Alaska. The turbine was tested during the summer of 2010 and provided power for Eagle Village. 
- Eastport Tidal Project - Eastport, Maine: The Ocean Renewable Power Corporation (ORPC) has been testing tidal energy devices in the Bay of Fundy near Eastport, Maine since 2004. In 2010 ORPC installed a $60-\mathrm{kW}$ tidal turbine off Eastport that provides power to charge batteries for a nearby coast guard station.

- Roosevelt Island Tidal Energy Project - New York City, New York: Verdant Power demonstrated six hydrokinetic turbines in the East River near New York City from 2006 to 2008. Power from the turbines was used to provide $70 \mathrm{MWh}$ of energy to a grocery store on Roosevelt Island.

A variety of turbine types are being developed to extract energy from tidal races and freely flowing rivers, and they can generally fall into two categories: horizontal-axis and vertical-axis turbines.

Horizontal-axis hydrokinetic turbines utilize either a fixed- or variable-pitch rotor with its rotational axis parallel to the flow. Due to variations in flow direction at some sites, horizontalaxis turbines may require yaw control in order to keep the rotor aligned with the flow direction. Horizontal-axis turbines can be rigidly mounted to the channel bottom or suspended from a floating structure. Depending on the flow speed and diameter of the rotor, horizontal-axis turbines can either directly drive a generator or connect to a generator via a reduction gear.

Open-rotor, horizontal-axis machines are very similar to modern wind turbines, consisting of a rotor driving a horizontally aligned drive-shaft. These machines can further be divided into rotors that use variable-pitch blades and rotors that use fixed-pitch blades. In addition, many machines of these types make provisions for either active or passive yaw of the turbine blades to orient with the flow direction. A gearbox is often incorporated into the nacelle of the turbine to increase the shaft speed and reduce the size of the generator required.
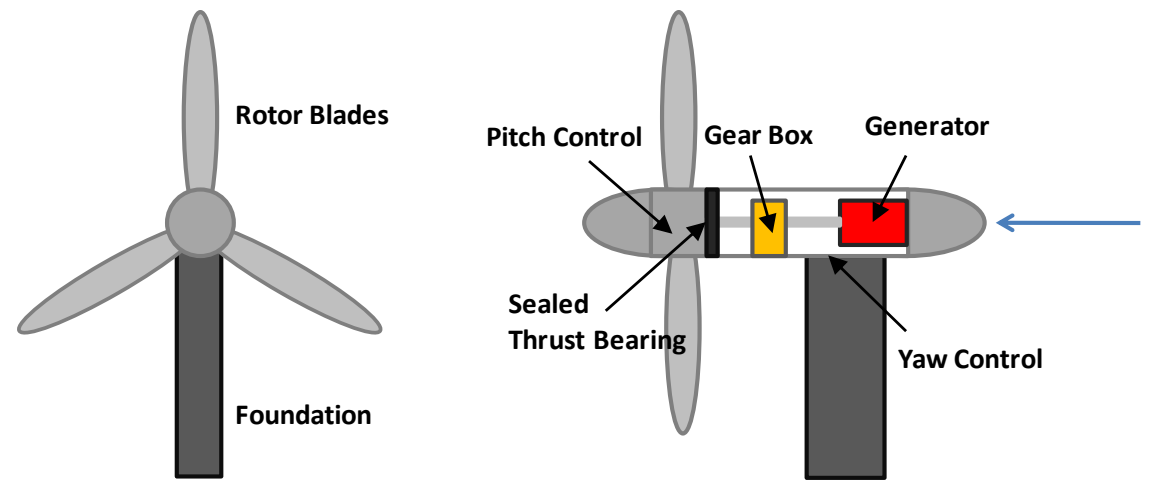

Figure 4. Open-rotor horizontal-axis turbine 
Ducted-rotor horizontal-axis turbines utilize a steel or fiberglass duct to align the direction of the flow with the rotor. This flow alignment allows the turbine to operate efficiently over a range of flow directions without yawing the rotor. The rotor directly drives a generator that is housed within the support structure for the rotor and duct. The diameter of the generator allows for a large number of generator poles, enabling the relatively slow speed of the turbine to be converted into electricity. A large-diameter bearing is required between the armature and the stature to maintain the alignment of the rotor.
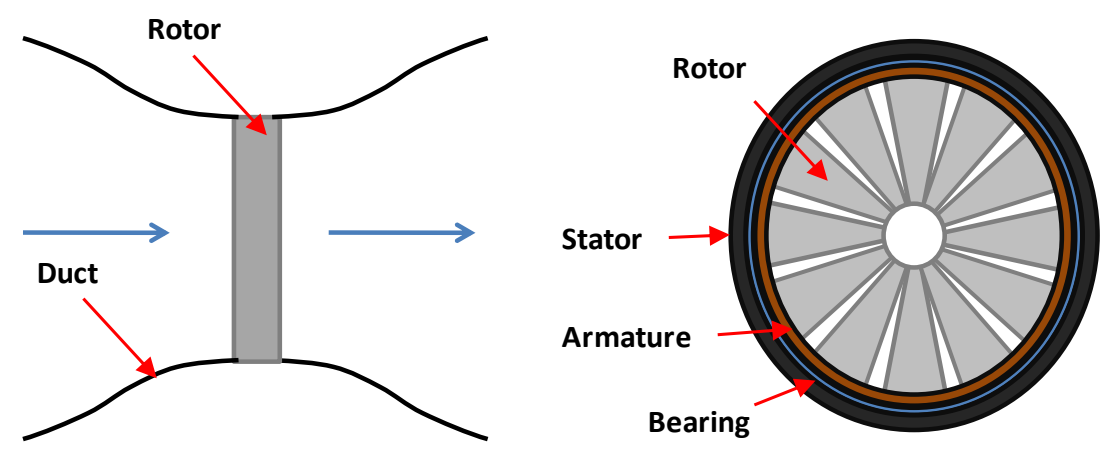

Figure 5. Ducted-rotor horizontal-axis turbine

Vertical-axis turbines consist of a rotor that turns around a vertical axis of rotation. Verticalaxis machines can accommodate fluid flows from all directions without having to reverse the direction of turbine rotation. Vertical-axis turbines are typically suspended from a structure on the water's surface, with the generator and associated electrical equipment installed above the water.

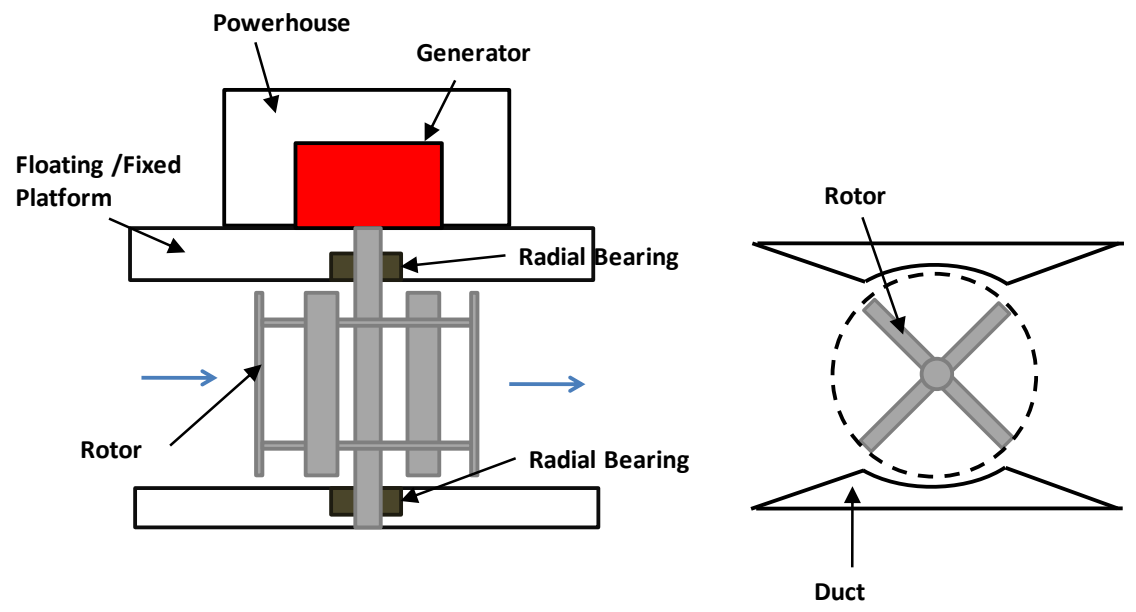

Figure 6. Vertical-axis turbine 
Cross-flow turbines utilize a helical rotor that can be either horizontally or vertically oriented. The direction of rotation of the rotor is independent of the flow direction, making this type of turbine ideally suited to bi-directional flows. The rotor can either directly drive a generator or be coupled to a generator via a reduction gear.

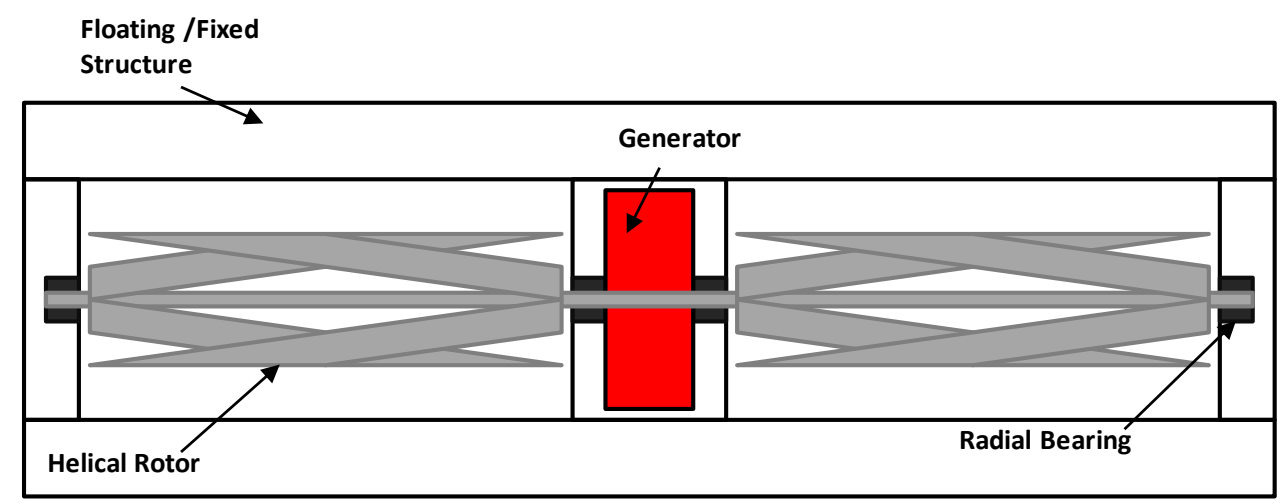

Figure 7. Cross-flow Turbine

Drag-type turbines typically consist of a vertical or horizontal arrangement with cups or flaps which use drag, not lift, to turn the rotor. The rotational speed of a drag turbine is low when compared to other turbines, since drag prevents the rotor from turning faster than the working fluid. They are typically used in situations where cost and maintainability are more important than efficiency and performance. A gearbox is generally not used, since this significantly increases the startup torque.
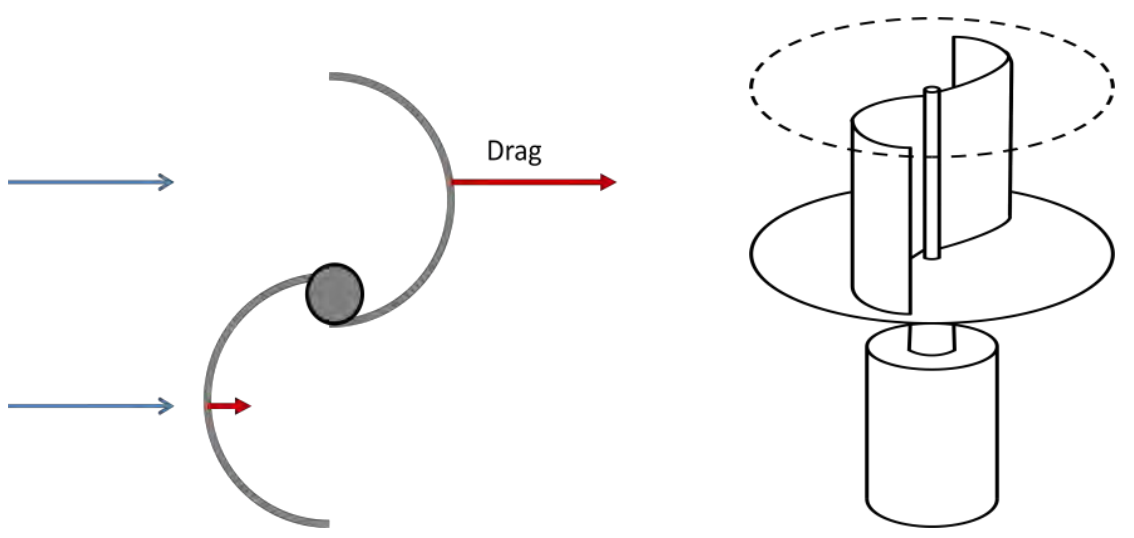

Figure 8. Drag-turbine, Savonius rotor shown. 
HDR contacted several hydrokinetic turbine technology developers to determine their level of interest in a hydrokinetic project on the lower Willamette River. The vendors contacted to provide conceptual cost and performance information included:

- ABS Alaskan - Fairbanks, Alaska-based vendor of the EnCurrent vertical-axis turbine with a pilot project on the Yukon River in Eagle and Ruby, Alaska.

- HydroVolts - Seattle, Washington-based technology developer currently working on the development of a drag turbine for instream hydrokinetic applications. HydroVolts has a demonstrated their turbine in the Roza Canal in eastern Washington.

- Verdant Power - New York City, New York-based technology developer whose horizontal-axis turbines were first demonstrated in the East River in 2006.

- Alstom Hydro - Nantes, France-based hydroelectric equipment manufacturer currently developing a 1-MW horizontal-axis turbine for tidal power applications.

- Voith Hydro - York, Pennsylvania-based hydroelectric equipment manufacturer developing a 1-MW horizontal-axis turbine for tidal power applications. The tidal turbine technology is being developed primarily in Germany with a demonstration project in South Korea.

- Ocean Renewable Power Corporation - Portland, Maine-based hydrokinetic turbine developer with a pilot project in the Bay of Fundy near Eastport, Maine.

\subsection{Conceptual Turbine Sizing for Each Site}

Of the six hydrokinetic turbine vendors contacted, two (HydroVolts and ABS Alaskan) provided information on turbine performance and cost for a system capable of operating at the low instream velocities anticipated under the County's bridges. The remaining four developers stated that their devices were tuned for higher velocities, and would not be suitable for this location. ABS Alaskan provided budgetary costs and performance data for a 25-kW EnCurrent vertical-axis turbine (the ENC-25L-F4). The unit proposed by HydroVolts is a horizontal dragtype turbine with a rated capacity of $11 \mathrm{~kW}$ (the Class 3 Savonius turbine). Vendor data is provided in a separate document to accompany this report.

The EnCurrent ENC-025L-F4 turbine can extract power at velocities as low as $2.5 \mathrm{ft} / \mathrm{s}(0.75$ $\mathrm{m} / \mathrm{s}$ ), based on information provided by ABS Alaskan. The minimum velocity for power extraction using the HydroVolts Class 3 Savonius turbine is $3.3 \mathrm{ft} / \mathrm{s}(1 \mathrm{~m} / \mathrm{s})$. Because the EnCurrent machine has a lower cut-in velocity and a higher rated capacity, for the purposes of this study it was deemed more appropriate for the Morrison and Broadway bridge sites. Further evaluation of the available resource and hydrokinetic turbine technologies would be required 
before determining what type of equipment is most appropriate for each site. A summary of HDR's conceptual turbine sizing based on information provided by potential vendors for this study is included below:

- Site 1 - Morrison Bridge

- Instream Velocity: 0.1 to $7.8 \mathrm{ft} / \mathrm{s}$

- Water Depth: 50 feet

- Average Electric Load: $28 \mathrm{~kW}$

- Turbine Type: Up to four 25-kW EnCurrent vertical-axis turbines.

- Turbine Sizing: 15.75-foot diameter by 8-foot depth

- Electrical Interconnection: New subsea cables interconnecting with the existing electrical meters at either end of bridge.

- Site 2-Broadway Bridge

- Instream Velocity: 0.1 to $7.6 \mathrm{ft} / \mathrm{s}$

- Water Depth: 45 feet

- Average Electric Load: $11 \mathrm{~kW}$

- Turbine Type: Up to two 25-kW EnCurrent vertical-axis turbines.

- Turbine Sizing: 15.75-foot diameter by 8-foot depth

- Electrical Interconnection: Existing subsea cables interconnecting to the existing electrical meters at either end of bridge.

- Site 3-Sellwood Bridge

- Instream Velocity: 0.2 to $10.4 \mathrm{ft} / \mathrm{s}$

- Water Depth: 15 feet

- Average Electric Load: $5 \mathrm{~kW}$

- Turbine Type: Single 11-kW HydroVolts drag turbine or four 25-kW EnCurrent turbines.

- Turbine Sizing: 7.5-foot diameter by 9.8-foot width (HydroVolts) or 15.75-foot diameter by 8-foot depth (EnCurrent)

- Electrical Interconnection: New subsea cable interconnecting to the existing electrical meter.

At each site the hydrokinetic turbine (or turbines) could be suspended below a floating pontoon barge mounted to the bridge piers. The pontoon barge would be secured to a set of rails running vertically on the pier, allowing it to move up and down with the level of the river. Two debris booms would run between the barge and the pier to keep floating debris away from the turbine and provide a safety barrier to vessels operating near the device. Finally, a subsea cable would 
run from the turbine through a catenary to the adjacent bridge pier. The cable would interconnect into the existing electrical distribution system on the bridge.

Conceptual layouts of hydrokinetic turbines adjacent to bridge piers are included as Attachment 3 to this letter report. These layouts have been used to develop conceptual cost and energy estimates for all three sites.

\subsection{Energy Production Estimates}

The mean channel velocity data measured under the Morrison Bridge by the USGS was combined with the predictions of the one-dimensional hydraulic model to develop ten years of synthetic mean channel velocity data for each bridge site. Measured flow and velocity data from October 1999 through September 2010 was used to develop a time series of mean channel velocity based on current operations of the Willamette river system. Based on the results of the instream flow measurements, and experience with the range of flow velocities in similar channels, the velocity at the turbine centerline was estimated to be $50 \%$ higher than the mean channel velocity, assuming the turbine is located adjacent to one of the existing bridge piers in a higher velocity section of the river.

The synthetic turbine centerline velocity was used to develop energy models to estimate the annual energy production at each site. Turbine and generator efficiencies were based on information provided by ABS Alaskan (the US vendor of the EnCurrent turbine) and HydroVolts (a Seattle-based hydrokinetic turbine technology developer).

Detailed results from the energy models are included in Attachment 4 to this report. The estimated energy production for single $25-\mathrm{kW}$ EnCurrent turbine at the Morrison Bridge site is approximately 4,600 $\mathrm{kWh}$ per year; at Broadway the turbine could produce approximately $4,200 \mathrm{kWh}$, and at Sellwood the turbine could produce approximately 9,000 kWh per year.

These energy estimates are based on the following key assumptions:

- EnCurrent ENC-025L-F4 turbine with an 11.7-square-meter (126-square-foot) swept area and rated efficiency of $30 \%$.

- Maximum operating velocity of $2.4 \mathrm{~m} / \mathrm{s}(7.9 \mathrm{ft} / \mathrm{s})$.

- Minimum (cut-in) velocity of $0.75 \mathrm{~m} / \mathrm{s}(2.5 \mathrm{ft} / \mathrm{s})$.

- $\quad$ Forced outage rate of $3 \%$.

- Interconnection losses of $2 \%$. 
At the Sellwood Bridge site a single 11-kW HydroVolts Class 3 Savonius turbine is estimated to produce approximately $3,400 \mathrm{kWh}$ of electricity per year. This estimate of the annual energy production is based on the following key assumptions:

- HydroVolts Class 3 Savonius turbine with a 6.9-square-meter (74-square-foot) swept area and rated efficiency of $20 \%$.

- Maximum operating velocity of $2.5 \mathrm{~m} / \mathrm{s}(8.2 \mathrm{ft} / \mathrm{s})$.

- Minimum (cut-in) velocity of $1 \mathrm{~m} / \mathrm{s}(3.3 \mathrm{ft} / \mathrm{s})$.

- $\quad$ Forced outage rate of $3 \%$.

- Interconnection losses of $2 \%$.

\subsection{Regulatory Overview}

This section provides a summary of the licensing requirements for the hydrokinetic projects under consideration in this report, and provides initial recommendations for an approach to necessary licenses.

\subsection{FERC Jurisdiction}

Part I of the Federal Power Act (FPA) authorizes the Federal Energy Regulatory Commission (FERC) to issue licenses for the construction, operation, and maintenance of hydroelectric projects located on public lands, reservations, or in navigable waterways of the United States. FERC has also held that proposed hydropower projects that will be connected to the interstate electric power grid are within FERC's jurisdiction, and require a license. Since the bridgeturbine project assessed in this feasibility report would generate power from navigable waters of the US, it should be expected that the County will be required to obtain a license or license exemption from FERC prior to the commencement of project construction.

Pursuant to 18 CFR $\S 5.1(\mathrm{f})$ of FERC's implementing regulations, the Integrated Licensing Plan (ILP) is FERC's default licensing process for hydroelectric projects. The ILP is designed to create efficiencies by integrating a potential license applicant's pre-filing consultation requirements with FERC's scoping pursuant to the National Environmental Policy Act (NEPA). The ILP is a deadline-driven process that requires the applicant, agencies, and stakeholders to follow a process plan and schedule for licensing activities ${ }^{1}$.

\footnotetext{
1 http://www.ferc.gov/industries/hydropower/indus-act/order-2002.asp
} 
With FERC's permission, an applicant may also pursue a license from FERC using the Traditional Licensing Process (TLP). The three-stage consultation process provided in the TLP provides the opportunity for additional consultation with agencies and stakeholders, but lacks the comprehensive schedule provided in the ILP or the up-front NEPA scoping mandated by the ILP.

A second alternative to the ILP is the Alternative Licensing Process (ALP) which was promulgated between the establishment of the TLP and, more recently, the ILP. Like the ILP, the ALP is a front-loaded collaborative process but one developed in consultation primarily with the resource agencies. The ILP was designed to address the inequities that became apparent with the resource agencies holding the key to approval to use of the ALP, and the ALP process is not often chosen by applicants since the ILP became the default. However, the agencies still favor and promote the use of the ALP for licensing hydroelectric projects, so it's not unusual to have this suggested as an alternative to the default ILP process.

\subsection{Initial Screening for Fatal Flaws}

FERC is precluded from licensing hydroelectric projects in wilderness areas, those with Wild and Scenic River designations, or on federal reservations (e.g., National Forests) where such use would be inconsistent with the purpose for which the reservation was created. In addition, FERC will not accept an application for a license for a project that would develop the same water resources that would be developed by another project for which a preliminary permit is in effect. Based on HDR's understanding of the projects studied in this report, current ownership, and land use designations, none of these "fatal flaws" are applicable to the Multnomah Bridge Turbine Project locations studied and an application for license or license exemption would be considered by FERC.

The FPA requires FERC to consider both power and non-power uses of the project, including fish and wildlife resources, cultural and tribal resources, water quality, and recreation, when licensing a hydroelectric project; examination of these resources is among the primary purposes of a FERC licensing effort, and beyond the scope of this screening study. In addition, FERC must consult with the US Fish and Wildlife Service (USFWS) and National Marine Fisheries Service (NMFS) regarding the potential effects of a licensing on species or critical habitat listed under the Endangered Species Act (ESA).

Although not a definite fatal flaw, the Multnomah Bridge Hydrokinetic Project sites lie within potential range or designated critical habitat for the following species:

- Upper Willamette River Steelhead (Threatened)

\section{HDR}


- The designated population segment includes all naturally spawned anadromous O. mykiss (steelhead) populations below natural and manmade impassable barriers in the Willamette River, Oregon, and its tributaries upstream from Willamette Falls to the Calapooia River (inclusive).

- Upper Willamette River Chinook (Threatened)

- The evolutionary significant unit includes all naturally spawned populations of spring-run Chinook salmon in the Clackamas River and in the Willamette River, and its tributaries, above Willamette Falls, Oregon, as well as seven artificial propagation programs.

- Bull Trout

- A small remnant population of bull trout was identified in the middle fork of the Willamette River, but appears to be isolated due to manmade obstructions. As a result, bull trout should not be impacted from project activity.

The Oregon Water Resources Department (OWRD) manages the issuance of permits for hydropower projects on the state level and they have enacted state laws that provide strict protections for salmon and steelhead. To approve a small hydropower project in Oregon, the OWRD must find that the proposed project will satisfy the resource protection standards fully set forth in Oregon Administrative Rule (OAR) 690-51-190 to OAR 690-51-260, among other relevant state laws and regulations. Oregon state biologists and water-resource regulators commonly refer to one of the other relevant statutes at Oregon Revised Statutes (ORS) 543.017 as "the no dead fish rule" that was reportedly enacted to prohibit the development of hydropower projects within the range of anadromous salmon and steelhead. The lower Willamette River supports runs of Chinook, coho, and steelhead and these statutes will need to be addressed during the state permitting process. By working with the state, Ocean Power Technologies (OPT) was able obtain an exemption from this rule (enacted as ORS 543.014) and was permitted to install their proposed Reedsport OPT Wave Park; however, HDR is not aware of any other exemptions from this rule being issued by the state exempting hydropower projects from the "no dead fish rule."

The potential effects of any proposal on ESA-listed species or critical habitat will warrant careful consideration and consultation with the Oregon resource agencies and hydropower regulators to address this broad prohibition on hydropower development in the lower Willamette River during a licensing or license exemption effort. Potential restrictions on construction and/or operation and maintenance activities that could affect project costs will need further consideration during the permitting and design process.

The bridges in consideration for this project lie within a 'protected area' designated by the Pacific Northwest Electric Power and Conservation Planning Council. Although these 
potential projects are located within a protected area, this is not deemed to be a fatal flaw. These protected river segments are designed to protect fish against unacceptable harm stemming from development of hydropower projects which could damage anadromous and resident populations. This type of in-stream hydrokinetic development is currently considered to be a hydropower development under ORS 469A.025, and thus does not qualify for the Renewable Portfolio Standard (RPS). Furthermore, per ORS 469A.025(4)(a), a post-1994 facility is eligible for the RPS only if it is "located outside any protected area." This means that the Multnomah County project is not eligible for Renewable Energy Credits (RECs), which could amount to $\$ 0.02 / \mathrm{kWh}$. Although RECs are not available at this time, they may become available in the future as public interest in these developments increases, and the technology is further proven.

Given the shipping and recreational use of the navigable Willamette River in the project vicinity, HDR has also identified potential navigation and public safety issues that will need to be successfully negotiated with the USACE and U.S. Coast Guard during the project's design phase.

\subsection{Exemptions from FERC Licensing}

The FPA and its implementing regulations provide for two possible exemptions from licensing: conduit exemptions and "5-MW" exemptions for certain small hydro projects. These exemptions do not eliminate the requirement to consult with agencies, tribes, and stakeholders, and in most circumstances will actually transfer to state agencies powers not available to them under a standard FERC license.

FERC exemptions primarily provide an expedited regulatory process that allows a certain class of small FERC jurisdictional projects to operate without the need to relicense the project in the future. In other words, for those projects that meet FERC's exemption criteria, the exemption order issued by FERC does not expire and is valid in perpetuity. However, the terms and conditions of the exemption order are set by FERC using a set of standard terms and conditions for the type of exemption issued with project-specific operating terms and conditions set by the fish and wildlife resource agencies. These agencies provide terms and conditions which can be amended anytime under the exemption and FERC treats agency recommendations as mandatory and attaches them to the exemption order as submitted.

Exempt projects are still FERC-jurisdictional and are inspected routinely by FERC at the same frequency as licensed projects, and FERC monitors compliance with the terms of the issued exemption order.

FERC's implementing regulations provide procedures for obtaining a license exemption for small hydroelectric power projects of $5 \mathrm{MW}$ or less. Small hydroelectric power projects are defined by FERC at 18 CFR 4.30(b)(29) and applications for a small hydro exemption must 
obtain the bulk of the powerhouse head from the dam and not the conduit. In our past work on similar projects, HDR has confirmed with FERC that small hydrokinetic projects are eligible for FERC's small hydropower exemption program, but we are not aware of any hydrokinetic project that has obtained, or is presently attempting to obtain, a 5-MW exemption today. The one project in Maine that had pursued a small hydro exemption for a tidal project abandoned the exemption process earlier this year when the resource agencies filed terms and conditions that required the barge-mounted turbine to be screened and velocities through the turbine reduced to less than $2 \mathrm{fps}$, which made the proposed project completely infeasible.

The following presents an overview of the criteria for seeking a small hydropower exemption from FERC:

- Total authorized installed capacity is less than $5 \mathrm{MW}$;

- The proposed project involves the development of new capacity;

- The project uses the potential of a non-government owned dam (for those projects that include a dam in their plan of development);

- The project cannot retain water for storage and release operations;

- The project can use a natural water feature without the need for a dam (hydrokinetic projects fit well here);

- The exemption application must demonstrate that applicant either owns all non-Federal lands needed or has an option to obtain title to all needed non-Federal lands (in other words, an exemption applicant cannot rely on eminent domain to obtain the lands needed to construct and operate the project); and

- An applicant cannot obtain an exemption for a portion of a currently licensed FERC project.

As framed in this feasibility study, the proposed bridge turbine project would qualify for a small hydropower exemption from FERC. However, given the current unknowns about the effects of proposed tidal turbines in general, it seems like the Maine resource agencies ruled conservatively on the side of caution in conditioning the barge-mounted turbines proposed for tidal waters off Maine and ordered provisions that they knew would avoid harm to potentially affected aquatic resources. Given that there is little to no precedence to work with here, there is a great deal of uncertainty in the outcome of pursuing a small hydro exemption for the bridge turbine projects.

18 CFR $\S 4.90$ implements Section 30 of the FPA and provides procedures for obtaining a license exemption for small-conduit hydroelectric facilities. These regulations are designed to expedite licensing of water supply projects where generation of power is an ancillary benefit 
rather than the primary project purpose. The bridge turbine projects would not be eligible for a conduit exemption.

\subsection{FERC's Hydrokinetic Pilot Licensing Process}

In April 2008, FERC staff issued a white paper providing guidance on hydrokinetic pilot project licensing procedures authorized by FERC's November 2007 Policy Statement ${ }^{2}$. In this white paper, FERC staff outlined the criteria and process for obtaining a pilot license for innovative projects that generate electricity from the motion of waves or the "unimpounded flow of tides, ocean currents, or inland waterways." As outlined by FERC staff, a pilot license could be obtained using specific waivers of the Integrated Licensing Process (ILP) for hydroelectric projects, defined in 18 CFR Part 5 of the FERC's implementing regulations. These waivers would expedite the ILP timeframe for small experimental hydrokinetic projects, and would provide a short license term that would allow an applicant to gather some data before beginning the relicensing process that would lead to a full term FERC operating license.

The purpose of the hydrokinetic pilot licensing process is to test new technologies and conduct studies in support of the technology testing and site selection. Hydrokinetic pilot licenses include mandatory safeguard plans to protect the public and the environment, with defined triggers for project shutdown and complete removal and site restoration if adverse effects cannot be addressed anytime during the pilot license period. Pilot licenses were designed to encourage the agencies to take a chance on supporting the deployment of emerging technology by ensuring that the safeguard measures will address any adverse effects that might occur.

For long term projects that initially pursue a hydrokinetic pilot license, FERC regulations require that the licensee begin relicensing the pilot project 5 years before expiration of the pilot license. For this reason, most applicants are requesting short pilot license duration terms of 8-10 years to allow the transition from the pilot license to a full FERC project license of greater duration, and without the required safeguard plans mandated under FERC's pilot license program.

\section{5 Seeking Non-Jurisdictional Status}

On March 23, 2010 FERC issued an $\operatorname{order}^{3}$ to the Maine Maritime Academy (Academy) finding that its proposal to deploy and test hydrokinetic devices at two coastal sites in Hancock County, Maine did not require licensing under Part I of the Federal Power Act. This was a precedent-setting decision that the HDR office in Maine helped develop that established a new option for an otherwise FERC-jurisdictional project to generate power without obtaining a FERC license.

\footnotetext{
${ }^{2}$ FERC Policy Statement on Conditioned Licenses for Hydrokinetic Projects, 121 ๆ 61,221 (2007).

${ }^{3}$ Maine Maritime Academy, 130 FERC $\uparrow$ 62,234 (2010)
} 
This finding of non-jurisdiction was supported by the Academy's October 28, 2009 proposal to "offer its students new educational opportunities, develop and codify means to engage the community in the advancement of tidal power, and provide a special relationship for the regulatory agencies to engage in studying the effects of proposed tidal energy devices". In summary, FERC applied the "Verdant Criteria"4 which allows deployment and testing of hydrokinetic devices under certain conditions and found that Academy's proposal met the three Verdant criteria. These criteria are:

1. the technology in question is experimental;

2. the proposed facilities are to be utilized for a short period for the purpose of conducting studies necessary to prepare a license application; and

3. power generated from the test project will not be transmitted into, or displace power from, the national electric energy grid.

Although the Academy's proposal clearly met criteria 1, compliance with criteria 2 and 3 was more vague and HDR sees some opportunity here for other parties interested in assessing if a similar approach might work for them. From a high-level perspective, FERC found that the primary purpose of the project was not power production but was more focused on testing, outreach and education.

We mention this option in this feasibility study only as a possible alternative to licensing if the County decides to explore teaming agreements with nearby schools or universities to configure and establish an approach to this project that can similarly be fashioned to satisfy FERC's Verdant Criteria. The Academy still had to obtain state and local approval for the proposed project, but this was done outside of FERC jurisdiction and oversight.

\section{6 Initial Recommendations for FERC Licensing Approach}

Based on HDR's current understanding of the Multnomah County Hydrokinetic project, current ownership, and resource designations, these sites appear to meet FERC criteria for a full license, a 5-MW license exemption, and a hydrokinetic pilot license.

As discussed above in Section 3.1, FERC's default licensing process is the Integrated Licensing Process (ILP), which was designed to create efficiencies by integrating a potential license applicant's pre-filing consultation requirements with FERC's scoping pursuant to the National Environmental Policy Act (NEPA). HDR has found that the ILP provides applicants with advantages in many licensing proceedings, especially during the negotiation and development of study plans. However, the ILP was designed for relicensing efforts, and is often viewed as less flexible than FERC's Traditional Licensing Process (TLP), which does not include mandated timelines and schedules. FERC has recently made efforts to expedite

${ }^{4}$ Verdant Power LLC, 111 FERC \ 61,024 (2005), order on clarification, 112 FERC \ 61,143 (2005). 
licensing for new small hydro projects use the TLP; nearly 30 such projects have been licensed within one year of their Notice of Intent to file a license application. Because the TLP likely offers the most potential for a reduced-cost, expedited licensing process, HDR's initial recommendation for the bridge turbine project would be to initiate a TLP if the decision is made to move forward with the project. If the County were to team with a local educational institution on the project, then non-jurisdictional status could be sought with FERC. In this cased the County would still need to obtain state and local approval for a project without FERC jurisdiction and oversight.

\subsection{Other Federal and State Permitting}

Other federal and state permits or authorizations that are expected to be needed are summarized in Table 1.

Table 1. Summary of federal and state permits or authorizations that are likely to be required.

\begin{tabular}{|l|l|l|}
\hline \multicolumn{1}{|c|}{ Agency } & \multicolumn{1}{|c|}{ Regulation } & \multicolumn{1}{|c|}{ Permit/Authorization } \\
\hline U.S. Army Corps of Engineers & $\begin{array}{l}\text { Clean Water Act Section 404; } \\
\text { Rivers and Harbors Act Section 10 }\end{array}$ & $\begin{array}{l}\text { Section 404 Permit; } \\
\text { Section 10 Permit }\end{array}$ \\
\hline $\begin{array}{l}\text { Oregon Water Resources } \\
\text { Department }\end{array}$ & $\begin{array}{l}\text { Oregon Revised Statute 543- } \\
\text { Hydroelectric Projects (ORS 543) }\end{array}$ & State Hydroelectric License \\
\hline Oregon Department of State Lands & $\begin{array}{l}\text { Oregon Administrative Rules 141- } \\
125\end{array}$ & $\begin{array}{l}\text { Section 401 } \\
\text { Water Quality Certification }\end{array}$ \\
\hline $\begin{array}{l}\text { Oregon Department of } \\
\text { Environmental Quality }\end{array}$ & $\begin{array}{l}\text { Clean Water Act Section 401 and } \\
\text { OAR 340-048 }\end{array}$ & Removal-Fill Permit \\
\hline Oregon Department of State Lands & Oregon Administrative Rule 141-85 & $\begin{array}{l}\text { Private Aids to Navigation } \\
\text { Permit }\end{array}$ \\
\hline U.S. Coast Guard & $\begin{array}{l}\text { Title 33 Code of Federal } \\
\text { Regulations 33 part 62 and 66 }\end{array}$ & \\
\hline $\begin{array}{l}\text { Oregon Department of Land and } \\
\text { Conservation Development }\end{array}$ & Coastal Zone Management Act & \\
\hline
\end{tabular}

\subsection{Capitol Costs and Project Economics}

This section provides an overview of the conceptual cost opinions for different turbine layouts at each site, and an economic assessment of each option over 40 years.

\subsection{Capitol Cost Opinions}

American Association of Cost Engineering (AACE) Class 4 cost opinions for the three potential projects described herein have been completed to support a review of project 
economics and are discussed below. Summary cost opinions for each option are included as Attachment 5 to this report.

Project features for each site include:

- one to four hydrokinetic turbines,

- associated electrical equipment,

- structural supports attached to the existing bridge piers,

- a floating pontoon barge, and

- electrical interconnection features.

Cost estimates for the hydrokinetic turbines were received from ABS Alaskan and HydroVolts. The cost for the structural supports, electrical interconnections features, and pontoon barge(s) for each site were estimated based on experience with similar projects. The cost of new subsea cable to interconnect the turbines with the existing electrical distribution system on the bridges was estimated at $\$ 200$ per linear foot and the cost of new electrical conduit to be run along the bridge was estimated at $\$ 50$ per linear foot. At the Broadway Bridge site it was assumed that the existing subsea cables could be used to interconnect two $25-\mathrm{kW}$ hydrokinetic turbines.

Using these assumptions, and including projected fees for engineering and licensing and a 30-percent contingency due to the conceptual level of the design, HDR estimated the total cost of developing a hydrokinetic project at each site. For the Broadway and Morrison Bridge sites both single-turbine and multiple-turbine projects were considered with generation up to the current energy consumption at the bridge.

The total project cost for a single $25-\mathrm{kW}$ EnCurrent turbine at the Broadway Bridge site is estimated to be approximately $\$ 523,000$ and a single unit at the Morrison site is estimated to cost approximately $\$ 575,000$. The additional cost for a project at the Morrison site is due to the need to install new subsea cables for interconnecting the turbine to the bridge's electrical distribution system. Similarly, the cost of single 11-kW HydroVolts turbine at the Sellwood Bridge site is estimated to be approximately $\$ 491,000$.

Installation of multiple turbines at any of the bridge sites would benefit from economies of scale due to shared costs for engineering, licensing, and electrical interconnection. Accordingly, the estimated cost of two $25-\mathrm{kW}$ EnCurrent turbines installed under the Broadway Bridge is approximately $\$ 754,000$ and the cost of four turbines under the Morrison Bridge is approximately $\$ 1,292,000$. The estimated cost of a four-turbine project under the Sellwood Bridge is $\$ 1,422,000$. 


\subsection{Project Economics}

The Good Company completed a review of available funding options for the project that is included as Attachment 6 to this report. Their research identified several opportunities for project funding from state, federal, not-for-profit, and private entities. In addition, they also helped identify potential teaming partners that could provide monetary and in-kind support for a project, and provided guidance on appropriate assumptions for economic analysis of the proposed projects. A preliminary analysis of the payback period for each project was conducted based on the conceptual cost opinions, energy estimates, and review of available funding options. The following key assumptions were included in the economic analysis:

- Avoided cost of power at the Broadway and Morrison bridges starting at $\$ 0.095 / \mathrm{kWh}$ in 2012 and escalating at 6 percent per year based on data provided by the County;

- Renewable Energy Credits (RECs) are not available

- Power-purchase price based on PGE wholesale rate forecast from 2012 through 2030.

- Operating expenses of $\$ 0.02$ per $\mathrm{kWh}$, escalating at 4 percent per year;

- Turbine replacements after 20 years of operation;

- A bond term of 20 years and a financing rate of 5.5 percent per year; and

- Grant funding for $50 \%$ of the estimated cost of the project.

The assessment of the hydrokinetic resource showed that the velocities in the Lower Willamette River are to low to support commercial hydrokinetic generation. Payback periods ranged from a minimum of 320 years for one EnCurrent Turbine at Sellwood Bridge to over 350 years for other devices and conceptual layouts. The avoided cost of an $11 \mathrm{~kW}$ HydroVolts turbine at Sellwood Bridge was about $\$ 347$ per year, while the avoided cost with a $25 \mathrm{~kW}$ EnCurrent machine at the same location was about $\$ 905$ per year. This revenue stream is not sufficient to repay the cost of the project during its useful life. The low estimated annual production for both commercial devices in consideration was the primary driver of the long payback periods estimated by the economic analysis. Details of the economic analysis for a one turbine project at the Sellwood Bridge site are included as Attachment 7 to this memorandum.

\subsection{Summary and Conclusions}

A summary of the results of HDR's feasibility study is included in Table 2 on the following page. As can be seen, the minimum estimated economic payback period is 320 years for a single net metered $25 \mathrm{~kW}$ EnCurrent turbine at the Sellwood Bridge. The long payback periods are caused 
by the low velocities at the sites in consideration. The frequency and duration of high flow events which provide suitable velocities is not sufficient to support a commercial installation.

Table 2. Feasibility assessment results summary. Assume net metering unless otherwise noted.

\begin{tabular}{|l|c|c|c|c|c|c|}
\hline Development Option & $\begin{array}{c}\text { Total } \\
\text { Capacity }\end{array}$ & $\begin{array}{c}\text { Energy } \\
\text { Production }\end{array}$ & $\begin{array}{c}\text { Energy } \\
\text { Consumption }\end{array}$ & $\begin{array}{c}\text { Total Project } \\
\text { Cost }\end{array}$ & $\begin{array}{c}\text { Annual } \\
\text { Avoided Cost } \\
\text { (Revenue) }\end{array}$ & $\begin{array}{c}\text { Simple } \\
\text { Payback } \\
\text { Period }\end{array}$ \\
\hline \multicolumn{1}{|c|}{ non-dim } & kW & kWh/year & kWh/year & $\mathbf{2 0 1 2 ~ \$}$ & $\mathbf{2 0 1 2 ~ \$ / y e a r ~}$ & years \\
\hline $\begin{array}{l}\text { Broadway Bridge Two } \\
\text { EnCurrent Turbines }\end{array}$ & 50 & 8,300 & 99,000 & $\$ 754,000$ & $\$ 838$ & $>350^{*}$ \\
\hline $\begin{array}{l}\text { Morrison Bridge Four } \\
\text { EnCurrent Turbines }\end{array}$ & 100 & 18,400 & 239,000 & $\$ 1,292,000$ & $\$ 1,800$ & $350^{*}$ \\
\hline $\begin{array}{l}\text { Sellwood Bridge } \\
\text { Single HydroVolts } \\
\text { Turbine }\end{array}$ & 11 & 3,500 & 46,000 & $\$ 491,000$ & $\$ 347$ & $>350^{*}$ \\
\hline $\begin{array}{l}\text { Sellwood Single } \\
\text { EnCurrent }\end{array}$ & 25 & 9,000 & 46,000 & $\$ 582,000$ & $\$ 905$ & $320^{*}$ \\
\hline $\begin{array}{l}\text { Sellwood Bridge } \\
\text { Single EnCurrent } \\
\text { Turbine - PPA }\end{array}$ & 25 & 9,000 & 46,000 & $\$ 582,000$ & $\$ 375$ & $>350^{*}$ \\
\hline
\end{tabular}

* Simple payback periods were calculated based on the County's investment, assuming $50 \%$ of the project would be funded by grants.

Although the available energy in the river is not sufficient to support commercial generation, the opportunity exists to develop a hydrokinetic test site which could function as an educational site for the general public. Several local universities with engineering interest in renewable energy may be interested in a partnership which could provide funding for projects which foster education and promote technical development in hydrokinetic technology. This approach would encourage increased funding for a potential project, while also providing a positive community relations opportunity for the County.

Should the County choose to move forward with any of these projects, the next steps would be to initiate contacts with the OWRD to explore whether the project can be permitted under Oregon's restrictive statutes that prohibit development of hydropower within designated anadromous salmon and steelhead habitat, develop a preliminary design of each project, continue to measure instream velocities to validate conceptual design assumptions, and begin licensing and permitting of the project(s) if the project is determined feasible and permissible by the ORWD. We estimate that the time required to complete the preliminary design, environmental studies, permitting, and final design will be approximately three years for any of the projects. Once the permitting process has been completed, we estimate that construction can be completed within six months. 
Mr. Tye Aldana

March 15, 2012

Page 28 of 28

It is our pleasure to provide this study of the technical feasibility and potential permitting issues of these proposed hydrokinetic projects on the County's bridges. If you have any further questions or comments, or wish to proceed with our services, please let us know. 
Attachment 1

Screening Study Memo, October 31, 2011 


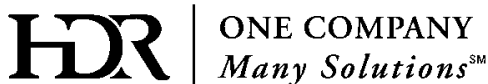

Memo

\begin{tabular}{|l|l|l|l|}
\hline To: & \multicolumn{2}{|l|}{ Tye Aldana, P.E. } \\
\hline From: & $\begin{array}{l}\text { David Elwood, P.E. and } \\
\text { Steve Meicke, E.I.T }\end{array}$ & Project: & $\begin{array}{l}\text { Multnomah County Hydrokinetic Feasibility } \\
\text { Study }\end{array}$ \\
\hline cc: & John Henderson, Stephen Spain, P.E. & Job No: & 150650 \\
\hline Date: & October 31, 2011 & \multicolumn{2}{|l}{} \\
\hline RE: & Preliminary Screening Study, Potential Hydrokinetic Generation Sites \\
\hline
\end{tabular}

\section{Project Description}

HDR Engineering Inc. (HDR) is currently under contract with Multnomah County (the County) to complete a feasibility study of hydrokinetic energy generation on six of the County's existing bridges on the Willamette River near Portland, OR. The County is interested in determining the costs and benefits of a potential hydrokinetic project at one or more of its bridges and the regulatory and environmental issues that might be associated with such a project. HDR has completed an initial screening study to determine which bridges have the best potential for a hydrokinetic project based on the available hydrokinetic resource. Based on the results of the screening study the County will decide which of the potential projects (if any) is most viable and whether to proceed with a formal feasibility study for the most attractive site(s).

In August 2011 HDR met with the County for a kick-off meeting to discuss the detailed scope and schedule for the hydrokinetic feasibility study. At the meeting HDR provided the County with a list of desired data to be used in the study. As part of the initial screening study HDR has reviewed the information provided by the County and others on the existing infrastructure, previous in-stream velocity measurements, energy consumption at each bridge, and other pertinent information. A bibliography of the documents reviewed as part of this screening study is included as Attachment 1 to this memo.

On September 21, 2011 HDR and County staff visited four of the potential hydrokinetic sites (Hawthorne, Morrison, Burnside, and Broadway bridges) to assess the existing infrastructure and potential for energy generation. A summary of the findings of the site visit is included as an Attachment 2 to this memorandum. During the site visit HDR and County staff discussed the hydrokinetic potential at the Sauvie Island bridge site and concluded that, due to its location on the Multnomah channel, the hydrokinetic resource there would be substantially less than under the bridges on the main-stem Willamette River. A desktop assessment of the available hydrokinetic energy under the remaining five bridges (Hawthorne, Morrison, Broadway, Burnside, and Sellwood) was performed using a one-dimensional (1-D) numerical hydraulic model (HEC-RAS). Based on the resource a conceptual hydrokinetic turbine capacity and size was estimated for each site. 
This memo provides recommendations for those sites that should be investigated in a more detailed feasibility study based on the following selection criteria: mean channel velocity; hydrokinetic power density; existing subsea cables; nearby electrical loads; and potential navigation impacts.

Table 1: Potential Sites for Hydrokinetic Generation

\begin{tabular}{|c|c|c|c|c|c|}
\hline Site & $\begin{array}{l}\text { Mean Channel } \\
\text { Velocity* (ft/s) }\end{array}$ & $\begin{array}{c}\text { Hydrokinetic } \\
\text { Power Density } \\
\text { (Watts/ft^2) }\end{array}$ & $\begin{array}{c}\text { Existing Subsea } \\
\text { Cable }\end{array}$ & $\begin{array}{c}\text { Average Electrical } \\
\text { Load }\end{array}$ & $\begin{array}{c}\text { Potential } \\
\text { Navigation } \\
\text { Impacts }\end{array}$ \\
\hline Hawthorne Bridge & 2.7 & 25 & $\mathrm{~N} / \mathrm{A}$ & $\begin{array}{c}7 \mathrm{~kW} \text { at bridge. } \\
5 \mathrm{~kW} \text { at shop. } \\
\text { (12 kW total) }\end{array}$ & More likely \\
\hline Morrison Bridge & 2.9 & 36 & N/A & $23 \mathrm{~kW}$ & Unlikely \\
\hline Burnside Bridge & 2.8 & 34 & Existing DC Cable. & $14 \mathrm{~kW}$ & More likely \\
\hline Broadway Bridge & 2.8 & 34 & $\begin{array}{l}\text { Existing } \mathrm{DC} \text { and } \mathrm{AC} \\
\text { cables. }\end{array}$ & $11 \mathrm{~kW}$ & Unlikely \\
\hline Sellwood Bridge & 3.7 & 50 & N/A & Less than $1 \mathrm{~kW}$ ** & Very Unlikely \\
\hline
\end{tabular}

*Mean channel velocity at Willamette River flow of 110,000 cfs (5\% Exceedance)

** While the electric load at Sellwood is currently less than $1 \mathrm{~kW}$ there is potential for the load to increase substantially after replacement of the bridge

Table 1 provides a summary of the finding of the screening study for the five bridges on the main-stem Willamette River. Based on the results of the screening study HDR believes that the three sites with the best potential for hydrokinetic energy generation are (in no particular order):

- Sellwood Bridge - The Sellwood bridge site has the best hydrokinetic resource based on the results of the 1-D hydraulic modeling and would have the least impact on navigation due to its location upstream of Ross Island.

- Broadway Bridge - The Broadway Bridge has slightly less hydrokinetic resource than Sellwood but the existing subsea cabling at the site could significantly reduce the cost of electrical interconnection. Navigational impacts are unlikely under the Broadway Bridge since the lift span pier spacing is over 275 feet.

- Burnside Bridge - The Burnside Bridge has slightly less hydrokinetic resource than Sellwood but the existing subsea cabling at the site could significantly reduce the cost of electrical interconnection. Navigational impacts are more likely under the Burnside Bridge if hydrokinetic turbine(s) are installed within the lift span. Hydrokinetic turbine(s) could be installed on the shoreward sides of the bridge piers without significantly impacting navigation.

Should the County wish to move forward with a formal feasibility study at one or more of the sites we would recommend the following near-term activities to assess the technical, environmental, regulatory, and economic feasibility of hydrokinetic energy generation under the County’s bridges:

- Contact potential hydrokinetic turbine vendors to confirm assumptions on turbine sizing, efficiency, cut-in velocity, and cut out velocity.

- Assess the site-specific hydrodynamics of the top three sites to determine the potential for local areas of higher velocity within the channel.

- Identify potential environmental, navigation, and recreation impacts at each site; 


\section{Preliminary Hydraulic Modeling and Hydrokinetic Resource Assessment}

Since the available energy in the Willamette changes in each stretch of the river, a model of the lower Willamette River was created in order to identify which of the sites in consideration has the highest hydrokinetic potential. A 1-D hydraulic model developed by the United States Army Corps of Engineers (USACE) called HEC-RAS was used to model the river starting approximately one mile upstream of the Sellwood Bridge and ending at the confluence of the Willamette and Columbia Rivers. Bathymetric data obtained from the USACE was used to define the contours of the river bottom. Using cross sectional data from 160 stations along the river length in consideration, the model determines the energy loss in the flow due to bottom friction (across various types of river bed) and interaction with in-stream structures such as bridges. The model then calculates the mean channel velocity at each cross section and bridge location based on the modeled hydraulic grade line.

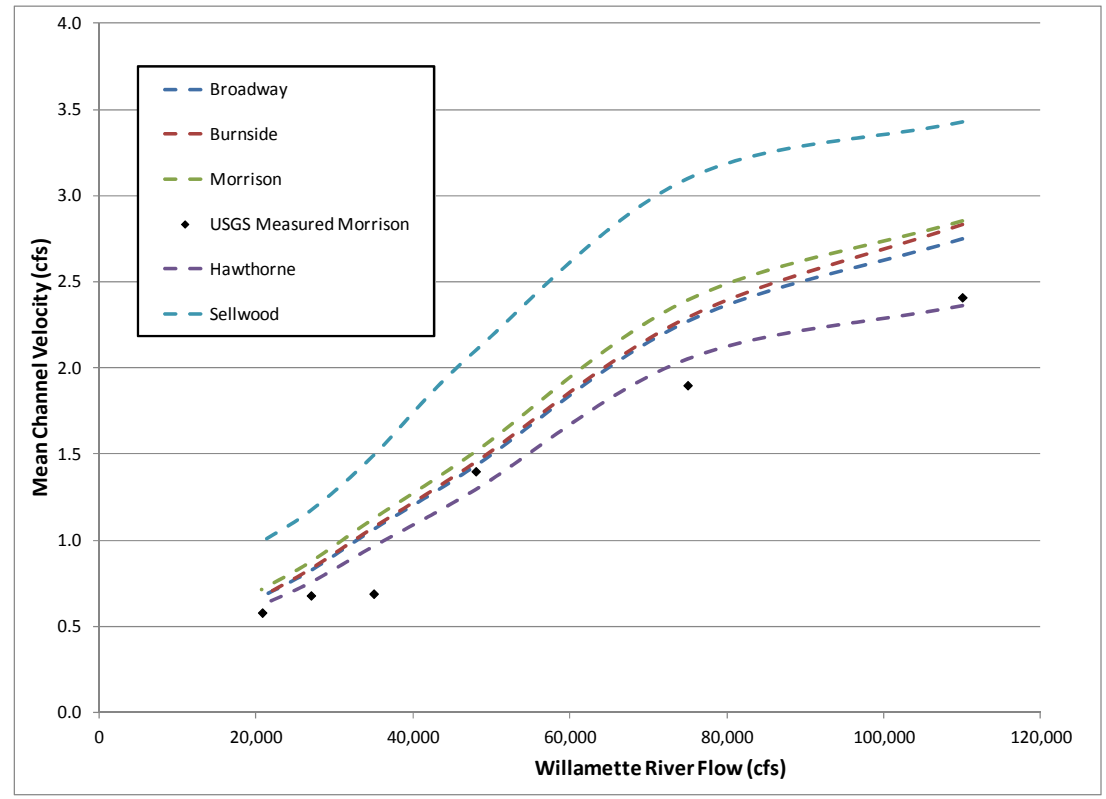

Figure 1. Predicted Mean Channel Velocity Under Each Bridge (from HEC-RAS) and Measured Velocity under the Morrison Bridge (USGS)

The model was calibrated using velocity and stage data from a United States Geologic Survey (USGS) gage located within the dolphin on the South pier of the Morrison Bridge. HDR's analysis of the measured flow and velocity data from under the Morrision Bridge is included in Attachment 3 to this memorandum. Model results were compared to velocity and stage measurements taken at the Morrison Bridge during six separate measured flow conditions ranging from 20,800 cfs to 110,000 cfs. Adjustments to the modeled channel roughness were made as needed to obtain agreement with known boundary conditions and gage measurements. Boundary conditions for the model were obtained from USGS river stage gages at Willamette Falls, Morrison Bridge, and a National Oceanographic and Atmospheric Administration (NOAA) tide gage near the confluence of the Willamette and Columbia rivers. Other key assumptions of the modeling include:

- One-dimensional hydraulic model based on the Manning’s Equation. Steady, sub-critical, openchannel flow was assumed.

- Effect of tide on hydraulics is minimal over the range of flows selected (Calibration data was selected from periods where the effect of tide was minimized). 
- Flow split around Ross Island based on the ratio of the channel area on the right and left side of the island.

- Bridge pier geometry and spacing based on as-built drawings of the Hawthorne, Morrison, Burnside and Sellwood bridges. Pier geometry and spacing for the Sellwood Bridge was based on conceptual drawings of the planned new piers.

As can be seen in Figure 1 the mean channel velocity under each of the bridges, as predicted by the hydraulic model, varies from less than one to over three feet per second over the range of river flows investigated. These flow velocities are lower than would typically be desired for a commercial hydrokinetic project (commercial project developers typically desire velocities exceeding 3 feet per second). While the mean channel velocity is generally low there may be locations within the channel where the flow is accelerated by site-specific hydraulic features in the river. In general the measured and modeled mean channel velocities in the lower Willamette River indicate that a small (approximately $5 \mathrm{~kW}$ ) hydrokinetic turbine is technically feasible at any of the six bridge sites investigated. The size, type, cost, and potential energy generation from such a turbine would require further study in a more in-depth feasibility study. This study should include an assessment of the hydrodynamics of the river adjacent to the potential hydrokinetic generation sites.

\section{Conceptual Turbine Sizing}

To develop a conceptual size for potential turbines at each site the hydrokinetic power density was calculated based on the modeled mean channel velocity. This mean channel power density represents the average power in the channel per unit area. As discussed previously, the velocity in river channels is rarely uniform and the power density will vary depending on the location of the turbine in the channel. Flow velocities also tend to increase near instream structures (like bridge piers) creating areas of higher power density within the channel. More study of the site-specific hydrodynamics should allow for placement of the turbines at the area of the channel with the highest energy density, potentially reducing the size (and cost) of the turbine.

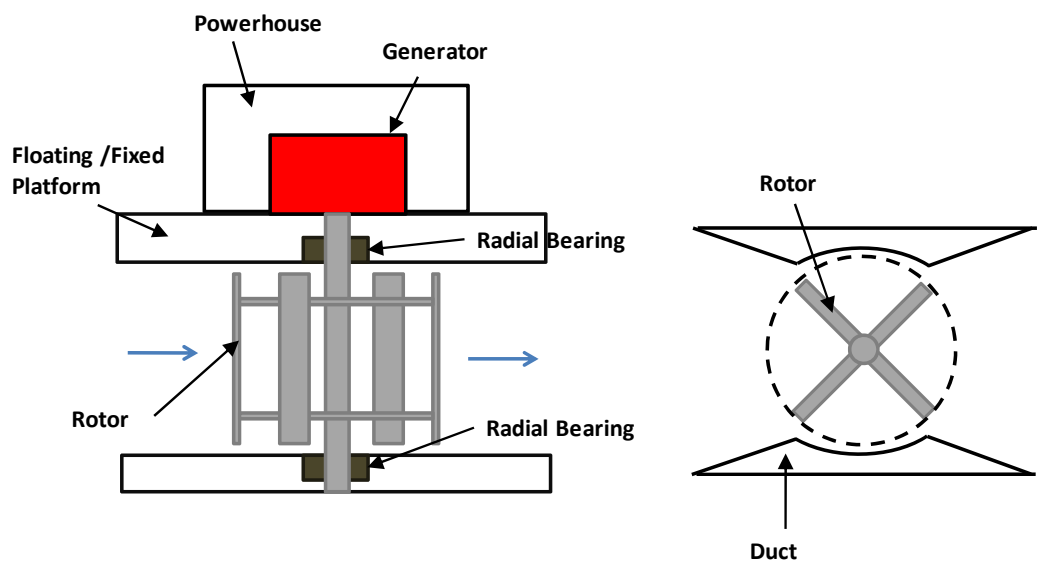

Figure 2. Typical Vertical- Axis Hydrokinetic Turbine

For this conceptual study a vertical-axis hydrokinetic turbine (similar to the Encurrent turbine cut sheet included in Attachment 4) was assumed at each site. These turbines consist of a rotor that turns about a vertical axis of rotation similar to a vertical-axis wind turbine, as shown in Figure 2. Vertical axis machines can accommodate fluid flows from all directions without having to reverse the direction of turbine rotation and generally have lower cut-in speeds than horizontal-axis machines. Vertical axis turbines are typically suspended from a structure on the water's surface with the generator and associated electrical equipment 
above water. The efficiency of this type of turbine varies depending on the flow velocity, turbulence, percentage of the channel flow blocked by the turbine, and other factors. For the purposes of this study a water-to-wire efficiency of 30-percent was assumed, based on experience with the measured performance of similar equipment, and was used to calculate the extractable power density. At each site a rotor diameter of 15-feet was assumed and the required depth of the rotor for a 5-kilowatt machine was calculated. A summary of the results of the conceptual turbine sizing is provided in Table 2.

Table 2. Conceptual Hydrokinetic Turbine Sizing

\begin{tabular}{|c|c|c|c|c|}
\hline & \multicolumn{2}{|c|}{ Mean Channel Power Density } & \multicolumn{2}{c|}{ Size of 5kW Turbine } \\
\hline Site & $\begin{array}{c}\text { Gross Power } \\
\text { (Watts/ft^2) }\end{array}$ & $\begin{array}{c}\text { Extractable } \\
\text { Power } \\
\text { (Watts/ft^2)* }\end{array}$ & $\begin{array}{c}\text { Turbine } \\
\text { Diameter (ft) }\end{array}$ & $\begin{array}{c}\text { Turbine Depth } \\
\text { (ft) }\end{array}$ \\
\hline Hawthorne Bridge & 25 & 8 & 15 & 45 \\
\hline Morrison Bridge & 36 & 11 & 15 & 31 \\
\hline Burnside Bridge & 34 & 10 & 15 & 33 \\
\hline Broadway Bridge & 34 & 10 & 15 & 22 \\
\hline Sellwood Bridge & 50 & 15 & 15 & 33 \\
\hline
\end{tabular}

*Assumes turbine efficiency of $30 \%$ based on a typical vertical-axis turbine.

As can be seen in Table 2 the depth of turbine required for 5-kilowatt machine varies from 22-feet (Sellwood) to 45-feet (Hawthorne). A 10-percent increase in velocity could reduce the required turbine depth of a turbine at Sellwood to approximately 18-feet. Based on prior experience we believe it is likely that there are areas within the channel under each bridge where the velocity is more than 10-percent greater than the mean channel velocity.

\section{Existing Subsea Cables}

Four of the five bridges evaluated in this screening study are lift bridges that require provisions for providing power on either side of the lift span. In the past power was transferred from one side of the river to the other at the Burnside and Broadway Bridges via subsea cables. Currently power is supplied to the bridges via separate utility interconnections of either end of each bridge and the subsea cables are not utilized for power distribution. The existing cables could be used to interconnect hydrokinetic turbines installed under the bridges to the utility grid. Having existing subsea cables under these two bridges for potential interconnection of the turbines could reduce the cost of installing a turbine at either site.

\section{Electrical Loads at Bridges}

HDR has completed a preliminary analysis of electrical usage data provided by the County for the five bridges being considered in this study. The analysis indicates that the average electrical load at the bridges currently ranges from less than one kilowatt (Sellwood bridge) to over twenty kilowatts (Morrison bridge). The load at the lift bridges in downtown Portland varies with operation of the lifting motors, street lights, heaters, and other electrical equipment. Based on discussions with County staff the minimum (idling) load for the lift bridges varies from five to ten kilowatts depending on the bridge. While the current average load at the 
Sellwood bridge is less than one kilowatt it is our understanding that the new Sellwood Bridge will have significantly greater loads. Further analysis of the current and planned energy consumption and cost of energy at the bridges is recommended should the County move forward with a formal feasibility study. A summary of HDR analysis of the available electric data is included as Attachment 5 to this memorandum.

\section{Potential Navigational Impacts}

From its confluence with the Columbia River to Ross Island, the Willamette River passes through the commercial, industrial and downtown waterfront of Portland. This section of the river is utilized by numerous existing users including commercial and recreational water craft. Upstream from the Ross Island Bridge, the river enters a green belt area and commercial navigation is reduced. Based on discussions with County bridge operators, the largest crafts that typically transit between the Broadway Bridge and Ross Island are double wide commercial barges transporting material to and from the Ross Island Sand and Gravel Mine (see Figure 3). As a result it is very unlikely that installation of hydrokinetic turbines under the Sellwood bridge would impact commercial navigation since the bridge is upstream of the Ross Island Sand and Gravel Mine. Potential impacts on navigation are more likely for the bridges in downtown Portland.

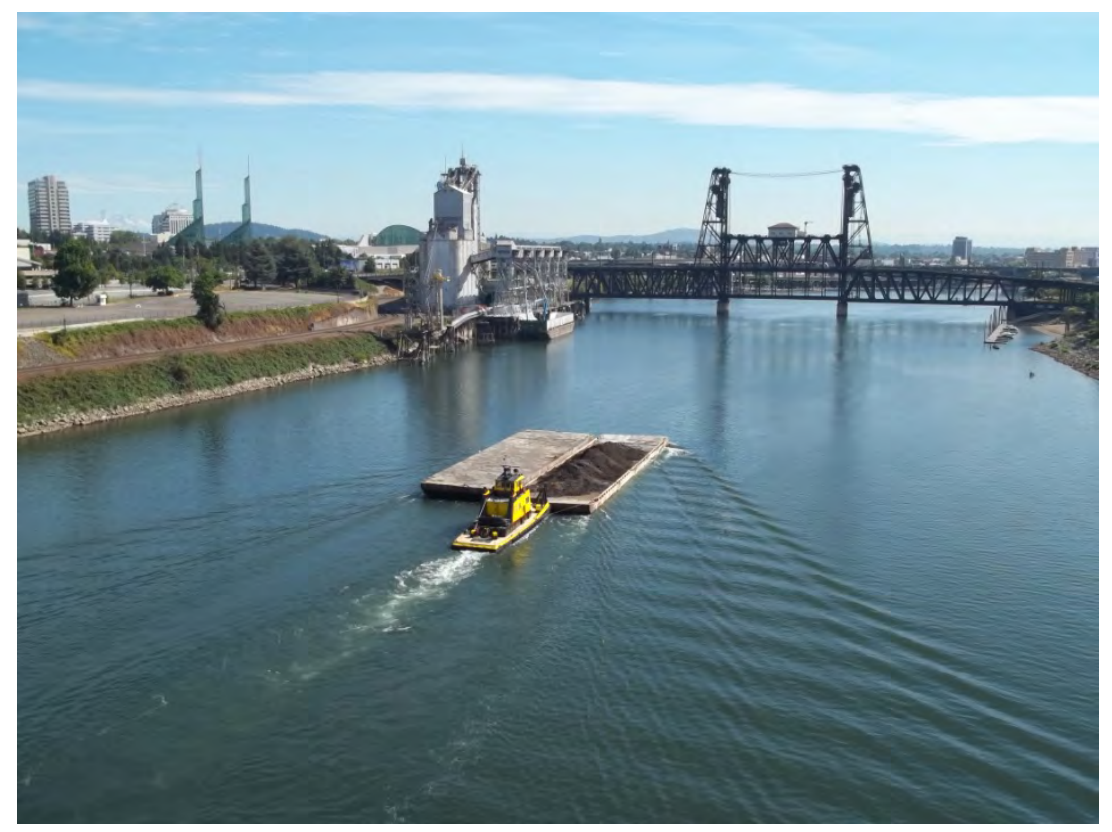

Figure 3. Barge Transiting downstream from Broadway Bridge toward the Steel Bridge

Currently the minimum horizontal clearance in the downtown Portland navigation channel is at the Burnside Bridge, where the piers under the lift span are approximately 240 -feet apart. The horizontal clearance between the lift span piers on the other downtown bridges range from approximately 250-feet (Hawthorne bridge) to approximately 285-feet (Morrison Bridge). If two 15-foot diameter hydrokinetic turbines are installed in the navigational channel under the Morrison or Broadway bridges more than 240-feet of horizontal clearance could be maintained between the piers. Therefore impacts to navigation at these two bridges from a potential hydrokinetic project are unlikely. Impacts to navigation would be more likely if turbines were installed under either the Hawthorne or Burnside bridges where installing a single 15-foot diameter turbine within the lift span could reduce the horizontal clearance to less than 240 -feet. Depending on the site-specific velocities under each bridge the turbines might also be positioned outside the navigational channel further reducing the potential navigational impacts of the turbines. 
Additional analysis of existing uses of the lower Willamette waterway will be required as part of a formal feasibility study to identify potential impacts of a hydrokinetic project under one or more of the County's bridges. For the downtown bridges, bridge opening logs provided by the County could be used to quantify the current level of vessel traffic in the lower Willamette.

\section{Summary and Recommendations}

HDR has completed an initial screening study to determine which of the County's bridges on the main-stem Willamette River have the best potential for a hydrokinetic project. The screening study was based on HDR's review of available information, field reconnaissance of the bridges, analysis of existing instream velocity data, and a preliminary 1-D hydraulic analysis. The results of the screening study indicate that hydrokinetic generation is technically feasible under all of the County's bridges. While the extractable hydrokinetic power density in the lower Willamette is lower than most sites being considered for commercial hydrokinetic project, there is sufficient potential for one or more $5 \mathrm{~kW}$ turbines that could provide enough power to offset a portion of the energy consumed on the bridges. HDR has compared the relative merits of each of the six bridge sites considered in this screening study on the basis of mean channel velocity, hydrokinetic power density, existing subsea cables for electrical interconnection, existing (and planned) electric loads, and potential navigational impacts. Based on the results of the screening study HDR believes that the three sites with the best potential for hydrokinetic energy generation are (in no particular order):

- Sellwood Bridge - The Sellwood bridge site has the best hydrokinetic resource based on the results of the 1-D hydraulic modeling and would have the least impact on navigation due to its location upstream of Ross Island.

- Broadway Bridge - The Broadway Bridge has slightly less hydrokinetic resource than Sellwood but the existing subsea cabling at the site could significantly reduce the cost of electrical interconnection. Impacts to commercial navigation are unlikely for turbines installed under the Broadway bridge.

- Burnside Bridge - The Burnside Bridge has slightly less hydrokinetic resource than Sellwood but the existing subsea cabling at the site could significantly reduce the cost of electrical interconnection. Navigational impacts are more likely under the Burnside Bridge if hydrokinetic turbine(s) are installed within the lift span. As a result a turbine(s) would likely need to be installed on the shoreward sides of the bridge piers. 
Attachment 2

Willamette Historical Velocity Measurements 


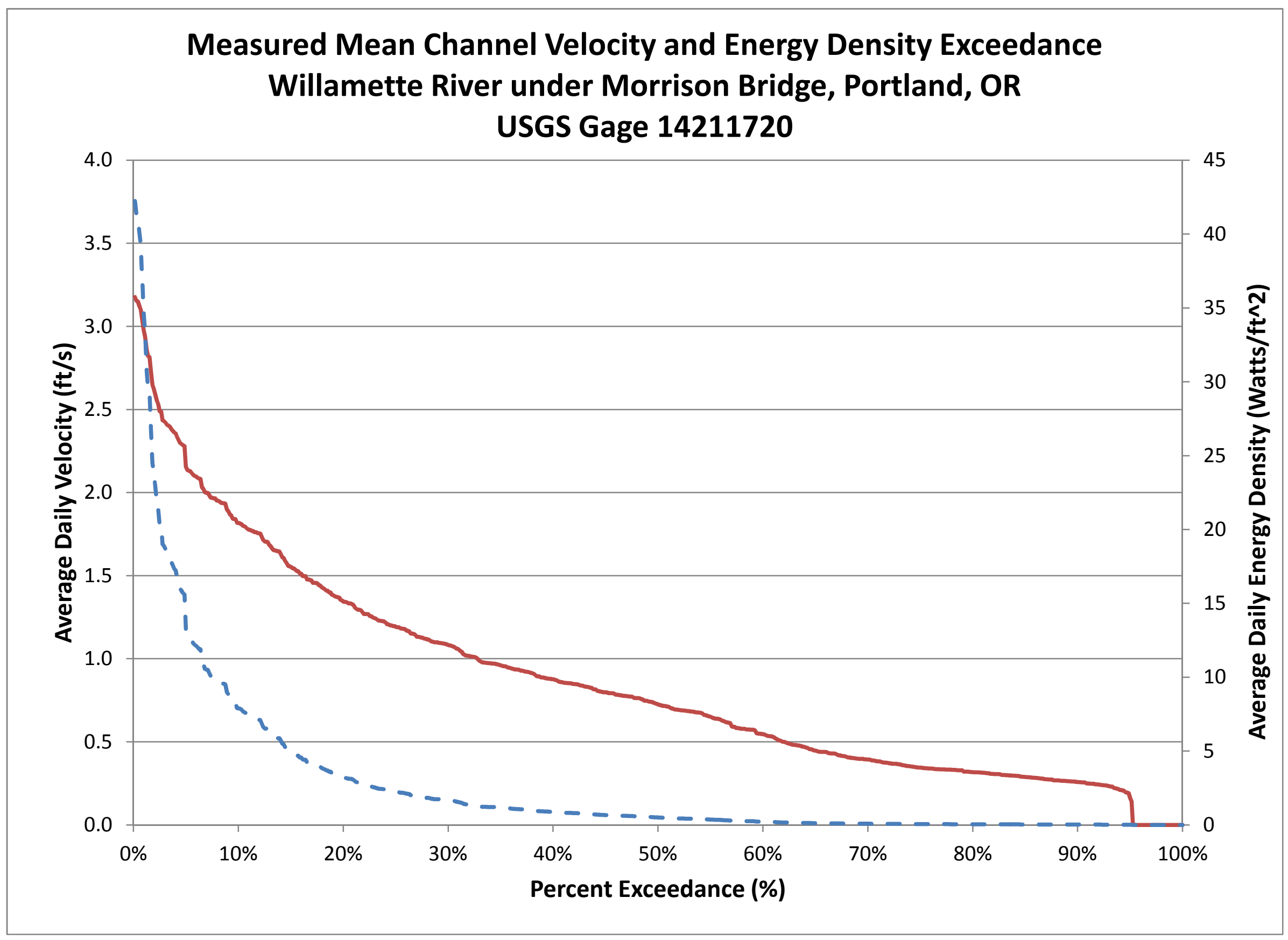




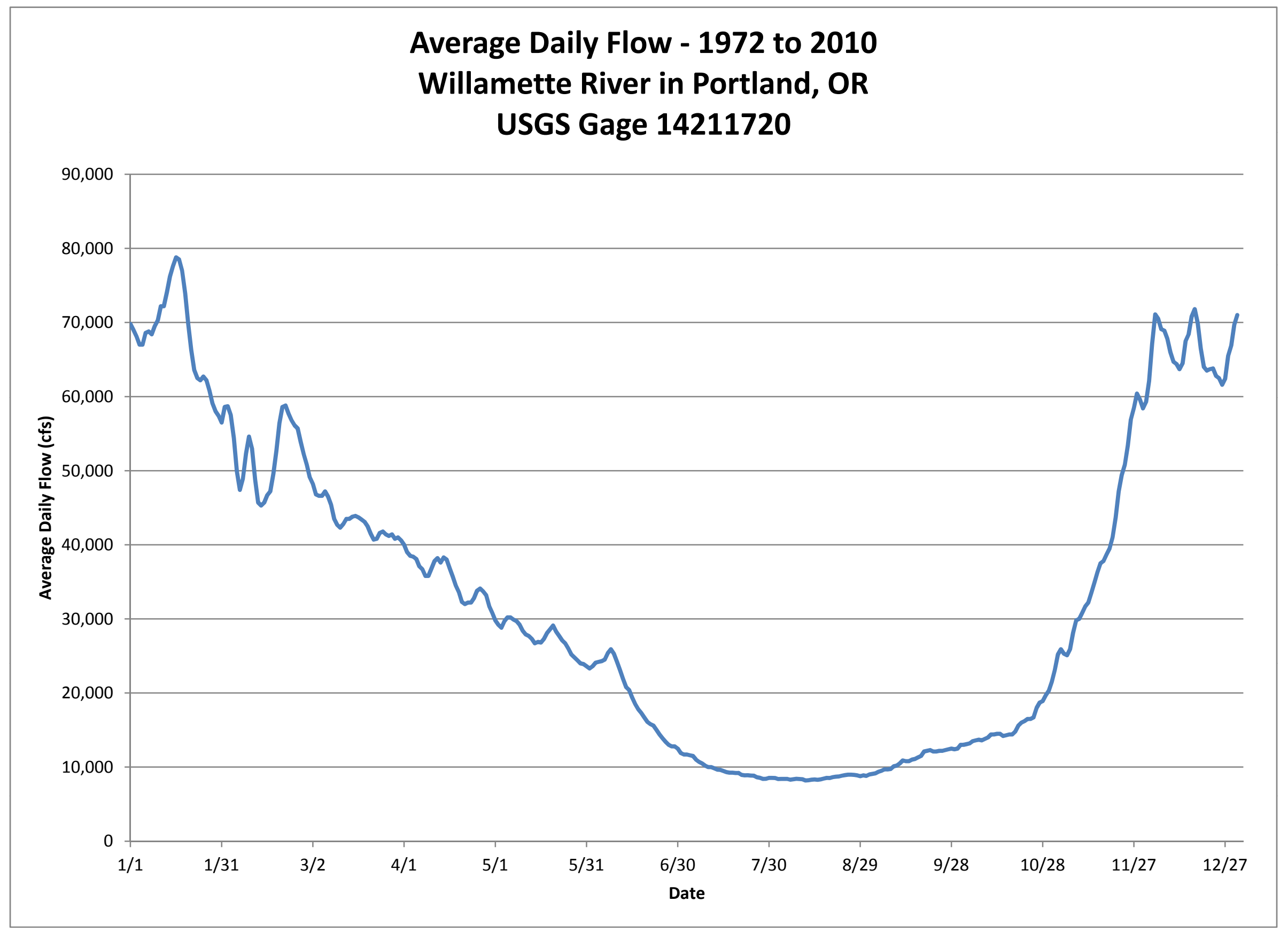




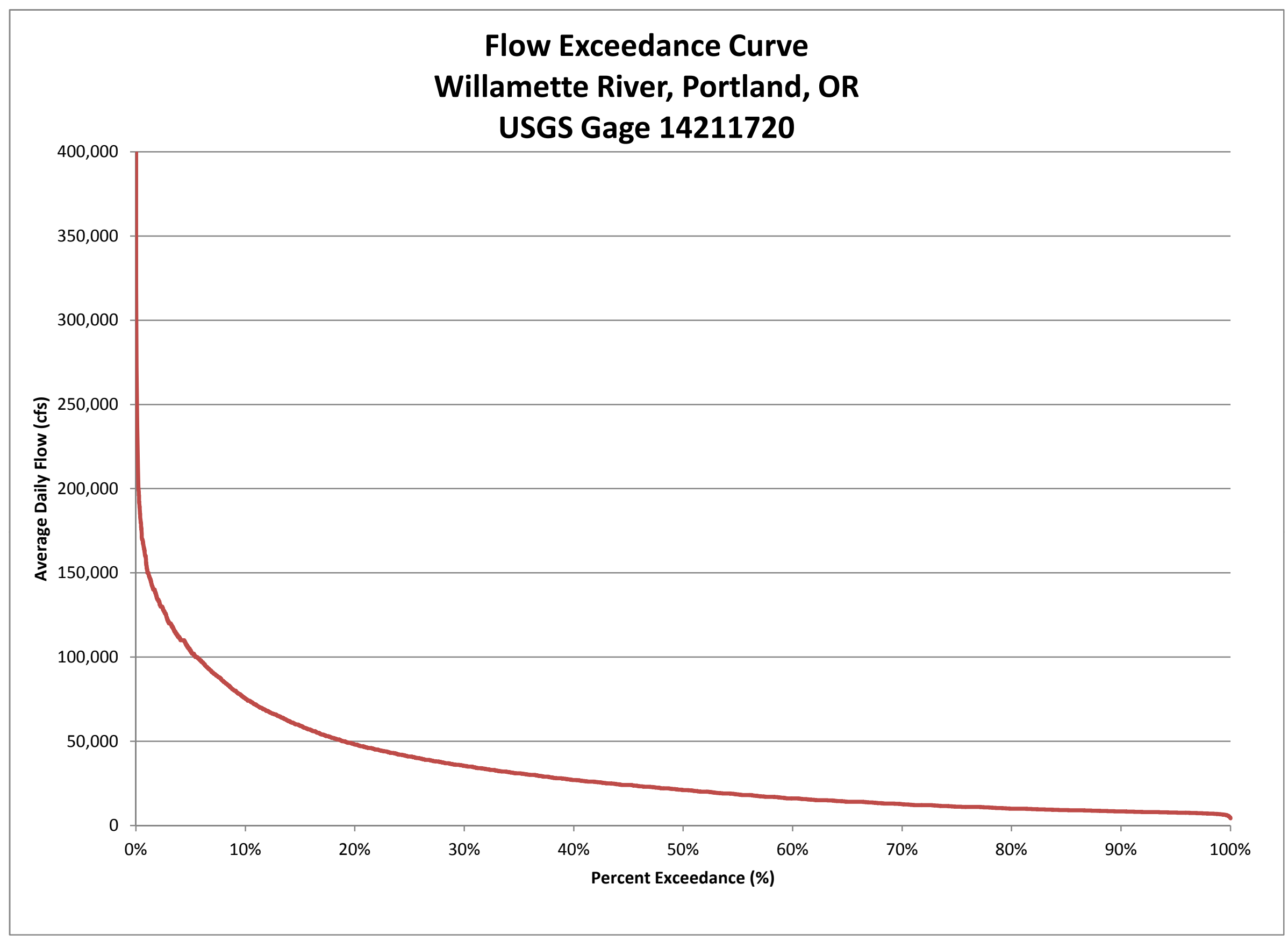


Attachment 3

Conceptual Layouts 

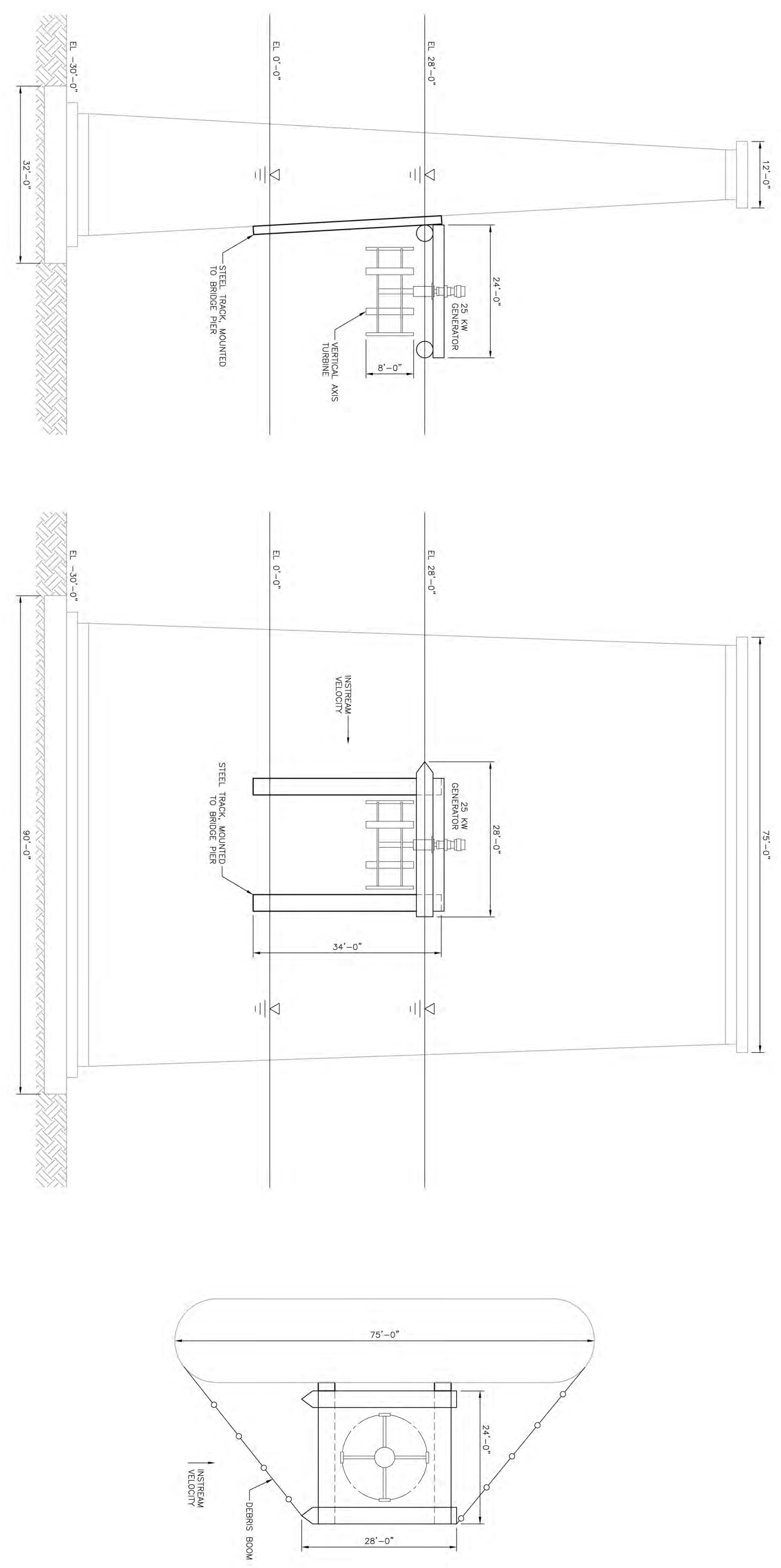

Conceptual Turbine Arrangement 


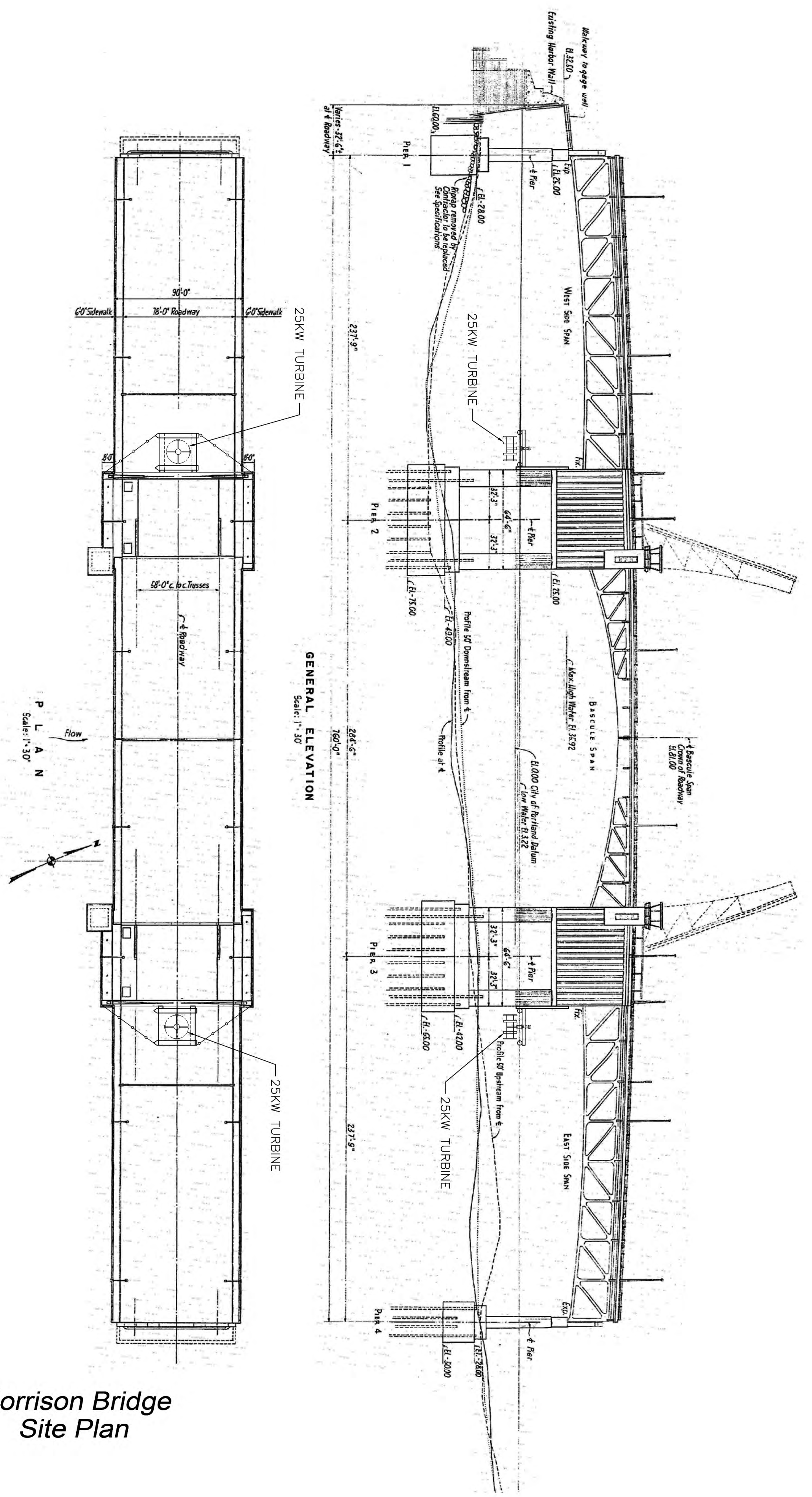




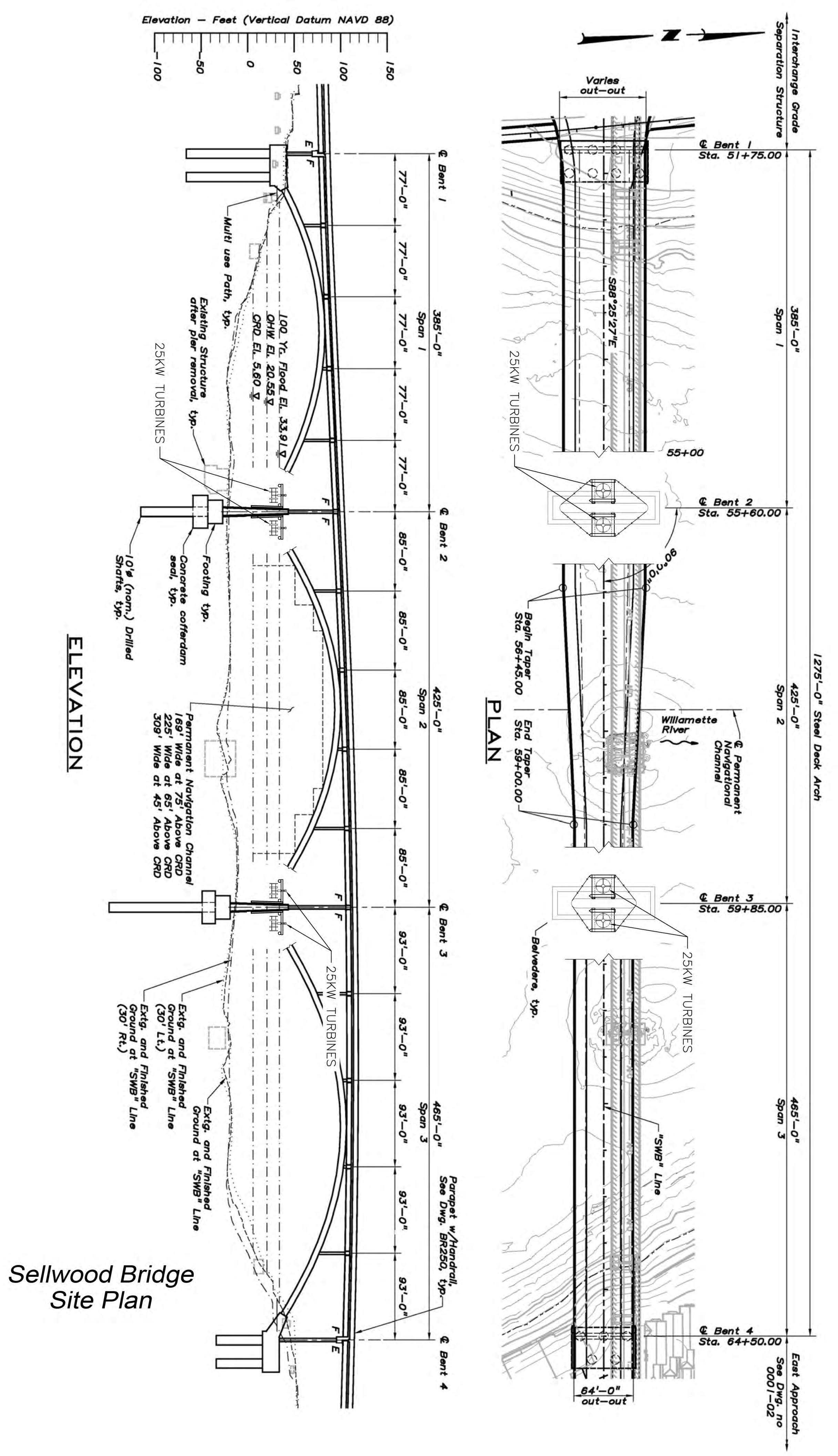


Attachment 4

\section{Energy Estimates}


Multnomah County Hydrokinetic Feasibility

Broadway Bridge Energy Estimate - Encurrent ENC025

By: Stephen Meicke, EIT

Checked By: Leanne A Greisen. EIT

Energy Estimate
Ened

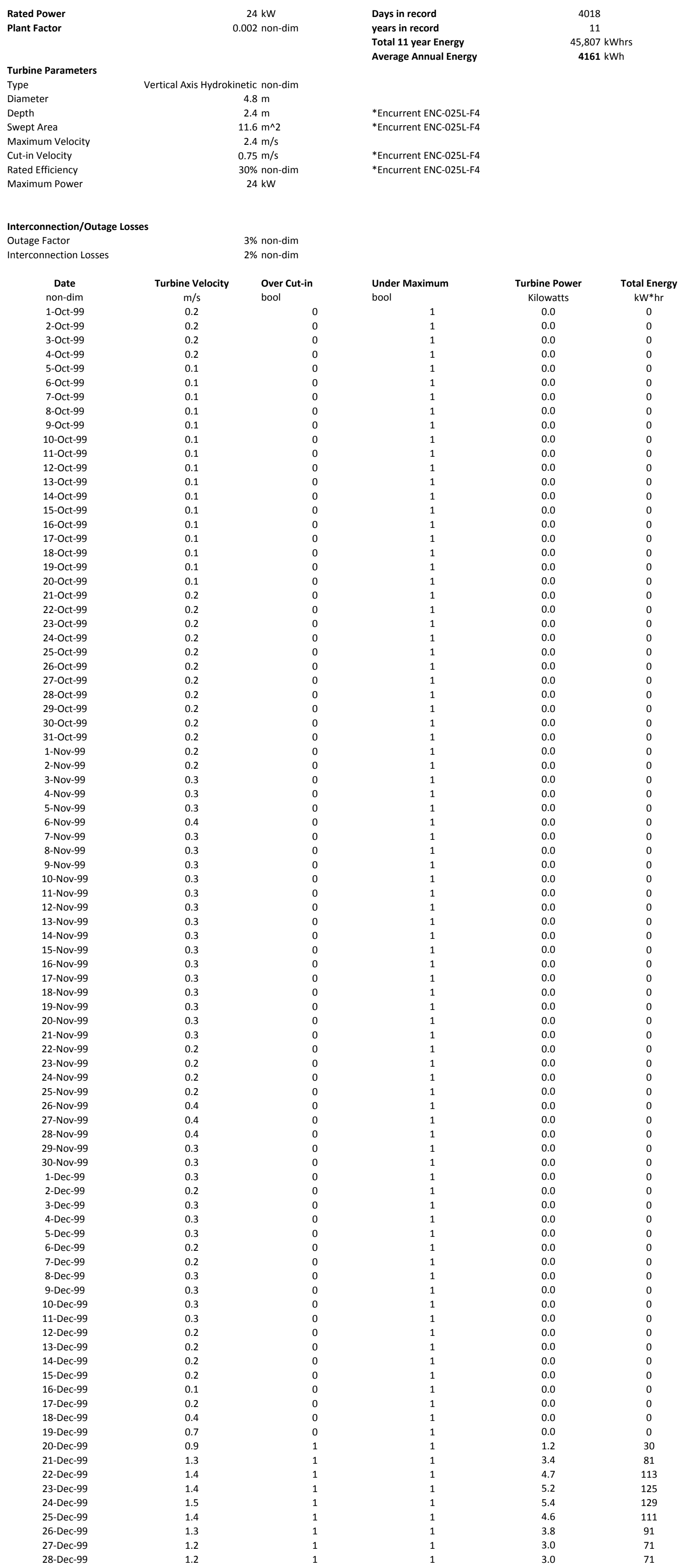


Multnomah County Hydrokinetic Feasibility

Morrison Bridge Energy Estimate - Encurrent ENC025L HDR Engineering Inc.
By: Stephen Meicke,

By: Stephen Meicke, EIT
Checked By: Leanne Greisen, EIT

Checked By: Leanne Greisen, EIT
Approved By: Stephen Spain, PE

Energy Estimate

\begin{tabular}{|c|c|c|c|}
\hline Rated Power & $24 \mathrm{~kW}$ & Number of days in record & 4018 \\
\hline \multirow[t]{3}{*}{ Plant Factor } & 0.002 non-dim & Number of years in record & 11 \\
\hline & & Total 11 Year Energy & $50,593 \mathrm{kWhrs}$ \\
\hline & & Average Annual Energy & 4596 kWh \\
\hline \multicolumn{4}{|l|}{ Turbine Parameters } \\
\hline Type & Vertical Axis Hydrokinetic non-dim & & \\
\hline Diameter & $4.8 \mathrm{~m}$ & & \\
\hline Depth & $2.4 \mathrm{~m}$ & ${ }^{*}$ Encurrent ENC-025L-F4 & \\
\hline Swept Area & $11.6 \mathrm{~m}^{\wedge} 2$ & *Encurrent ENC-025L-F4 & \\
\hline Maximum Velocity & $2.4 \mathrm{~m} / \mathrm{s}$ & & \\
\hline Cut-in Velocity & $0.75 \mathrm{~m} / \mathrm{s}$ & *Encurrent ENC-025L-F4 & \\
\hline Rated Efficiency & $29.8 \%$ non-dim & ${ }^{*}$ Encurrent ENC-025L-F4 & \\
\hline Maximum Power & $24 \mathrm{~kW}$ & & \\
\hline
\end{tabular}

Interconnection/Outage Losses

Outage Factor

Interconnection Losses

$3 \%$ non-dim

\begin{tabular}{|c|c|c|c|c|c|}
\hline $\begin{array}{c}\text { Date } \\
\text { non-dim }\end{array}$ & $\begin{array}{c}\text { Turbine Velocity } \\
\mathrm{m} / \mathrm{s}\end{array}$ & $\begin{array}{l}\text { Over Cut-in } \\
\text { bool }\end{array}$ & $\begin{array}{l}\text { Under Maximum } \\
\text { bool }\end{array}$ & $\begin{array}{l}\text { Turbine Power } \\
\text { Kilowatts }\end{array}$ & $\begin{array}{c}\text { Total Energy } \\
\mathrm{kW} h \mathrm{hr}\end{array}$ \\
\hline 1-Oct-99 & 0.2 & 0 & 1 & 0.0 & 0 \\
\hline 2-Oct-99 & 0.2 & 0 & 1 & 0.0 & 0 \\
\hline 3-Oct-99 & 0.2 & 0 & 1 & 0.0 & 0 \\
\hline 4-Oct-99 & 0.2 & 0 & 1 & 0.0 & 0 \\
\hline 5-Oct-99 & 0.1 & 0 & 1 & 0.0 & 0 \\
\hline 6-Oct-99 & 0.1 & 0 & 1 & 0.0 & 0 \\
\hline 7-Oct-99 & 0.1 & 0 & 1 & 0.0 & 0 \\
\hline 8-Oct-99 & 0.1 & 0 & 1 & 0.0 & 0 \\
\hline 9-Oct-99 & 0.1 & 0 & 1 & 0.0 & 0 \\
\hline 10-Oct-99 & 0.1 & 0 & 1 & 0.0 & 0 \\
\hline 11-Oct-99 & 0.1 & 0 & 1 & 0.0 & 0 \\
\hline 12-Oct-99 & 0.1 & 0 & 1 & 0.0 & 0 \\
\hline 13-Oct-99 & 0.2 & 0 & 1 & 0.0 & 0 \\
\hline 14-Oct-99 & 0.2 & 0 & 1 & 0.0 & 0 \\
\hline 15-Oct-99 & 0.2 & 0 & 1 & 0.0 & 0 \\
\hline 16-Oct-99 & 0.2 & 0 & 1 & 0.0 & 0 \\
\hline 17-Oct-99 & 0.1 & 0 & 1 & 0.0 & 0 \\
\hline 18-Oct-99 & 0.1 & 0 & 1 & 0.0 & 0 \\
\hline 19-Oct-99 & 0.1 & 0 & 1 & 0.0 & 0 \\
\hline 20-Oct-99 & 0.1 & 0 & 1 & 0.0 & 0 \\
\hline 21-Oct-99 & 0.2 & 0 & 1 & 0.0 & 0 \\
\hline 22-Oct-99 & 0.2 & 0 & 1 & 0.0 & 0 \\
\hline 23-Oct-99 & 0.2 & 0 & 1 & 0.0 & 0 \\
\hline 24-Oct-99 & 0.2 & 0 & 1 & 0.0 & 0 \\
\hline 25-Oct-99 & 0.2 & 0 & 1 & 0.0 & 0 \\
\hline 26-Oct-99 & 0.2 & 0 & 1 & 0.0 & 0 \\
\hline 27-Oct-99 & 0.2 & 0 & 1 & 0.0 & 0 \\
\hline 28-Oct-99 & 0.2 & 0 & 1 & 0.0 & 0 \\
\hline 29-Oct-99 & 0.2 & 0 & 1 & 0.0 & 0 \\
\hline 30-Oct-99 & 0.2 & 0 & 1 & 0.0 & 0 \\
\hline 31-Oct-99 & 0.2 & 0 & 1 & 0.0 & 0 \\
\hline 1-Nov-99 & 0.2 & 0 & 1 & 0.0 & 0 \\
\hline 2-Nov-99 & 0.2 & 0 & 1 & 0.0 & 0 \\
\hline 3-Nov-99 & 0.3 & 0 & 1 & 0.0 & 0 \\
\hline 4-Nov-99 & 0.3 & 0 & 1 & 0.0 & 0 \\
\hline 5-Nov-99 & 0.3 & 0 & 1 & 0.0 & 0 \\
\hline 6-Nov-99 & 0.4 & 0 & 1 & 0.0 & 0 \\
\hline 7-Nov-99 & 0.3 & 0 & 1 & 0.0 & 0 \\
\hline 8-Nov-99 & 0.3 & 0 & 1 & 0.0 & 0 \\
\hline 9-Nov-99 & 0.3 & 0 & 1 & 0.0 & 0 \\
\hline 10-Nov-99 & 0.3 & 0 & 1 & 0.0 & 0 \\
\hline 11-Nov-99 & 0.4 & 0 & 1 & 0.0 & 0 \\
\hline 12-Nov-99 & 0.4 & 0 & 1 & 0.0 & 0 \\
\hline 13-Nov-99 & 0.3 & 0 & 1 & 0.0 & 0 \\
\hline 14-Nov-99 & 0.3 & 0 & 1 & 0.0 & 0 \\
\hline 15-Nov-99 & 0.3 & 0 & 1 & 0.0 & 0 \\
\hline 16-Nov-99 & 0.3 & 0 & 1 & 0.0 & 0 \\
\hline 17-Nov-99 & 0.3 & 0 & 1 & 0.0 & 0 \\
\hline 18-Nov-99 & 0.3 & 0 & 1 & 0.0 & 0 \\
\hline 19-Nov-99 & 0.3 & 0 & 1 & 0.0 & 0 \\
\hline 20-Nov-99 & 0.3 & 0 & 1 & 0.0 & 0 \\
\hline 21-Nov-99 & 0.3 & 0 & 1 & 0.0 & 0 \\
\hline 22-Nov-99 & 0.3 & 0 & 1 & 0.0 & 0 \\
\hline 23-Nov-99 & 0.3 & 0 & 1 & 0.0 & 0 \\
\hline 24-Nov-99 & 0.2 & 0 & 1 & 0.0 & 0 \\
\hline 25-Nov-99 & 0.2 & 0 & 1 & 0.0 & 0 \\
\hline 26-Nov-99 & 0.4 & 0 & 1 & 0.0 & 0 \\
\hline 27-Nov-99 & 0.4 & 0 & 1 & 0.0 & 0 \\
\hline 28-Nov-99 & 0.4 & 0 & 1 & 0.0 & 0 \\
\hline 29-Nov-99 & 0.3 & 0 & 1 & 0.0 & 0 \\
\hline 30-Nov-99 & 0.3 & 0 & 1 & 0.0 & 0 \\
\hline 1-Dec-99 & 0.3 & 0 & 1 & 0.0 & 0 \\
\hline 2-Dec-99 & 0.3 & 0 & 1 & 0.0 & 0 \\
\hline 3-Dec-99 & 0.3 & 0 & 1 & 0.0 & 0 \\
\hline 4-Dec-99 & 0.3 & 0 & 1 & 0.0 & 0 \\
\hline 5-Dec-99 & 0.3 & 0 & 1 & 0.0 & 0 \\
\hline 6-Dec-99 & 0.2 & 0 & 1 & 0.0 & 0 \\
\hline 7-Dec-99 & 0.2 & 0 & 1 & 0.0 & 0 \\
\hline 8-Dec-99 & 0.3 & 0 & 1 & 0.0 & 0 \\
\hline 9-Dec-99 & 0.3 & 0 & 1 & 0.0 & 0 \\
\hline 10-Dec-99 & 0.3 & 0 & 1 & 0.0 & 0 \\
\hline 11-Dec-99 & 0.3 & 0 & 1 & 0.0 & 0 \\
\hline 12-Dec-99 & 0.2 & 0 & 1 & 0.0 & 0 \\
\hline 13-Dec-99 & 0.2 & 0 & 1 & 0.0 & 0 \\
\hline 14-Dec-99 & 0.2 & 0 & 1 & 0.0 & 0 \\
\hline 15-Dec-99 & 0.2 & 0 & 1 & 0.0 & 0 \\
\hline 16-Dec-99 & 0.2 & 0 & 1 & 0.0 & 0 \\
\hline 17-Dec-99 & 0.2 & 0 & 1 & 0.0 & 0 \\
\hline 18-Dec-99 & 0.4 & 0 & 1 & 0.0 & 0 \\
\hline 19-Dec-99 & 0.7 & 0 & 1 & 0.0 & 0 \\
\hline 20-Dec-99 & 0.9 & 1 & 1 & 1.3 & 31 \\
\hline 21-Dec-99 & 1.3 & 1 & 1 & 3.7 & 89 \\
\hline 22-Dec-99 & 1.4 & 1 & 1 & 5.2 & 125 \\
\hline 23-Dec-99 & 1.5 & 1 & 1 & 5.7 & 137 \\
\hline & & & & & \\
\hline
\end{tabular}


Multnomah County Hydrokinetic Feasibility

Sellwood Bridge Energy Estimate - Encurrent ENC025L

HDR Engineering Inc.

By. St Bhen Meicke,

Approved By: Stephen Spain, PE

Energy Estimate

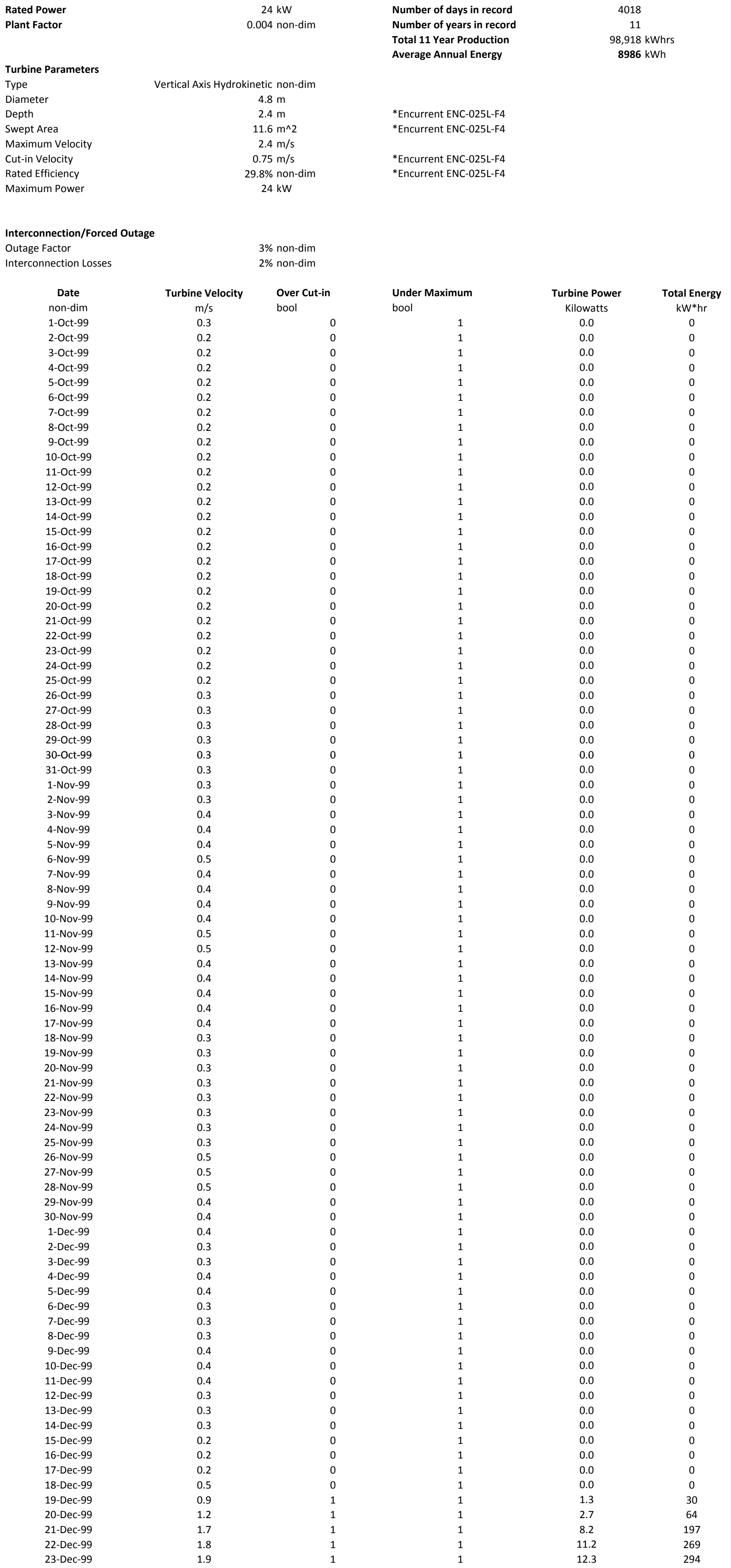




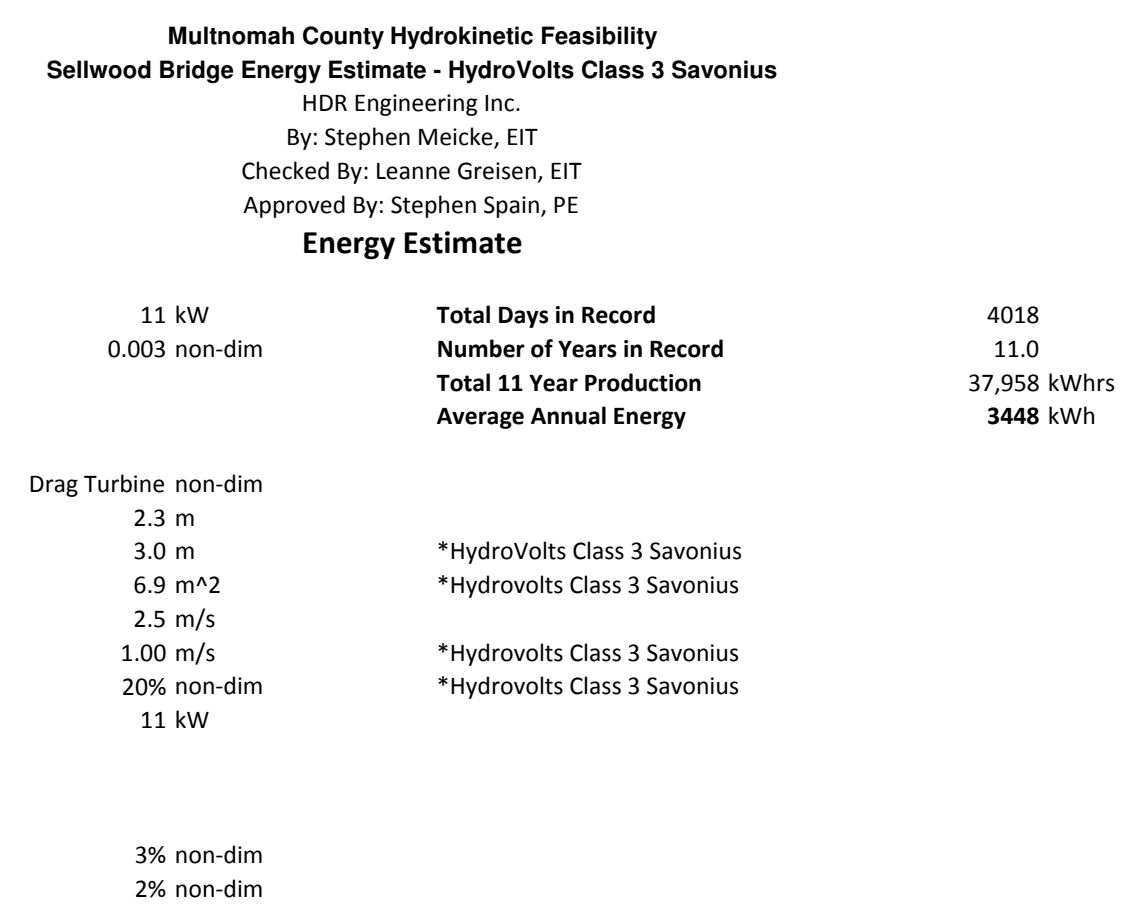

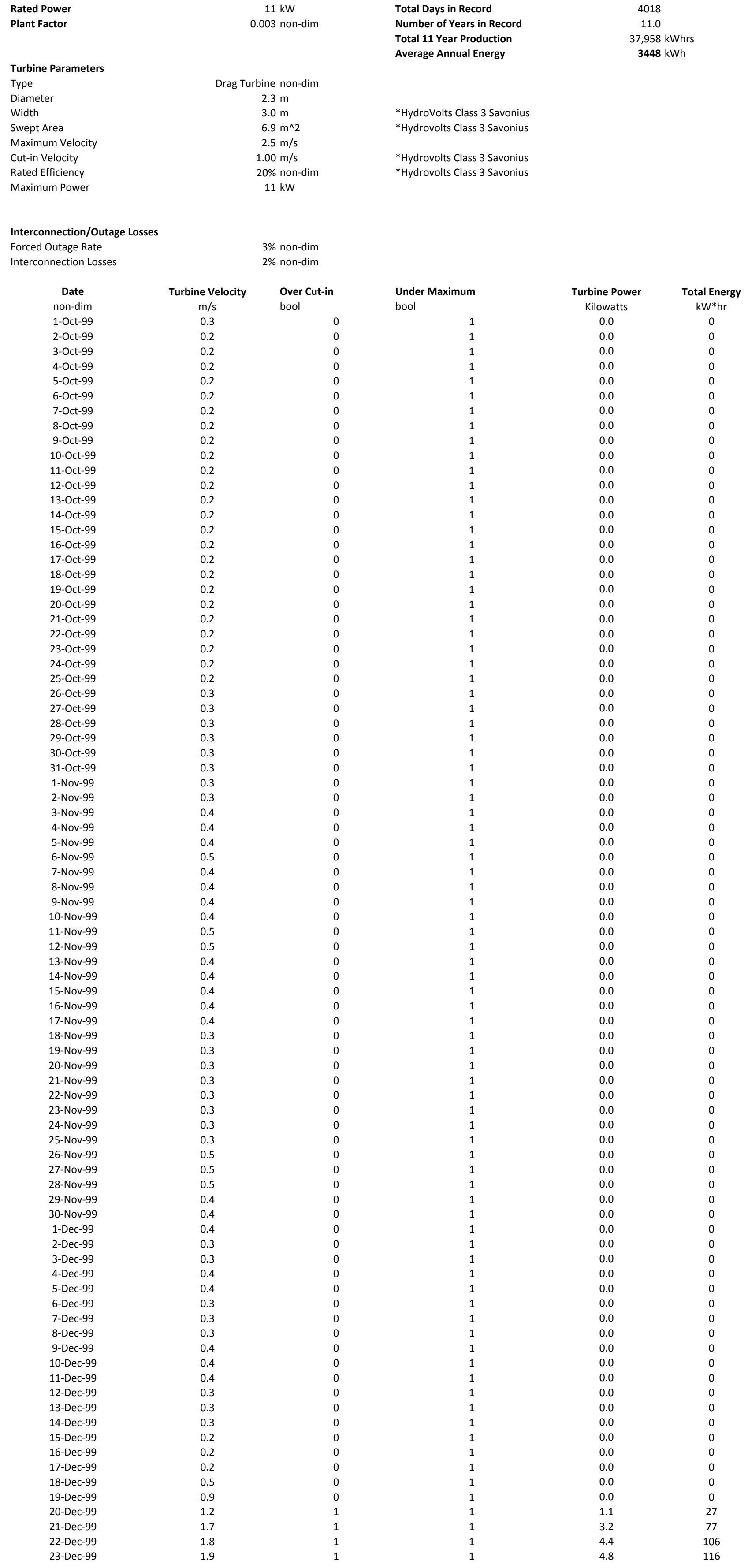


Attachment 5

Conceptual Cost Opinions 
Multnomah County Hydrokinetic Feasibility Study Capital Cost Opinion - Broadway Bridge - Single 25 kW EnCurrent

Prepared By: David Elwood, PE

Checked By: Stephen Meicke, EIT

\begin{tabular}{|cc|ccc|}
\hline \multicolumn{2}{|c|}{ Turbine Location: Broadway Bridge } & \multicolumn{3}{|c|}{ Capacity: Broadway Bridge } \\
\hline Latitude & Longitude & Rated Power & Unit Cost & Total Cost \\
degrees & degrees & $\mathrm{kW}$ & $\$ / \mathrm{kW}$ & $\$$ \\
45.532 & -122.674 & 25.0 & 20,900 & 523,600 \\
\hline
\end{tabular}

\begin{tabular}{|ccc|}
\hline \multicolumn{3}{|c|}{ Hydrokinetic Turbine Characterisitcs } \\
\hline $\begin{array}{c}\text { Diameter } \\
\mathrm{ft}\end{array}$ & $\begin{array}{c}\text { Depth } \\
\mathrm{ft}\end{array}$ & $\begin{array}{c}\text { Type } \\
\text { non-dim }\end{array}$ \\
\hline 7.90 & 15.90 & Vertical-axis \\
\hline
\end{tabular}

\begin{tabular}{|c|c|c|c|c|}
\hline Item & Quantity & Unit & Unit Costs (\$/unit) & Amount (\$) \\
\hline Support Structure & & & & 20,000 \\
\hline Structural Steel & 1000 & lb & $\$ 5$ & 5,000 \\
\hline Pontoon Barge & 1 & LS & $\$ 10,000$ & 10,000 \\
\hline Debris Boom & 1 & LS & $\$ 5,000$ & 5,000 \\
\hline Turbine, Generator, and Switchgear & & & & 147,000 \\
\hline Turbine-generator Unit & 25 & $\mathrm{~kW}$ & $\$ 5,000$ & 125,000 \\
\hline $\mathrm{DC} / \mathrm{AC}$ Invertor & 1 & LS & $\$ 2,000$ & 2,000 \\
\hline Installation & 1 & LS & $\$ 20,000$ & 20,000 \\
\hline Electrical Interconnection & & & & 5,000 \\
\hline Subsea Cable & 0 & feet & $\$ 200$ & 0 \\
\hline Conduit-run Cable & 0 & feet & $\$ 50$ & 0 \\
\hline Switchgear and Controls & 1 & LS & $\$ 5,000$ & 5,000 \\
\hline Equipment Subtotal & & & & 152,000 \\
\hline Support Structure Subtotal & & & & 20,000 \\
\hline Capitol Cost Subtotal & & & & 172,000 \\
\hline Engineering, Licencing and Permitting & & & & 300,000 \\
\hline Contingency & & & Add $30 \%$ of Subtotal & 51,600 \\
\hline Total Cost of System Including Contingency & & & Total $=$ & 523,600 \\
\hline
\end{tabular}


Multnomah County Hydrokinetic Feasibility Study Capital Cost Opinion - Broadway Bridge - Two 25 kW EnCurrent

Prepared By: David Elwood, PE

Checked By: Stephen Meicke, EIT

\begin{tabular}{|cc|ccc|}
\hline \multicolumn{2}{|c|}{ Turbine Location: Broadway Bridge } & \multicolumn{3}{c|}{ Capacity: Broadway Bridge } \\
\hline Latitude & Longitude & Rated Power & Unit Cost & Total Cost \\
degrees & degrees & $\mathrm{kW}$ & $\$ / \mathrm{kW}$ & $\$$ \\
45.532 & -122.674 & 50.0 & 15,100 & 753,700 \\
\hline
\end{tabular}

\begin{tabular}{|ccc|}
\hline \multicolumn{3}{|c|}{ Hydrokinetic Turbine Characterisitcs } \\
\hline $\begin{array}{ccc}\text { Diameter } \\
\mathrm{ft}\end{array}$ & $\begin{array}{cc}\text { Depth } \\
\mathrm{ft}\end{array}$ & Type \\
& 15.84 & non-dim \\
\hline 7.90 & Vertical-axis \\
\hline
\end{tabular}

\begin{tabular}{|c|c|c|c|c|}
\hline Item & Quantity & Unit & Unit Costs (\$/unit) & Amount (\$) \\
\hline Support Structure & & & & 40,000 \\
\hline Structural Steel & 2000 & $\mathrm{lb}$ & $\$ 5$ & 10,000 \\
\hline Pontoon Barge & 2 & LS & $\$ 10,000$ & 20,000 \\
\hline Debris Boom & 2 & LS & $\$ 5,000$ & 10,000 \\
\hline Turbine, Generator, and Switchgear & & & & 304,000 \\
\hline Turbine-generator Unit & 50 & kW & $\$ 5,000$ & 250,000 \\
\hline DC/AC Invertor & 2 & LS & $\$ 2,000$ & 4,000 \\
\hline Installation & 1 & LS & $\$ 50,000$ & 50,000 \\
\hline Electrical Interconnection & & & & 5,000 \\
\hline Subsea Cable & 0 & feet & $\$ 200$ & 0 \\
\hline Conduit-run Cable & 0 & feet & $\$ 50$ & 0 \\
\hline Switchgear and Controls & 1 & LS & $\$ 5,000$ & 5,000 \\
\hline Equipment Subtotal & & & & 309,000 \\
\hline Support Structure Subtotal & & & & 40,000 \\
\hline Capitol Cost Subtotal & & & & 349,000 \\
\hline Engineering, Licencing and Permitting & & & & 300,000 \\
\hline Contingency & & & Add $30 \%$ of Subtotal & 104,700 \\
\hline Total Cost of System Including Contingency & & & Total $=$ & 753,700 \\
\hline
\end{tabular}


Multnomah County Hydrokinetic Feasibility Study Capital Cost Opinion - Morrison Bridge - Single 25 kW EnCurrent

Prepared By: David Elwood, PE

Checked By: Stephen Meicke, EIT

\begin{tabular}{|cc|ccc|}
\hline \multicolumn{2}{|c|}{ Turbine Location: Morrison Bridge } & \multicolumn{3}{|c|}{ Capacity: Morrison Bridge } \\
\hline Latitude & Longitude & Rated Power & Unit Cost & Total Cost \\
degrees & degrees & $\mathrm{kW}$ & $\$ / \mathrm{kW}$ & $\$$ \\
45.518 & -122.670 & 25.0 & 23,000 & 575,600 \\
\hline
\end{tabular}

\begin{tabular}{|ccc|}
\hline \multicolumn{3}{|c|}{ Hydrokinetic Turbine Characterisitcs } \\
\hline $\begin{array}{c}\text { Diameter } \\
\mathrm{ft}\end{array}$ & $\begin{array}{c}\text { Depth } \\
\mathrm{ft}\end{array}$ & $\begin{array}{c}\text { Type } \\
\text { non-dim }\end{array}$ \\
\hline 7.90 & 15.84 & Vertical-axis \\
\hline
\end{tabular}

\begin{tabular}{|c|c|c|c|c|}
\hline Item & Quantity & Unit & Unit Costs (\$/unit) & Amount (\$) \\
\hline Support Structure & & & & 20,000 \\
\hline Structural Steel & 1000 & lb & $\$ 5$ & 5,000 \\
\hline Pontoon Barge & 1 & LS & $\$ 10,000$ & 10,000 \\
\hline Debris Boom & 1 & LS & $\$ 5,000$ & 5,000 \\
\hline Turbine, Generator, and Switchgear & & & & 147,000 \\
\hline Turbine-generator Unit & 25 & $\mathrm{~kW}$ & $\$ 5,000$ & 125,000 \\
\hline $\mathrm{DC} / \mathrm{AC}$ Invertor & 1 & LS & $\$ 2,000$ & 2,000 \\
\hline Installation & 1 & LS & $\$ 20,000$ & 20,000 \\
\hline Electrical Interconnection & & & & 45,000 \\
\hline Subsea Cable & 200 & feet & $\$ 200$ & 40,000 \\
\hline Conduit-run Cable & 0 & feet & $\$ 50$ & 0 \\
\hline Switchgear and Controls & 1 & LS & $\$ 5,000$ & 5,000 \\
\hline Equipment Subtotal & & & & 192,000 \\
\hline Support Structure Subtotal & & & & 20,000 \\
\hline Capitol Cost Subtotal & & & & 212,000 \\
\hline Engineering, Licencing and Permitting & & & & 300,000 \\
\hline Contingency & & & Add $30 \%$ of Subtotal & 63,600 \\
\hline Total Cost of System Including Contingency & & & Total $=$ & 575,600 \\
\hline
\end{tabular}


Multnomah County Hydrokinetic Feasibility Study Captial Cost Opinion - Morrison Bridge - Four 25 kW Encurrent

Prepared By: David Elwood, PE

Checked By: Stephen Meicke, EIT

\begin{tabular}{|cc|ccc|}
\hline \multicolumn{2}{|c|}{ Turbine Location: Morrison Bridge } & \multicolumn{3}{c|}{ Capacity: Morrison Bridge } \\
\hline Latitude & Longitude & Rated Power & Unit Cost & Total Cost \\
degrees & degrees & $\mathrm{kW}$ & $\$ / \mathrm{kW}$ & $\$$ \\
45.518 & -122.670 & 100.0 & 12,900 & $1,291,900$ \\
\hline
\end{tabular}

\begin{tabular}{|ccc|}
\hline \multicolumn{3}{|c|}{ Hydrokinetic Turbine Characterisitcs } \\
\hline $\begin{array}{ccc}\text { Diameter } \\
\mathrm{ft}\end{array}$ & $\begin{array}{cc}\text { Depth } \\
\mathrm{ft}\end{array}$ & Type \\
& 15.84 & non-dim \\
\hline 7.90 & Vertical-axis \\
\hline
\end{tabular}

\begin{tabular}{|c|c|c|c|c|}
\hline Item & Quantity & Unit & Unit Costs (\$/unit) & Amount (\$) \\
\hline Support Structure & & & & 70,000 \\
\hline Structural Steel & 4000 & $\mathrm{lb}$ & $\$ 5$ & 20,000 \\
\hline Pontoon Barge & 4 & LS & $\$ 10,000$ & 40,000 \\
\hline Debris Boom & 2 & LS & $\$ 5,000$ & 10,000 \\
\hline Turbine, Generator, and Switchgear & & & & 608,000 \\
\hline Turbine-generator Unit & 100 & $\mathrm{~kW}$ & $\$ 5,000$ & 500,000 \\
\hline $\mathrm{DC} / \mathrm{AC}$ Invertor & 4 & LS & $\$ 2,000$ & 8,000 \\
\hline Installation & 2 & LS & $\$ 50,000$ & 100,000 \\
\hline Electrical Interconnection & & & & 85,000 \\
\hline Subsea Cable & 400 & feet & $\$ 200$ & 80,000 \\
\hline Conduit-run Cable & 0 & feet & $\$ 50$ & 0 \\
\hline Switchgear and Controls & 1 & LS & $\$ 5,000$ & 5,000 \\
\hline Equipment Subtotal & & & & 693,000 \\
\hline Support Structure Subtotal & & & & 70,000 \\
\hline Capitol Cost Subtotal & & & & 763,000 \\
\hline Engineering, Licencing and Permitting & & & & 300,000 \\
\hline Contingency & & & Add $30 \%$ of Subtotal & 228,900 \\
\hline Total Cost of System Including Contingency & & & Total $=$ & $1,291,900$ \\
\hline
\end{tabular}


Multnomah County Hydrokinetic Feasibility Study Capital Cost Opinion - Sellwood Bridge - Single 11 kW HydroVolts

Prepared By: David Elwood, PE

Checked By: Stephen Meicke, EIT

\begin{tabular}{|cc|ccc|}
\hline \multicolumn{2}{|c|}{ Turbine Location: Sellwood Bridge } & \multicolumn{3}{c|}{ Capacity: Sellwood Bridge } \\
\hline Latitude & Longitude & Rated Power & Unit Cost & Total Cost \\
degrees & degrees & $\mathrm{kW}$ & $\$ / \mathrm{kW}$ & $\$$ \\
45.464 & -122.666 & 11.0 & 44,600 & 491,100 \\
\hline
\end{tabular}

\begin{tabular}{|ccc|}
\hline \multicolumn{3}{|c|}{ Hydrokinetic Turbine Characterisitcs } \\
\hline $\begin{array}{ccc}\text { Diameter } \\
\mathrm{ft}\end{array}$ & $\begin{array}{cc}\text { Depth } \\
\mathrm{ft}\end{array}$ & Type \\
& 10.00 & non-dim \\
\hline 7.50 & Vertical-axis \\
\hline
\end{tabular}

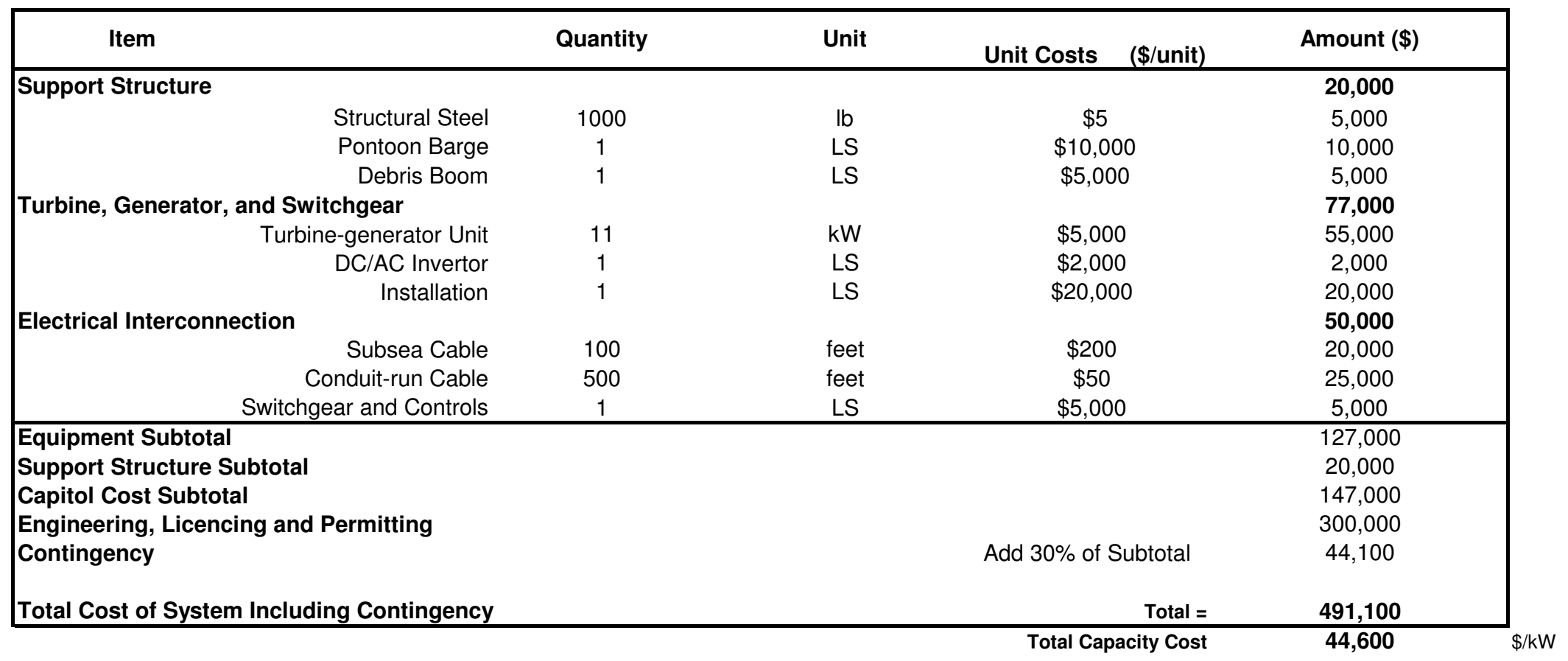


Multnomah County Hydrokinetic Feasibility Study Capital Cost Opinion - Sellwood Bridge - Single 25 kW EnCurrent

Prepared By: David Elwood, PE

Checked By: Stephen Meicke, EIT

\begin{tabular}{|cc|ccc|}
\hline \multicolumn{2}{|c|}{ Turbine Location: Sellwood Bridge } & \multicolumn{3}{c|}{ Capacity: Sellwood Bridge } \\
\hline Latitude & Longitude & Rated Power & Unit Cost & Total Cost \\
degrees & degrees & $\mathrm{kW}$ & $\$ / \mathrm{kW}$ & $\$$ \\
45.464 & -122.666 & 25.0 & 23,300 & 582,100 \\
\hline
\end{tabular}

\begin{tabular}{|ccc|}
\hline \multicolumn{3}{|c|}{ Hydrokinetic Turbine Characterisitcs } \\
\hline $\begin{array}{ccc}\text { Diameter } \\
\mathrm{ft}\end{array}$ & $\begin{array}{cc}\text { Depth } \\
\mathrm{ft}\end{array}$ & Type \\
& 15.84 & non-dim \\
\hline 7.90 & Vertical-axis \\
\hline
\end{tabular}

\begin{tabular}{|c|c|c|c|c|}
\hline Item & Quantity & Unit & Unit Costs (\$/unit) & Amount (\$) \\
\hline Support Structure & & & & 20,000 \\
\hline Structural Steel & 1000 & $\mathrm{lb}$ & $\$ 5$ & 5,000 \\
\hline Pontoon Barge & 1 & LS & $\$ 10,000$ & 10,000 \\
\hline Debris Boom & 1 & LS & $\$ 5,000$ & 5,000 \\
\hline Turbine, Generator, and Switchgear & & & & 147,000 \\
\hline Turbine-generator Unit & 25 & $\mathrm{~kW}$ & $\$ 5,000$ & 125,000 \\
\hline $\mathrm{DC} / \mathrm{AC}$ Invertor & 1 & LS & $\$ 2,000$ & 2,000 \\
\hline Installation & 1 & LS & $\$ 20,000$ & 20,000 \\
\hline Electrical Interconnection & & & & 50,000 \\
\hline Subsea Cable & 100 & feet & $\$ 200$ & 20,000 \\
\hline Conduit-run Cable & 500 & feet & $\$ 50$ & 25,000 \\
\hline Switchgear and Controls & 1 & LS & $\$ 5,000$ & 5,000 \\
\hline Equipment Subtotal & & & & 197,000 \\
\hline Support Structure Subtotal & & & & 20,000 \\
\hline Capitol Cost Subtotal & & & & 217,000 \\
\hline Engineering, Licencing and Permitting & & & & 300,000 \\
\hline Contingency & & & Add $30 \%$ of Subtotal & 65,100 \\
\hline Total Cost of System Including Contingency & & & Total $=$ & 582,100 \\
\hline
\end{tabular}




\section{Multnomah County Hydrokinetic Feasibility Study Capital Cost Opinion - Sellwood Bridge - Four 25 kW Cost Opinion \\ Prepared By: Steve Meicke, EIT \\ Checked By: Leanne Greisen, EIT}

\begin{tabular}{|cc|ccc|}
\hline \multicolumn{2}{|c|}{ Turbine Location: Sellwood Bridge } & \multicolumn{3}{|c|}{ Capacity: Sellwood Bridge } \\
\hline Latitude & Longitude & Rated Power & Unit Cost & Total Cost \\
degrees & degrees & $\mathrm{kW}$ & $\$ / \mathrm{kW}$ & $\$$ \\
45.464 & -122.666 & 100.0 & 14,200 & $1,421,900$ \\
\hline
\end{tabular}

\begin{tabular}{|c|c|c|}
\hline \multicolumn{3}{|c|}{ Hydrokinetic Turbine Characterisitcs } \\
\hline $\begin{array}{c}\text { Diameter } \\
\mathrm{ft}\end{array}$ & $\begin{array}{c}\text { Depth } \\
\mathrm{ft}\end{array}$ & $\begin{array}{c}\text { Type } \\
\text { non-dim }\end{array}$ \\
\hline 7.90 & 15.84 & Vertical-axis \\
\hline
\end{tabular}

\begin{tabular}{|c|c|c|c|c|}
\hline Item & Quantity & Unit & Unit Costs (\$/unit) & Amount (\$) \\
\hline Support Structure & & & & 70,000 \\
\hline Structural Steel & 4000 & $\mathrm{lb}$ & $\$ 5$ & 20,000 \\
\hline Pontoon Barge & 4 & LS & $\$ 10,000$ & 40,000 \\
\hline Debris Boom & 2 & LS & $\$ 5,000$ & 10,000 \\
\hline Turbine, Generator, and Switchgear & & & & 558,000 \\
\hline Turbine-generator Unit & 100 & kW & $\$ 5,000$ & 500,000 \\
\hline DC/AC Invertor & 4 & LS & $\$ 2,000$ & 8,000 \\
\hline Installation & 1 & LS & $\$ 50,000$ & 50,000 \\
\hline Electrical Interconnection & & & & 235,000 \\
\hline Subsea Cable & 400 & feet & $\$ 200$ & 80,000 \\
\hline Conduit-run Cable & 3,000 & feet & $\$ 50$ & 150,000 \\
\hline Switchgear and Controls & 1 & LS & $\$ 5,000$ & 5,000 \\
\hline Equipment Subtotal & & & & 793,000 \\
\hline Support Structure Subtotal & & & & 70,000 \\
\hline Capitol Cost Subtotal & & & & 863,000 \\
\hline Engineering, Licencing and Permitting & & & & 300,000 \\
\hline Contingency & & & Add $30 \%$ of Subtotal & 258,900 \\
\hline Total Cost of System Including Contingency & & & Total $=$ & $1,421,900$ \\
\hline
\end{tabular}


Attachment 6

Good Company Financing Memo, Revised 03/02/2012 


\section{December 2011, Revised February 3, 2012}

\section{Memorandum}

To: David Ellwood, PE, HDR

From: Joshua Proudfoot, Principal and Justin Overdevest, Research, Good Company

\section{Subject: Low-Impact Hydrokinetic Funding Market Research}

\section{IN SUMMARY}

A successful funded project will combine a number of different incentives, partnerships, and debt financing. As an example, the Juniper Ridge micro-hydro project leveraged funding from the Oregon Department of Energy (ODOE), Portland General Electric (PGE), Confederated Tribes, Oregon Watershed Enhancement Board (OWEB), Deschutes River Conservancy, and Energy Trust of Oregon. Nineteen of the twenty-six million, or $73 \%$ in project financing, consisted of loans and debt service. ${ }^{1}$

Federal Incentives: The Oregon Department of Energy represents the best opportunity for incentives or loan financing in funding a low-impact hydrokinetic project.

\begin{tabular}{|l|l|l|l|}
\hline Government Department & $\begin{array}{l}\text { Funding } \\
\text { Amount }\end{array}$ & Deadline & Fit \\
\hline Department of Energy (DOE) & & & \\
\hline Small Scale Energy Loan Program (SELP) & $\$ 20,000-\$ 100,000+$ & Open Submission & Strong \\
\hline Unsolicited Proposal- National Energy Technology Lab (NETL) & Case-by-case & Open Submission & Possible \\
\hline Small Business Innovation Research (SBIR) & Up to $\$ 100,000$ & Dec 20 (Intent Letter) & Possible \\
\hline Internal Revenue Service (IRS) & & & \\
\hline Federal Renewable Electricity Production Tax Credit (PTC) & 1.1 cents/kWh & Install before Jan 2014 & Weak \\
\hline Clean Renewable Energy Bonds (CREBs) & Varies & Not Currently Open & Weak \\
\hline Army Corps of Engineers & & & \\
\hline Technical Assistance & Negotiable & Open & Possible \\
\hline
\end{tabular}

Grant Making Foundations: Kresge and Meyer Memorial Foundations stand out as the most closely aligned in mission, project fit and funding options for renewable energy project financing. A number of other foundations such as the Bullitt Foundation demonstrate a good fit but do not accept unsolicited proposals. To approach them, we suggest a gentle approach by reaching their board members or other grantees to find out how to be invited to submit a proposal.

\footnotetext{
${ }^{1}$ http://nwrenewablenews.wordpress.com/2009/10/18/boom-begins-juniper-ridge-hydro-canalpiping-project/
} 


\begin{tabular}{|l|l|l|l|}
\hline Foundation & Grant Amount & Initial Contact & Deadline \\
\hline Doris Duke Foundation & $\$ 25,000-\$ 5,000,000$ & Letter of Inquiry-Submit Online & Open \\
\hline Kresge Foundation & $\$ 25,000-\$ 1,500,000$ & Preliminary Online Application & Open \\
\hline Meyer Memorial Foundation & $\$ 50,000-\$ 300,000$ & Register Online-Submit Inquiry & Open \\
\hline MJ Murdock Charitable Trust & $\$ 5,400-\$ 1,000,000$ & Letter of Inquiry & Open \\
\hline Pew Charitable Trust & $\$ 55,000-\$ 3,500,000$ & Letter of Inquiry & Open \\
\hline Surdna Foundation & $\$ 15,000-\$ 400,000$ & Letter of Inquiry or Full Proposal & Open \\
\hline William and Flora Hewlett Foundation & $\$ 20,000-\$ 7,000,000$ & Letter of Inquiry-Submit Online & Open \\
\hline
\end{tabular}

Potential Partnerships: The Energy Trust of Oregon (ETO) would perhaps be the best partnership, however, they will not fund a project on the Willamette River because it is a protected waterway. A wide variety of other organizations could provide technical assistance in specific areas including financing, renewable energy credit process or technical research.

\begin{tabular}{|l|l|l|}
\hline Organization & Participation & Contact \\
\hline Bonneville Environmental Foundation & REC Experience & Dick Wanderscheid, 503.248.1905 \\
\hline Center for Energy Efficiency and Renewables & RPS Implementation & Danielle Osborn Mills, 916.442.7785 \\
\hline Clean Energy States Alliance & Renewable Energy Finance & Mark Sinclair, 802.223.2554 \\
\hline Hydro Research Foundation & Research Assistance & David Reyes 202.682.1700 \\
\hline Low Impact Hydropower Institute (LIH) & Permitting Assistance for LIH & Fred Aire, 207.773.8190 \\
\hline
\end{tabular}

Debt Financing from Sustainability Focused Institutions: New Resource Bank in San Francisco, CA and Enterprise Cascadia in Portland represent the two best banking opportunities balancing both mission related offerings, good reputations, and are geographically close to the potential demonstration project. Ultimately, debt financing is more of a commodity market and beyond this list there are a number of capital institutions offering very similar financing packages.

\begin{tabular}{|l|l|l|l|}
\hline Banking Institution & Contact & Phone & Location \\
\hline Alyra & Mohammed Alam & 413.341 .3600 & North Hampton, MA \\
\hline Cascadia Capital & David Wyman & 206.436 .2500 & Seattle, WA \\
\hline Enterprise Cascadia & Adam Zimmerman & 503.688 .1708 & Portland, OR \\
\hline Leaf Clean Energy & Matthew Fedors & 2022897881 & Washington, DC \\
\hline New Resource Bank & Rob Holden & 415.995 .8151 & San Francisco, CA \\
\hline
\end{tabular}




\section{FEDERAL AND STATE LEVEL INCENTIVES}

Marine and in-river hydrokinetic is gaining momentum at the federal level in part due to the potential of in-stream hydrokinetic energy and large number of FERC preliminary permits on the Mississippi River. Senate Bill S. 630 co-sponsored by Sen. Ron Wyden is currently being proposed and would add $\$ 75$ million in allocated funding for hydrokinetic projects in marine and river environments. ${ }^{2}$ Additionally, in September 2011 the Senate Appropriations Committee increased funding for marine and in-river hydrokinetic funding by $\$ 9$ million for the Energy Efficiency and Renewable Energy (EERE) Water Power program. ${ }^{3}$

Apart from new program funding fiscal year 2012 there are currently available incentives and loan programs through federal and state offices. The following programs are the most relevant for a demonstration project.

\section{Oregon Department of Energy (ODOE)}

Small Scale Energy Loan Program (SELP): This low interest loan program does fund municipal governments to develop renewable energy resources including hydro. SELP provides fixed rate, fully amortized loans with rates that are dependent upon the type of borrower and project. Loan terms generally range from 10 to 15 years and the minimum loan amount is $\$ 20,000$. Estimated interest rates are 5.5\%-6\%. Applications for more than $\$ 100,000$ require an advisory committee review. SELP occasionally funds a demonstration project but it must meet specific criteria, such as showcasing new or improved technologies or designs that promise cost-effective production or conservation of energy. Even though a project is designated as a demonstration project does not mean that the loan underwriting or security measures will be lessened nor would it reduce the obligation for repayment of the loan if the project does not perform as anticipated. Many demonstration projects are not quite ready and thus are not the best fit for SELP, but rather a better fit for another type of investment funding where the returns are better matched with the risk of the project.

Contact: SELP Loan Program, Kathy Estes, kathy.estes@state.or.us http://www.oregon.gov/ENERGY/LOANS/selphm.shtml

Small Business Innovation Research (SBIR) Program: The Small Business Innovation Research (SBIR) programs aim to increase private sector commercialization of technology developed through DOE-supported research and development. Applications are accepted for competitive evaluation in response to an annual Program Solicitation. Approximately 300 Phase I awards are made for a nine-month project period in an amount not to exceed $\$ 100,000$ each. Note: In order to qualify for this funding, it would require Multnomah County to partner with a technology provider and an organization such as Oregon Built Environment and Sustainable Technologies Center (BEST) or a university doing research on in-river hydro projects such as Portland State university, Tulane University or University of Washington.

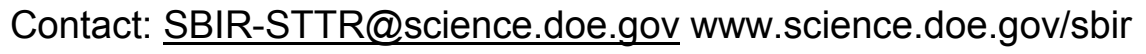

${ }^{2}$ U.S. Government Printing Office (GPO). SB 630. http://www.gpo.gov/fdsys/pkg/BILLS112s630rs/pdf/BILLS-112s630rs.pdf

${ }^{3}$ Renewable Energy World. September 12, 2011. http://www.renewableenergyworld.com/rea/partner/ocean-renewable-energy-coalition4809/news/article/2011/09/senate-appropriations-committee-passes-fy-2012-energy-waterappropriations-bill 


\begin{abstract}
Unsolicited Proposal to National Energy Technology Laboratory (NETL): The DOE encourages organizations and individuals to submit self-generated, unsolicited proposals that are relevant to the NETL's research and development mission and demonstrate a unique and innovative concept. Similarly to the SBIR program, an unsolicited proposal would need to partner with a technology research organization or firm such as one of the turbine manufacturers.
\end{abstract}

Contact: John Augustine, Unsolicited Proposal Manager, DOEUSP@NETL.DOE.GOV DOE National Energy Technology, http://www.netl.doe.gov/business/usp/unsol.html

\title{
INTERNAL REVENUE SERVICE (IRS):
}

Federal Renewable Electricity Production Tax Credit (PTC): In order to qualify for the PTC, the facility must have a capacity rating of at least 150 kilowatts, which could prove to be too large of a system for this project to qualify. Finally, the production facility needs to be placed in service before January 1,2014 . The PTC is 2.2 cents $/ \mathrm{kWh}$ for most renewables, adjusted for inflation, multiplied by the number of qualified kilowatt-hours of electricity produced. Currently, the PTC for marine and hydrokinetic is 1.1 cents, half the amount of other renewables. The PTC runs for ten years after a project is placed in service, but will be reduced by $50 \%$ if a project has already received tax exempt financing, a grant or another federal tax credit. ${ }^{4}$ To be eligible for Production Tax Credits the ownership of the facility must not be federally tax exempt. Property exempt from PTC eligibility is any property owned by any such governmental unit or tax-exempt entity. That includes property leased to any such governmental unit or tax-exempt entity as well. Under these conditions many energy projects involving governmental or tax exempt entities do not qualify for federal tax credit benefits.

So, a county is essentially not eligible for PTC. However, property under a service contract recognized under state law is treated as a lease for income tax purposes if it is properly characterized in the lease conditions. It cannot be a lease with option to buy, it must be a straight service contract with the right to use property. In that circumstance the owner (nongovernmental) can take the PTC and monetize it as a reduced cost to the user. That is the most common way that public entities take advantage of PTC and/or other tax incentives they wouldn't otherwise be eligible for. In some cases a lease nearly equivalent to $0 \%$ financing results.

Clean Energy Renewable Bonds (CREBs): Currently CREBs are not available to fund projects and there is no timeframe indicated for when or if those programs will be reinstated.

\section{ARMY CORPS OF ENGINEERS}

Portland Hydroelectric Design Center: The only such design center operated by the Corps of Engineers nationwide is located in Portland, Oregon and could offer a good opportunity for assistance with this project's feasibility analysis and design research and development.

Contact: 503-808-4200, 333 SW First Ave, Portland, Oregon www.nwp.usace.army.mil/hdc/.

\footnotetext{
${ }^{4}$ http://www.dsireusa.org/library/includes/incentive2.cfm? Incentive Code=US13F\&State=federal \&currentpageid $=1 \&$ ee $=0 \&$ re $=1$
} 


\section{ENERGY TRUST OF OREGON}

Normally Energy Trust funds low impact hydrokinetic projects. However, the project location of the Willamette River is a protected waterway and therefore Energy Trust's programs are not available. If it were an unprotected waterway Energy Trust would be able to provide for: (1) project development assistance allowing up to $\$ 40,000$ for cost sharing project needs, paid as a reimbursement, to help move the project forward (e.g. interconnection, engineering, feasibility) and (2) installation costs which are determined on a case by case basis. A financial proforma for the life of the project is developed and net present value calculations are compared to market rate of return. If the project is below market rate return then installation costs can be contributed to the project.

Contact: Jed Jorgenson, Senior Energy Project Manager- Hydropower 503.445.7611 jed.jorgensen@energytrust.org

\section{OREgon DEPARTMENT OF TRANSPORTATION (ODOT)}

ODOT Research Station: ODOT has ten staff researchers devoted to special project research. Each year the research team takes on a series of research proposals in addition to core research topics. Unfortunately, the special research grant application process closed on November $18^{\text {th }}$ and will not reopen until next November. However, due to the nature of the project and ownership/management of Sellwood, Burnside, and Broadway the research station is very interested in receiving a proposal next year for this project.

Contact: Linda (Lyn) Cornell, ODOT Multimodal and Sustainable Transportation Research 503.986.2853 linda.s.cornell@state.or.us

\section{FOUNDATION GRANT FUNDING}

A wide number of nonprofit organizations and foundations support renewable and innovative technologies to reduce carbon emissions. The most relevant matches for organizations to this type of project include: Alfred Sloan Foundation, Doris Duke Foundation, Kresge Foundation, Meyer Memorial Foundation, MJ Murdock Charitable Trust, Pew Charitable Trust, Surdna Foundation, and William \& Flora Hewlett Foundation. In the process of looking for all possible options we vetted a number of other possible foundations included in the table below. 


\begin{tabular}{|l|l|l|}
\hline Other Grant Making Foundations & Grant Amount & Rationale for Lack of Fit \\
\hline Alfred Sloan Foundation & $\$ 125,000+$ & Research related grants, no capital construction \\
\hline Bullitt Foundation & $\$ 2,000-\$ 1.2$ million & Good fit but give by invitation only* \\
\hline Energy Foundation & $\$ 25,000-\$ 200,000$ & Does not fund community energy or pilot projects \\
\hline Harder Foundation & $\$ 5,000-\$ 60,000$ & Good fit but give by invitation only* \\
\hline Kongsgaard-Goldman Foundation & $\$ 2,500-\$ 60,000$ & Possible but not direct fit \\
\hline Laird North Family Foundation & $\$ 10,000-\$ 40,000$ & Good fit but give by invitation onl ${ }^{* *}$ \\
\hline Lazar Foundation & $\$ 1,000-\$ 20,000$ & Good fit but give by invitation only* \\
\hline National Science Foundation & $\$ 2,000-\$ 1$ million+ & Does not fund hydro projects \\
\hline Turner Foundation & $\$ 10,000-\$ 1$ million & Different geographic focus \\
\hline
\end{tabular}

${ }^{*}$ Unsolicited proposals are not accepted by these organizations. This foundation would require some careful reach out to board members or staff to understand the best way to get on their radar - and cultivate a request.

\section{STRENGTH In PARTNERSHIPS}

Given the innovative nature of in-river hydrokinetic energy production, it is essential to develop many relevant partnerships to share in the costs, the knowledge gained and in the goodwill generated. There are a number of nonprofit and mission related organizations that may prove important in handling certain parts of project development. For example, the Low Impact Hydropower Institute would be a beneficial ally in the permitting effort for low impact hydropower. Universities and educational institutions are also good partnership opportunities but tend to be focused on research and technology commercialization rather than project implementation.

Oregon Built Environment \& Sustainable Technologies (BEST) Center: The BEST Center does focus part of their research on renewable energy. Oregon BEST offers two grant programs as well as connecting to a range of networks for being geared to research focused projects at regional educational institutions.

The Proposal Matching program would offer $10-33 \%$ matching funds, dependent upon if the project has state funding or not. Sue Safford mentioned that through this program, a principal investigator at a university research program would be able to increase the level of funding with other grant opportunities.

The Commercialization program is focused on two funding priorities: (1) Technology Testing/Characterization Grants (up to \$75,000) and (2) Product Development and Deployment (up to $\$ 150,000) .{ }^{5}$ One important requirement for this funding is that the technology manufacturer be Oregon-based, this is not the case with the Proposal Matching Program.

Sue Safford, the relevant Oregon BEST program lead is very interested in a potential partnership and would like further information on specific types of research projects that could stem from this demonstration project. Sue also mentioned that the Northwest National Marine

${ }^{5}$ http://oregonbest.org/commercialization/grants 
Renewable Energy Center (NNMREC) at Oregon State University is one of their partners and could served as a valuable contact for this project.

Contact: Sue Safford, 503.725.9826 susan.safford@oregonbest.org

Oregon Institute of Technology (OIT): OIT is known statewide for their strong engineering programs, while getting projects done on the ground.

Contact: Dr. Charles Riley, PE Assistant Professor, 541.885.1922, Charles.Riley@oit.edu Professor David Thaemert, Water Resources Engineering, 541.885.1518,

David.Thaemert@oit.edu

Oregon State University (OSU): OSU Engineering has been involved in the Pacific Northwest Water Regional Program which is a consortium of organizations that partner with the Environmental Protection Agency (EPA) to develop small, micro and in-river hydro systems. ${ }^{6}$ Additionally, the Northwest National Marine Renewable Energy Center (NNMREC) could prove as a valuable partner.

Contact:

Mike Gamroth, OSU Extension PNW Water Contact 541.737.3316

Greg Wheeler, OSU Director, Industrial Assessment Center, 541.737.2515, greg.wheeler@orst.edu

Belinda Batten, Director, Northwest National Marine Renewable Energy Center, belinda.batten@oregonstate.edu, 541.737.9492

Portland State University: While PSU does not have a hydrokinetic specialized program, the Institute for Sustainable Solutions, headed by Robert Constanza has done work in partnership with Portland-based Northwest Power and Conservation Council on the potential for micro hydrokinetic energy in the Mekong Basin in Asia.

http://www.web.pdx.edu/ kub/publicfiles/Mekong/LMB Report Appendices.pdf

Contact: Fletcher Beaudoin, Sustainability Partnerships Coordinator, beaudoin@pdx.edu, 503.784.5981

Tulane University: The River Sphere program is an in-river hydro program at Tulane University. The Mississippi River is a hotbed of in-river hydro potential and the River Sphere program has been created to further develop the technology and expertise to leverage financing opportunities.

Contact: Douglas Meffert, 504.988.6910, dmeffert@tulane.edu, http://riversphere.tulane.edu/

University of Alaska Fairbanks (UAF): UAF and the Institute of Northern Engineering based in Fairbanks are collaborating on hydrokinetic and tidal energy. A barge-mounted $25 \mathrm{~kW}$ New Energy turbine is being tested in Eagle, Alaska, by Alaska Power and Telephone with research support from INE. http://www.uaf.edu/acep/facilities/alaska-hydrokinetic-energ/ http://ine.uaf.edu/

Contact: Gwen Holdmann, Director of Alaska Center for Energy and Power, UAF, 907.590.4577, gwen.holdmann@alaska.edu

${ }^{6}$ http://www.pnwwaterweb.com/WQFlyers PNW146.pdf 
University of Washington (UW): Given opportunities in the Puget Sound for tidal energy, UW does have an energy research program devoted to tidal and hydrokinetic power.

Contact: Brian Polagye, 206.543.7544, bpolagye@u.washington.edu

Washington State University (WSU) Extension Energy Program: Also involved in the PNW Water Regional program WSU Extension is involved in research related to micro hydroelectric systems.

Contact: Dr. Carolyn Roos, 360.956.2156, RoosC@energy.wsu.edu, http://www.energy.wsu.edu/, Carloyn has past experience with Army Corps of Engineers and hydroelectric projects.

Washington State University (WSU) Engineering Program: Member of NSF industryuniversity collaborative research center Power System Engineering Research Center (PSERC) http://www.pserc.wisc.edu/home/index.aspx

\section{Renewable Portfolio Standards and Renewable Energy Credits}

Renewable Portfolio Standard (RPS): The Oregon Department of Energy establishes the renewable energy certificate system, and approves new energy sources as eligible under the RPS. Based on 2010 Oregon Legislature House Bill 3649 and 3674, low-impact hydro qualifies for Renewable Energy Credits (RECs) under the RPS. ${ }^{7}$ If the hydro project is certified as low impact and does not produce more than 40 average megawatts of electricity per year it can then sell RECs to energy producers such as PacifiCorp and PGE. The Western Regional General Information System manages REC output. ${ }^{8}$ Self-generation is eligible, and the RPS includes a goal of ensuring 8 percent of the state's retail electric load is from small-scale renewable energy projects with a generating capacity of $20 \mathrm{MW}$ or less.

Unfortunately, these facilities would not be considered eligible under the Oregon RPS. The RPS eligibility section (ORS 469A.025) distinguishes "wave, tidal, and ocean thermal energy" (1)(c) from hydropower (4) and (5). Therefore, in-river hydrokinetic projects are a part of the hydropower classification under the RPS. Under ORS 469A.025(4)(a), a post-1994 facility is eligible only if it is "located outside any protected area designated by the Pacific Northwest Electric Power and Conservation Planning Council." The Willamette River at Portland is clearly a protected area listed by the NW Power and Conservation Council.

Contact: Rebecca Sherman, Senior Policy Analyst, administers the Oregon Renewable Portfolio Standard program for the Department and covers hydropower for the technology division.

503.373.2295, rebecca.sherman@state.or.us

Renewable Energy Credits (RECs): The Multnomah County Portland Bridges Hydrokinetic Projects are not eligible to generate RECs. The following section is included for Multnomah County's education if they undertake similar projects or studies on non-protected waterways as listed by the NW Power and Conservation Council.

\footnotetext{
${ }^{7}$ Oregon Legislative Session. February 12, 2010. Senate Bill 3649

http://www.leg.state.or.us/10ss1/measpdf/hb3600.dir/hb3649.en.pdf

${ }^{8}$ Western Regional General Information System. http://www.wregis.org/
} 
The pathway to qualifying for and selling RPS-certified non-voluntary RECs includes: (1) Registering with Western Regional General Information System (WREGIS) (2) Ensuring that RECs are covered under Oregon RPS with the regional representative Oregon Department of Energy (3) and selling unbundled RECs via an active broker registered through WREGIS as opposed to selling bundled RECs as part of a Power Purchase Agreement (PPA).

REC buyers include: (1) Local customers (2) California RPS Market (3) Voluntary Market and (4) Oregon Utilities. The California market offers the highest prices, but is limited in the quantity of out-of-state bundled REC purchases to meet RPS and AB-32 requirements. While Oregon utilities require RECs to meet current the requirements of the Oregon RPS, both PGE and PacifiCorp already have enough RECs banked to meet RPS obligations through 2019.

One of the most qualified brokers for Western region RECs is Ben Reese, who heads the REC desk at Evolution Markets out of San Francisco, CA and has done a considerable number of work in the Pacific Northwest. Eugene Water \& Electric Board (EWEB) could serve as a recommendation for Reese's work.

In terms of pricing RECs, one renewable energy certificate is equal to one megawatt-hour of energy from a qualifying renewable energy source. Oregon Department of Energy (ODOE) ultimately has the power to determine any other eligible technologies except for nominating fossil fuels as renewables. A $25 \mathrm{~kW}$ system might generate about 50,000 kWh (50 MWh) a year. At a $\$ 50$ price per megawatt-hour, annual revenue from the sale of the 7 RECs would be about $\$ 2500$. $^{9}$ An example with hydro RECs through Tucson Electric Power, which sets a small hydro REC pricing 10-year agreement at \$0.06/kWh (15-year REC: \$0.056, 20-year REC $\$ 0.054$ ) would represent a $\$ 3,000$ annual contribution to project revenue for a one $25 \mathrm{~kW}$ system. ${ }^{10}$ Ben Reese at Evolution Markets shared that REC prices are currently much lower than \$50 per MW-hour, currently ranging from \$.003-.006 per kWh REC from 2013-2015 and \$.01-.02 per kWh REC 2016 forward. The difference in price is largely caused by oversupply and liquidity on the market although the longer term seems to look better as new renewable generation will be required to cover RPS goals.

\footnotetext{
${ }^{9}$ http://www.climatelawreport.com/2010/03/articles/financing-investing/california-rec-marketand-project-financing/ ${ }^{10}$ https://www.tep.com/Renewable/Other/Hydro/
} 


\section{Alternate REC Brokers}

\begin{tabular}{|l|l|l|l|}
\hline WREGIS Active Brokers & Contact & Location & Phone \\
\hline Amerex Energy & John Morrow & Sugar Land, TX & 281.340 .5200 \\
\hline BNY Mellon & Deven Shah & New York, NY & 212.495 .1784 \\
\hline CE2 Environmental Market LP & Gregory Arnold & Solana Beach, CA & $858.481-0024$ \\
\hline ICAP United & Rob Lawrence & Sugarland, TX & 281.340 .8300 \\
\hline IVG Energy & Matt Hicks & Houston, TX & 713.554 .3700 \\
\hline Nexant Clean Energy Markets & Erin Riley & Roswell, GA & 781.878 .2606 \\
\hline Palmetto Ventures Trading Ltd. & Chris Kemper & London, England & +44.203 .111 .9180 \\
\hline SVS Securities PLC & Simon Fox & London, England & +44.207 .638 .5600 \\
\hline Three Rivers Energy, Inc. & Doug Condon & Pleasanton, CA & 925.931 .0946 \\
\hline
\end{tabular}

${ }^{* *}$ The table above is developed based on information provided by the Western Regional Generation Information System (WREGIS).

Contact: Ben Rees, REC Lead, Evolution Markets, 415.690.0812, brees@evomarkets.com Ben is highly regarded in the field and should be considered as the first point of contact for selling RECs and project viability.

Overview of REC Market (Evolution Markets) http://renewableenergymarkets.com/docs/presentations/2011/aek11-17-11REMA.pdf

\section{EnCurrent Technology, Pricing and Alternatives}

Installations and Clients: Up to this point, EnCurrent Technologies has only installed one EnCurrent $5 \mathrm{~kW}$ vertical axis turbine in the United States, in rural Alaska. The technology was sold and installed via a distributor - ABS Alaskan, which at this stage will most likely handle the distribution for all $5 \mathrm{~kW}$ systems. Most of the EnCurrent Technologies that are in operation are the $25 \mathrm{~kW}$ model, with the Alaskan model being the only other $5 \mathrm{~kW}$ system currently in use. Clients for in-river systems are predominantly based in Canada and India. ABS Alaskan, and owner Jim Norman is the best contact for the $5 \mathrm{~kW}$ model.

EnCurrent Client List:

http://www.newenergycorp.ca/OurClients/DeploymentMap/tabid/83/Default.aspx

Pricing and Discount: With regard to price reductions or some form of partnership on this demonstration project, EnCurrent is interested in exploring that possibility. Prior to calling, they had received word that this was a potential project and is one they are interested in supporting. They would like to assist in assessing flow rates and other engineering considerations as well as identifying next steps for project implementation. At this time, EnCurrent sells its $5 \mathrm{~kW}$ exclusively through ABS Alaskan which prices the $5 \mathrm{~kW}$ system at $\$ 28,000$. $^{11}$

Contact: Andrew Walls, Sales Andrew.walls@newenergycorp.ca, 778.837.5300

${ }^{11}$ http://www.absak.com/catalog/product info.php/products id/1098 
Kevin Andersen, Engineer Kevin.andersen@newenergycorp.ca, 403.700 .6730 (cell) Jim Norman, owner of ABS Alaskan, (907) 451-7145

\section{Alternate Hydrokinectic Technology Providers:}

\begin{tabular}{|l|l|l|l|}
\hline Manufacturer & Location & Phone & Website \\
\hline Free Flow Power & Bellingham, WA & 978.283 .2822 & http://www.free-flow-power.com/ \\
\hline Bourne Energy & Malibu, CA & 310.456 .8112 & http://www.bourneenergy.com \\
\hline Hydrovolts & Seattle, WA & 206.658 .4380 & http://hydrovolts.com/ \\
\hline Verdant Power & New York, NY & 212.888 .8887 & http://verdantpower.com/ \\
\hline
\end{tabular}


Attachment 7

\section{Project Economics}




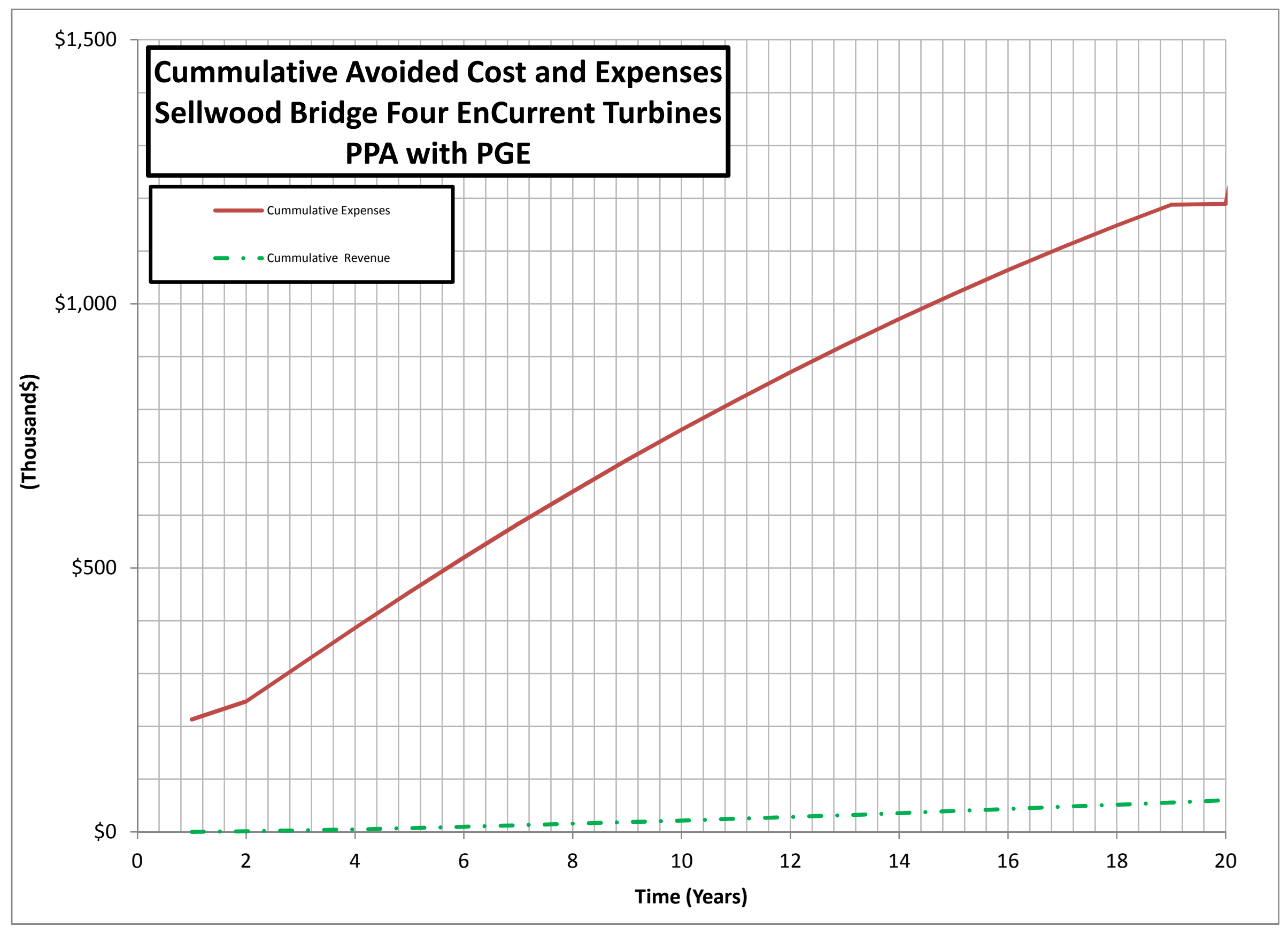




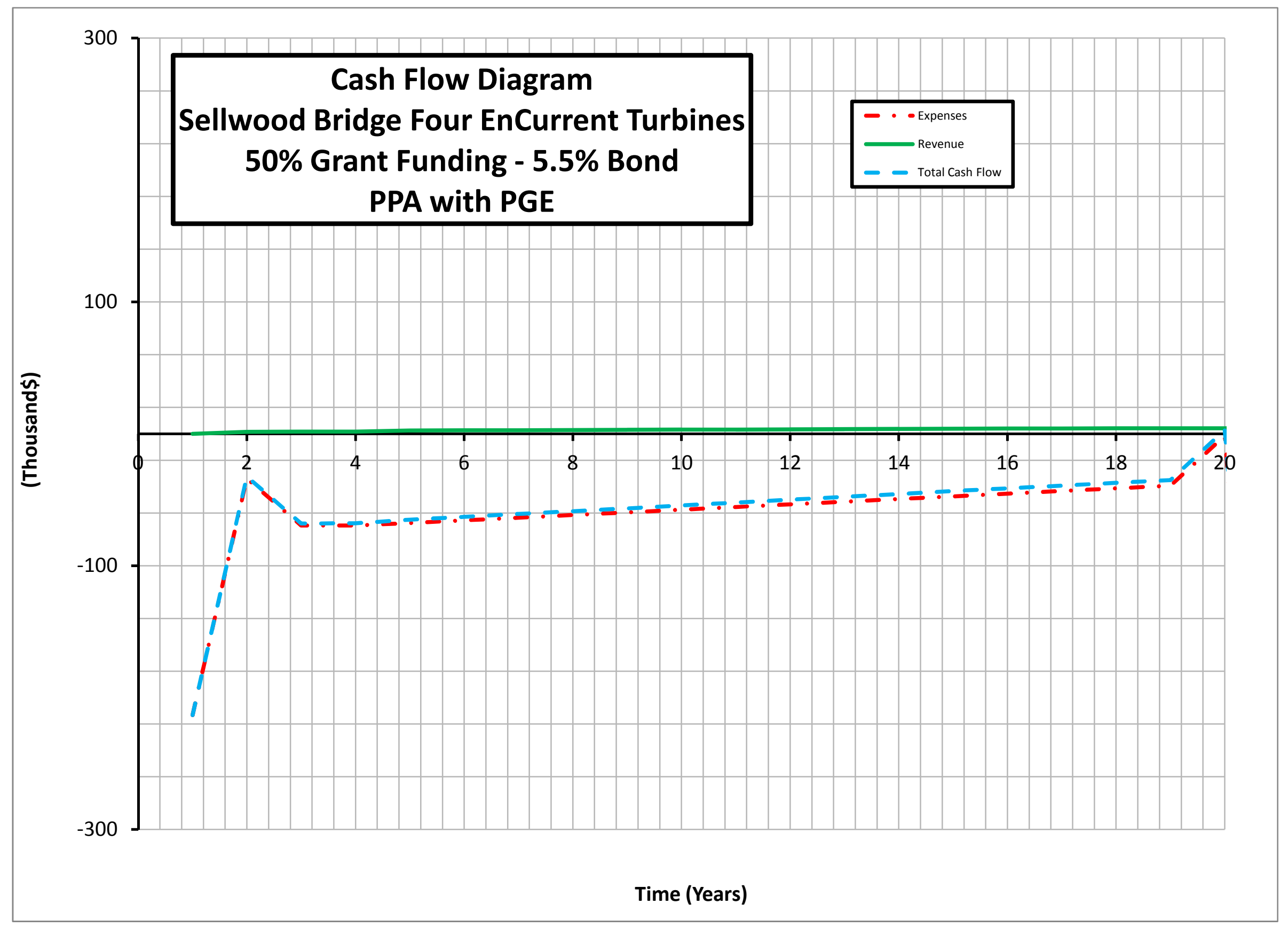




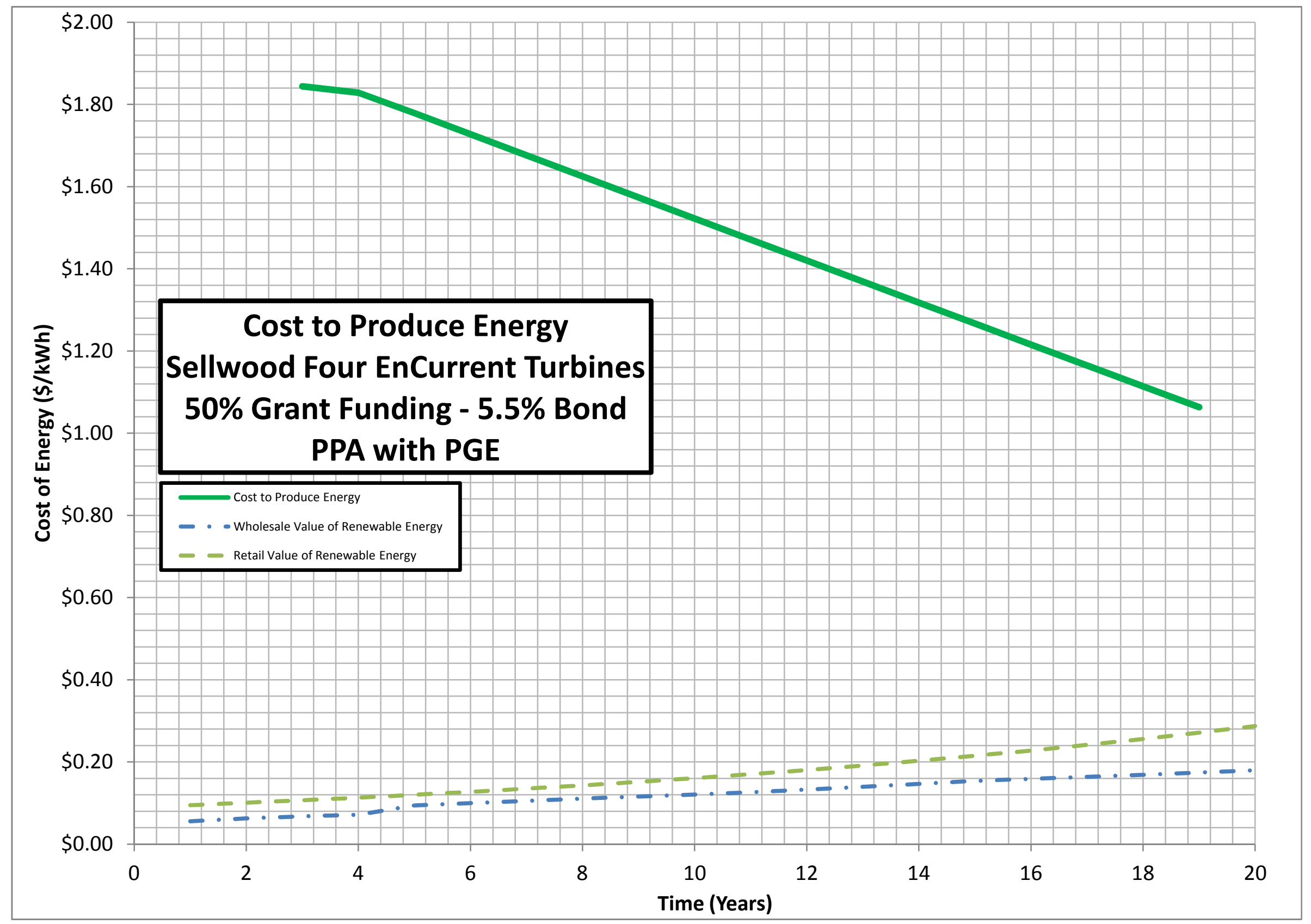


Attachment 8

Willamette River ADCP Measurements 


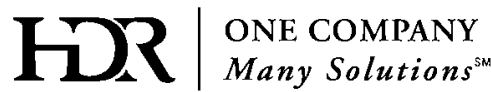

Memo

\begin{tabular}{|l|l|l|l|}
\hline To: & \multicolumn{2}{|l|}{ David Elwood, PE } \\
\hline From: & Jeff Smith & Project: & Multnomah County Hydrokinetic Feasibility Study \\
\hline cc: & Stephen Spain, PE & Job No: & 150650 \\
\hline Date: & $12 / 29 / 2011$ & \multicolumn{2}{|l|}{} \\
\hline RE: & \multicolumn{2}{|l|}{ Summary of Willamette River Instream Velocity Measurements } \\
\hline
\end{tabular}

On December 16, 2011 HDR Engineering Inc. (HDR) conducted a hydrokinetic study to quantify velocities near two bridges over the Willamette River in Portland, Oregon. A RDI $1200 \mathrm{khz}$ Rio Grande Acoustic Doppler was used for velocity collection. It was mounted on the side of a 20 foot aluminum hull Tuffboat. GPS positions were collected from a Trimble Pro XRS sub-meter accuracy GPS. The team was able to accurately measure a discharge and collect velocities near the Sellwood Bridge. Because of the very slow velocities near the Morrison Bridge, it was not possible to collect accurate data at that site. We did collect velocities at Morrison, but the boat speed to water speed ratio was too high to allow for accurate data collection. The boat is not maneuverable when the average instream velocity is near zero and the standard deviation for any collected velocities is greater than recommended by the instrumentation vendor.

At the Sellwood Bridge the team collected cross sectional profiles upstream and downstream of the bridge and longitudinal profiles through the middle of the bridge and the left side of the bridge looking upstream. Figures 1 and 2 show the location of the measured velocity profiles relative to the bridge.

Figure 1. Locations of cross sectional profiles

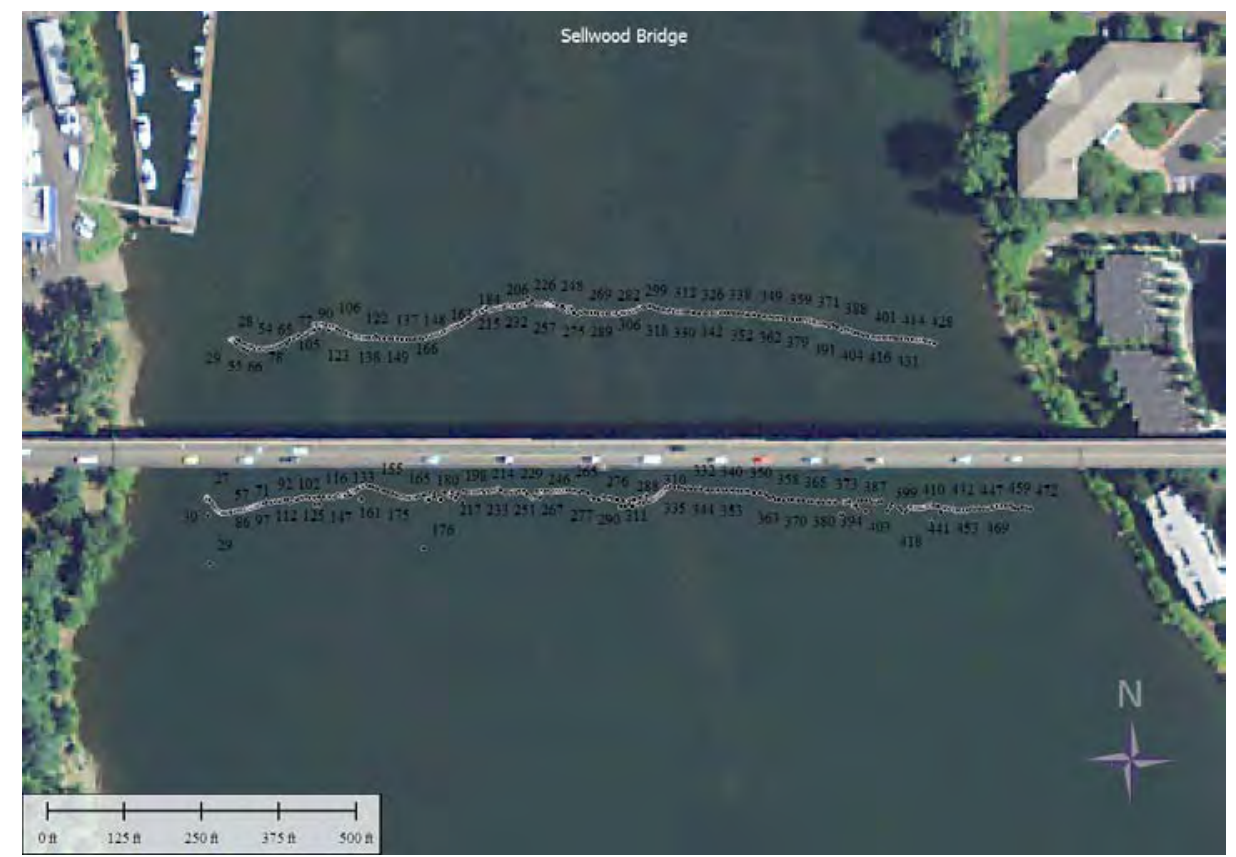


Figure 1 shows the location of the two cross section profiles. The measured velocity across these two cross sections can be seen in Figure 3 and 4. When measuring near obstructions such as bridges, GPS accuracy drops. Some points in the cross section don't follow the general direction of the transect due to the loss of GPS accuracy.

Figure 2. Locations of longitudinal profiles

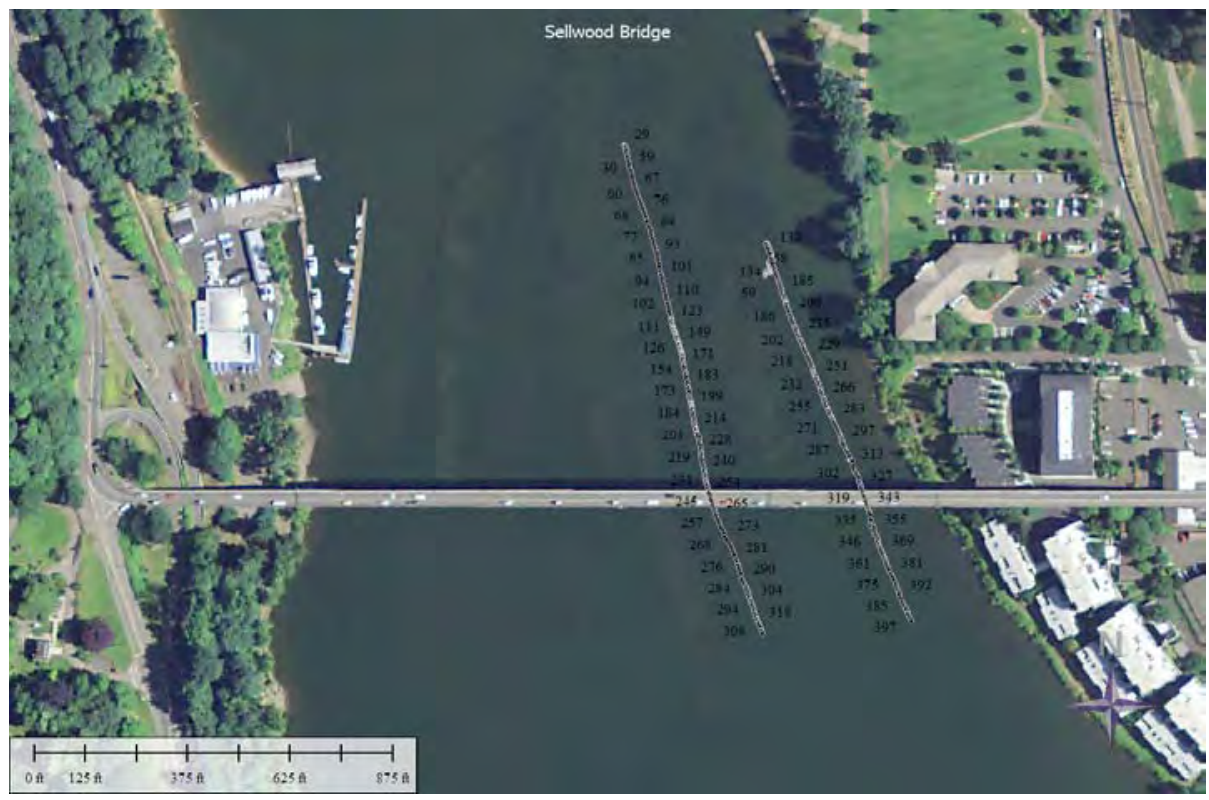

The velocity data from the transects in Figure 2 is summarized in Figures 5 and 6.

The velocity magnitude figures (Figures 3 through 6) graphically illustrate the instream velocities measured during the survey. The velocity data were collected in bins starting at 3.64 feet from the surface to the maximum depth of the channel at increments of 0.82 feet. An ensemble is a collection of bins at each vertical elevation within the water column.

Figure 3 shows a cross sectional velocity profile downstream (north) of the Sellwood Bridge. The view is from the right to the left looking upstream. Velocities in this cross section ranged from 0.01 to $2.34 \mathrm{fps}$. The average channel velocity was approximately $1.13 \mathrm{fps}$. The calculated discharge was 23,464 cfs at 11:07am. A total distance of 799 feet was measured.

Figure 3. Cross sectional profile downstream of Sellwood Bridge.

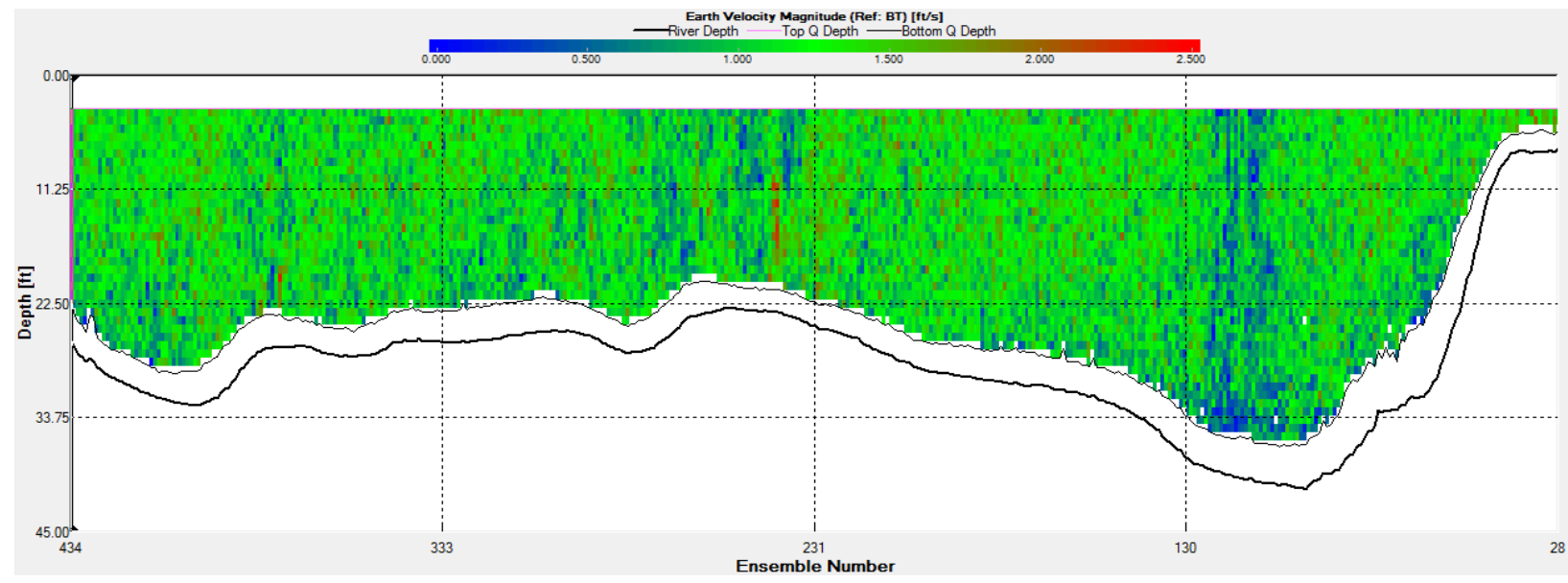


Figure 4 shows a cross-sectional profile upstream (south) of the Sellwood Bridge. The view is from the right to the left looking upstream. Velocities ranged from 0.03 to $1.96 \mathrm{fps}$ across this section. The average river velocity was approximately $0.89 \mathrm{fps}$. The calculated discharge was $21,577 \mathrm{cfs}$ at 11:19am. A total distance of 934 feet was measured.

Figure 4. Cross-sectional profile upstream of Sellwood Bridge.

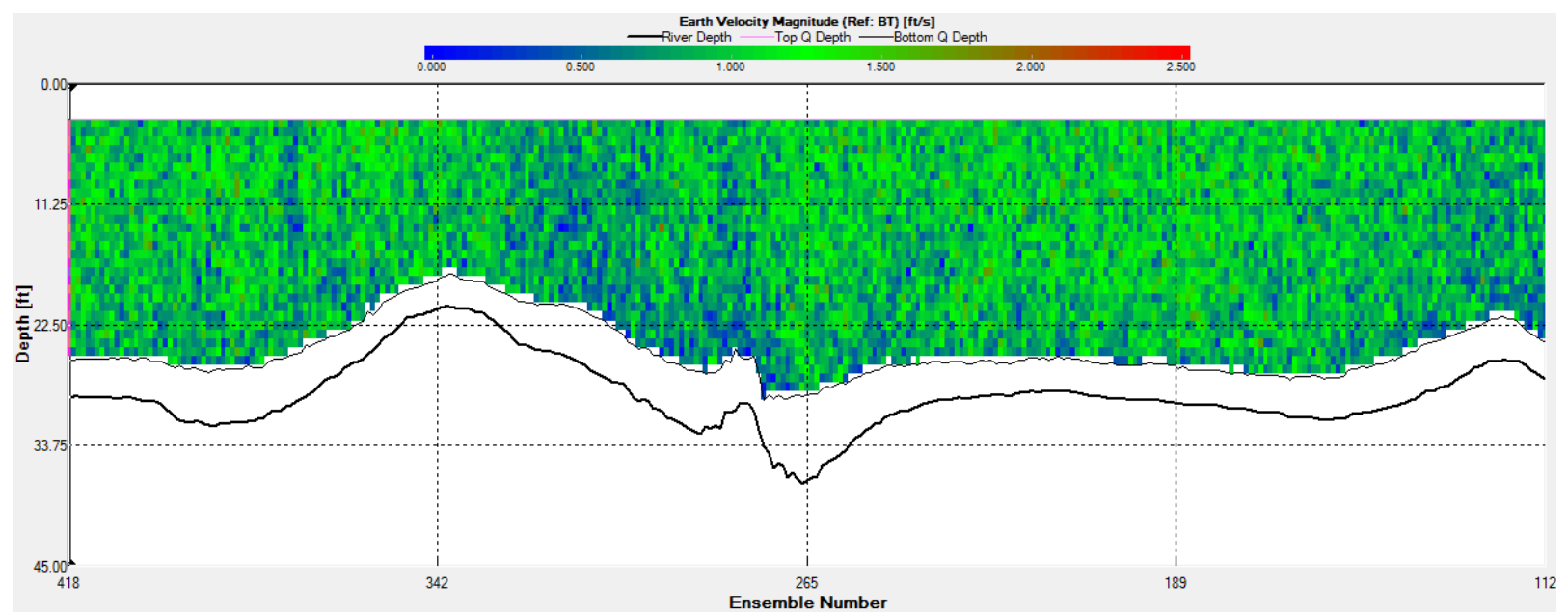

Figure 5 shows a longitudinal profile just left of the center of the Sellwood Bridge. The view is from left (north) to right (south). Velocities ranged from 0.02 to $3.14 \mathrm{fps}$. The average river velocity was approximately 1.05 fps along this transect. A total distance of 903 feet was measured. Ensembles 247 to 260 represent the area under the bridge and had an average velocity of 0.89 fps.

Figure 5. Left-of-center longitudinal profile

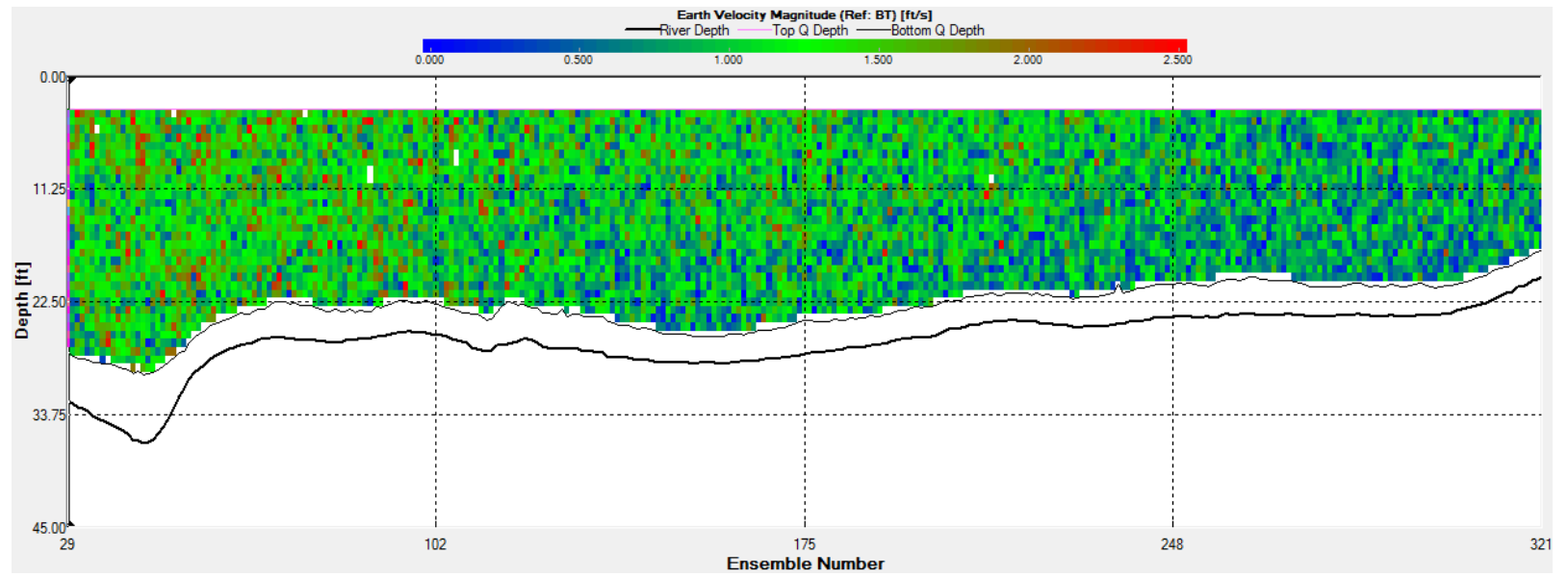


Figure 6 shows a longitudinal profile under the left side of the Sellwood Bridge looking upstream. The view is from left (north) to right (south). Velocities ranged from 0.02 to $2.72 \mathrm{fps}$. The average river velocity was approximately 0.98 fps along this transect. A total distance of 673 feet was measured. Ensembles 325 to 338 represent the area under the bridge and had an average velocity of $0.84 \mathrm{fps}$.

Figure 6. Left longitudinal Profile

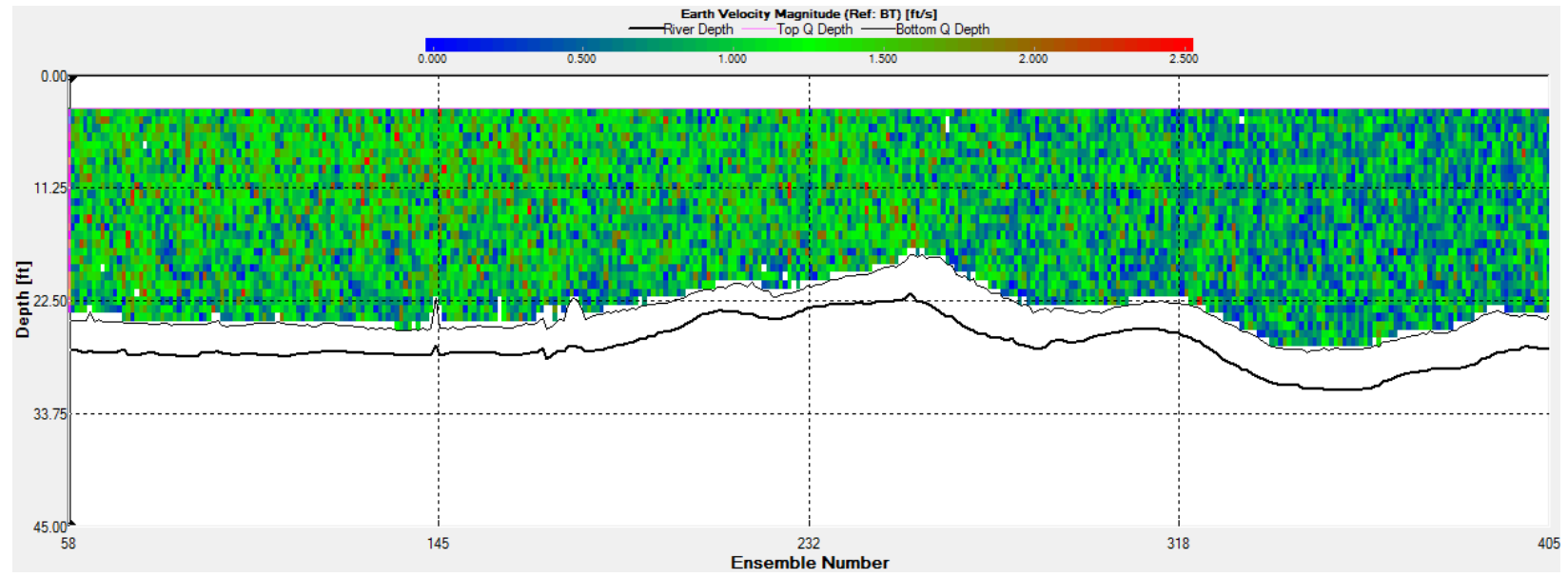

